\title{
CHARACTERIZATION OF THE MICROBIAL COMMUNITIES RESPONSIBLE FOR AMMONIA OXIDATION IN ACTIVATED SLUDGE SYSTEMS OF MUNICIPAL WASTEWATER TREATMENT PLANTS
}

\author{
by
}

\section{GM Itheshamul Islam}

Ryerson University, 2012

Master of Science, Molecular Science

Ryerson University, 2010

Bachelor of Science, Biology

\author{
A dissertation presented \\ to Ryerson University \\ in partial fulfillment of the requirements \\ for the degree of \\ Doctor of Philosophy \\ in the program of Molecular Science
}

Toronto, Ontario, Canada, 2018

CGM Itheshamul Islam, 2018 


\section{AUTHOR'S DECLARATION FOR ELECTRONIC SUBMISSION OF A DISSERTATION}

I hereby declare that I, GM Itheshamul Islam am the sole author of this dissertation. This is a true copy of the dissertation, including any final revisions as accepted by my examiners.

I hereby authorize the University of Ryerson to lend this dissertation to other institutions, organizations and individuals for the purpose of scholarly research.

I further authorize Ryerson University to reproduce this dissertation by photocopying or by other means, in total or in part, at the request of other institutions or individuals for the purpose of scholarly research.

I understand that my dissertation may be made electronically available to the public. 
CHARACTERIZATION OF THE MICROBIAL COMMUNITIES RESPONSIBLE FOR AMMONIA OXIDATION IN ACTIVATED SLUDGE SYSTEMS OF MUNICIPAL WASTEWATER TREATMENT PLANTS

\author{
GM Itheshamul Islam \\ Doctor of Philosophy, Molecular Science, Ryerson University, 2018
}

\begin{abstract}
Nitrification is an essential microbial process in the global nitrogen cycle. The first step of nitrification is ammonia oxidation which is achieved by bacteria and archaea and is crucial in decreasing ammonia concentrations that are persistently high in wastewater. This study examined the composition, abundance and identity of the microbial community in activated sludge with a focus on characterizing ammonia oxidizing bacteria and archaea in a full-scale municipal wastewater treatment plant (MWTP). Specifically, two pharmaceutical compounds Tetracycline and Ibuprofen, and their effects on the community composition of bacteria and protozoa in activated sludge was investigated using PCR coupled with denaturing gradient gel electrophoresis (DGGE). In addition, the composition, abundance and activity of the ammonia oxidizing bacteria (AOB) and ammonia oxidizing archaea (AOA) were analyzed from aerobic activated sludge, recycled sludge and anaerobic digesters of the Humber MWTP using molecular techniques such as PCR, Quantitative PCR, Reverse TranscriptionPCR and DGGE. The findings demonstrated that Tetracycline did not appear to alter community composition of bacteria in the activated sludge, rather, the operational parameters of the sequencing batch reactors such as feeding rates and SRT have shown to alter the richness of bacterial communities. However, Ibuprofen affected some members in the protozoan community in activated sludge. In the full-scale Humber MWTP using the conventional activated sludge system, the aeration tanks contained $1.8 \times 10^{5}$ copies of the AOB amoA gene per $100 \mathrm{ng}$ of DNA. In contrast, the anaerobic digester tanks contained $7.3 \times 10^{2}$ copies of the AOA amoA gene per 100ng of DNA. This study also found that AOB were dominant in activated sludge samples, regardless of the operational parameters. The quantification of cDNA transcripts of the amoA gene also indicated that AOB may be more active than AOA in the activated sludge system. Overall, it appears that AOA are very niche specific and thrive in very low oxygenated environments, while AOB proliferate and play a major role in aerobic ammonia oxidation occurring in MWTPs.
\end{abstract}




\section{ACKNOWLEDGEMENTS}

Just as the farmer toils day and night for the seeds he plants to blossom and bear fruit, my parents have toiled day and night for me to achieve success in whatever I have desired.

Thank you Abbu (Dad), for being the rock that has kept me from withering away by providing shelter, support, protection and discipline. Your support as a father will always live on for me and for the next generations to come.

To my mother, Ammu (Mom), the greatest gift of my life has been you. You taught me never to say NO when anybody asks something of you, it may seem like a weakness to many, but it is my greatest strength as it leads me to be always helpful, kind and generous. I count the blessings from high above to be more than enough for me because I get to see you smile everyday.

To my wife, you are my present and future. The way you have shown me understanding and patience and love, nobody in the world can match. I can only promise you that in my heart, I will always appreciate the sacrifices you make for us.

To my family, thank you for being the source of peace for me through good times and bad. My son Zaid and my nephew Rayan (lalu), I love you.

To my supervisor, Dr. Kimberley Gilbride, I do not think I will ever meet a better role model, who taught me how to tackle challenges with patience, perseverance and confidence. You always found a way to raise my spirit and motivated me to continue striving, and I will be forever indebted to your support and guidance.

To my friend Adil Syed, no matter where the road leads us, I know one of us will wait at the destination and be eager to meet and laugh about our childhood and the things we have seen and learned as we grew older. I would like to thank my lab mates, Simon, Farhan and everybody that I had the pleasure to meet and interact with throughout my whole project. My friends Amir, Krishna, Micheal, Christian, Tracy and Farhana. Thanks for being there.

A special thanks to Dr. Hausner, Dr. Wolfaardt, Dr. Botelho, Dr. McCarthy and all of the faculty members and staff here at Ryerson who made my education here a pleasant experience. I also would like to thank my committee members, Dr. Andrew Laursen, Dr. Robert Delatolla, Dr. Mehrab Mehrvar and Dr. Marthinus Kroukamp. 


\section{QUOTE}

"Verily After Hardship, Comes Ease"

- Surah Al Inshirah 


\section{TABLE OF CONTENTS}

AUTHOR'S DECLARATION FOR ELECTRONIC SUBMISSION OF A DISSERTATION..........ii

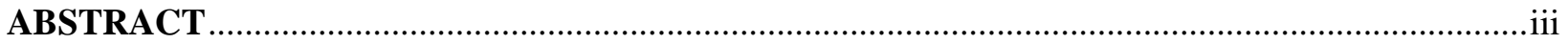

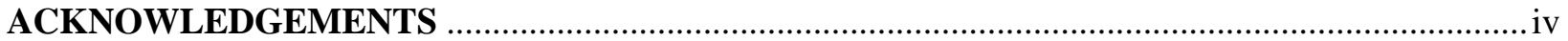

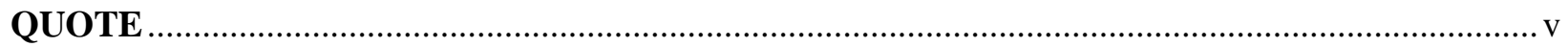

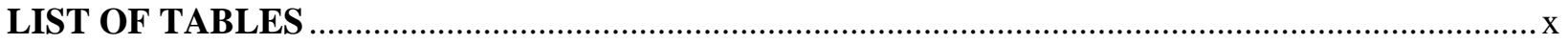

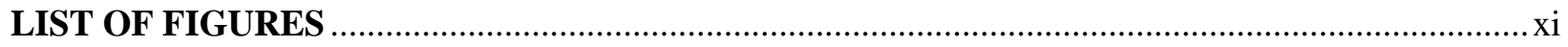

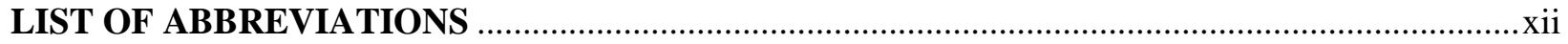

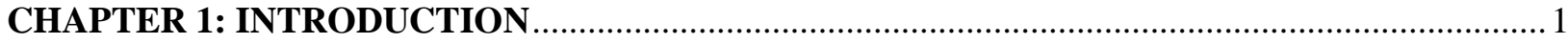

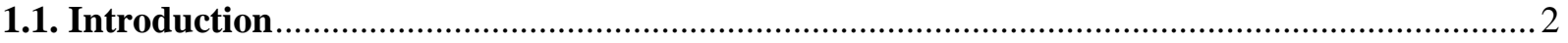

1.2. Purpose

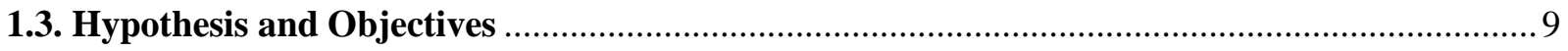

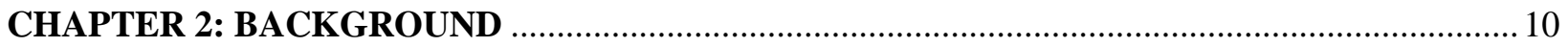

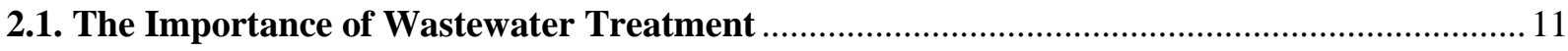

2.2. The Wastewater Treatment Process …............................................................................... 15

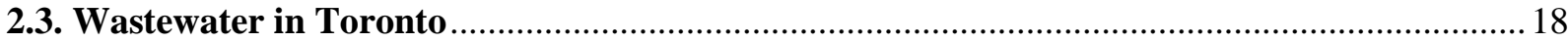

2.3.1. Humber Wastewater Treatment Plant........................................ 19

2.4. Different Types of Biological Wastewater Treatment ........................................................... 20

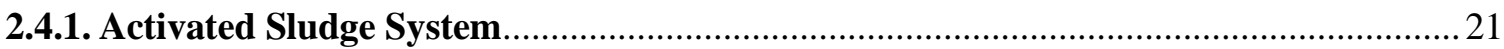

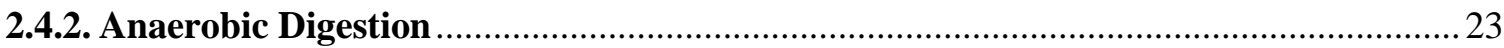

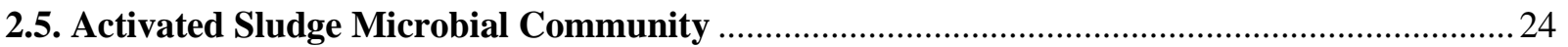

2.6. Methods to Study the Composition of the Microbial Community........................................26

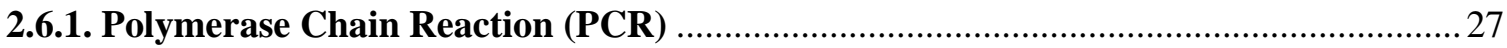

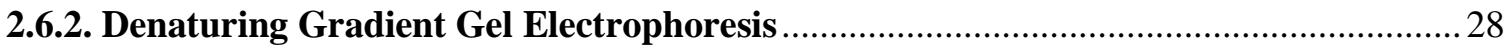

2.7. Structure and Composition of Microbial Communities in Activated Sludge .........................29

2.8. Factors Affecting the Composition and Function of Activated Sludge .................................. 33

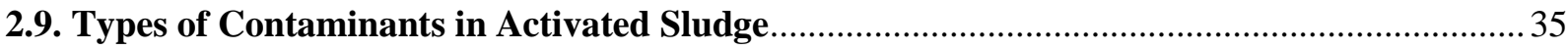

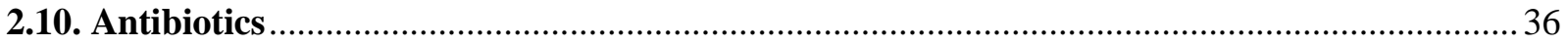

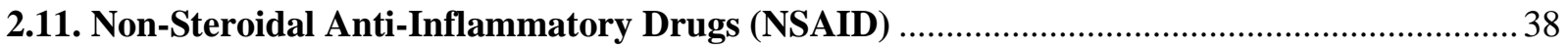

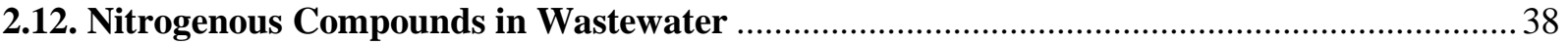

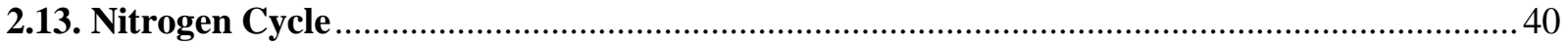

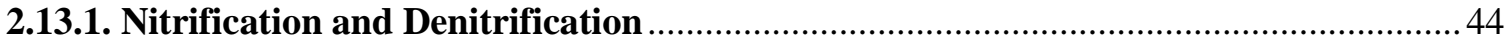

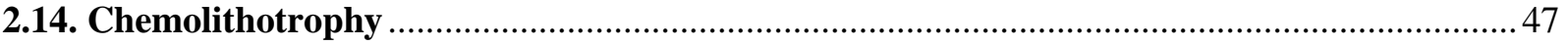




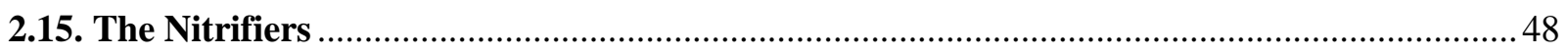

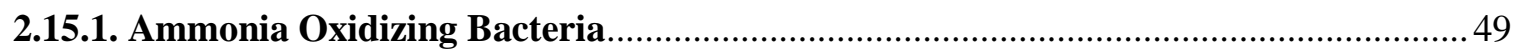

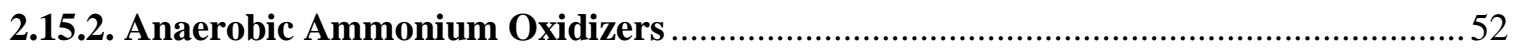

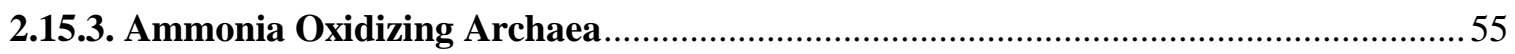

2.16. Factors Affecting Ammonia Oxidation by Archaea ...........................................................59

2.17. Detecting Ammonia Oxidizing Microorganisms in Activated Sludge .................................62

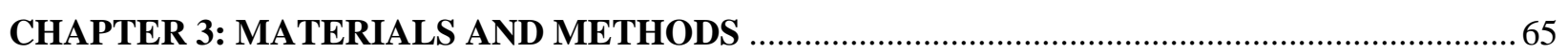

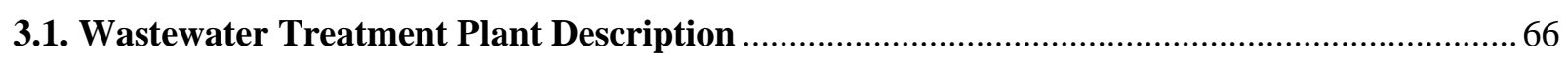

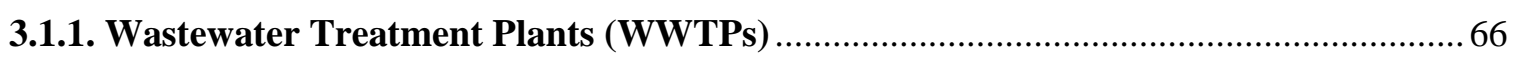

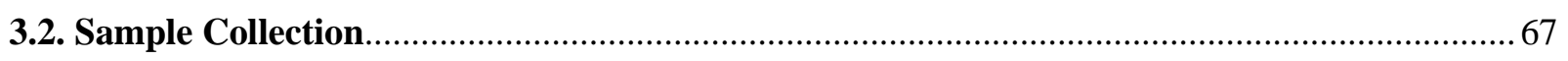

3.2.1. Samples for Lab Scale Reactors to Investigate the Impact of Tetracycline on

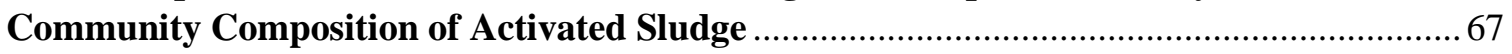

3.2.2. Samples for Lab Scale Reactors to Investigate the Impact of Tetracycline and Ibuprofen on Community Composition

3.2.3. Samples for the Presence and Function of $\mathrm{AOA}$ and $\mathrm{AOB}$ in the Activated Sludge System.....

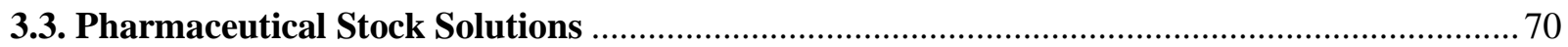

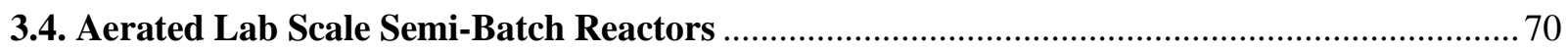

3.4.1. Reactor Set-Up to Determine Effect of Tetracycline on Bacterial Community Composition.

3.4.2. Reactor Setup to Determine Effect of Ibuprofen and Tetracycline on the Bacterial and Protozoan Composition and Community Structure ....................................................... 73

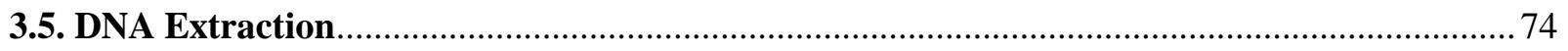

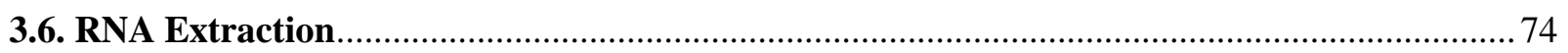

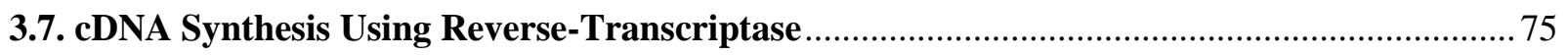

3.8. Polymerase Chain Reaction (PCR) Methods................................................................... 76

3.8.1. 16S rRNA Gene Amplification Using PCR for Bacteria ............................................. 77

3.8.2. 18S rRNA Gene Amplification Using PCR for Protozoa ............................................ 77

3.8.3. 16S rRNA Gene Amplification for Ammonia Oxidizing Bacteria............................... 78

3.8.4. 16S rRNA Gene Amplication for Ammonia Oxidizing Archaea …............................. 78

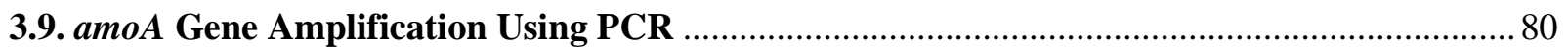

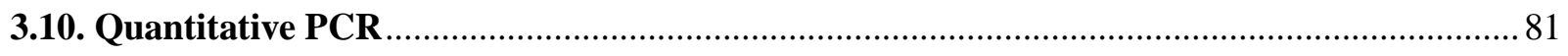

3.11. Preparation of the Standard Curve Using Cloning and Transformation ............................ 83

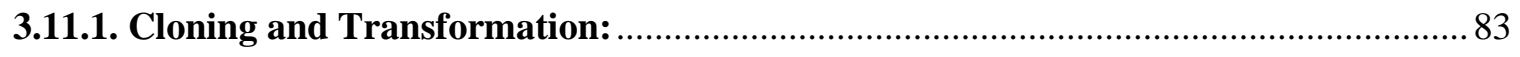

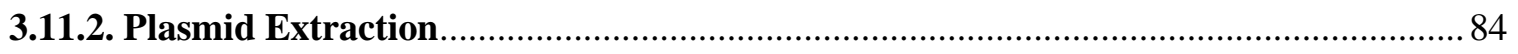

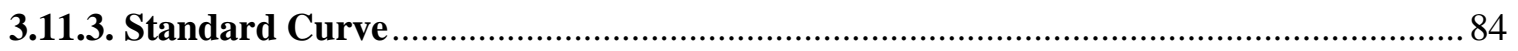


3.12. Community Composition and Diversity Profiles and Identification Using Denaturing

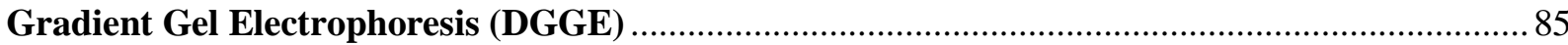

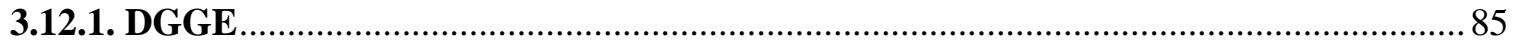

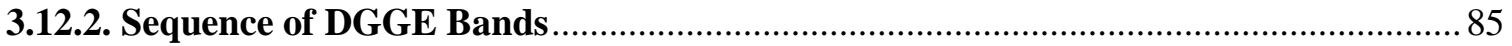

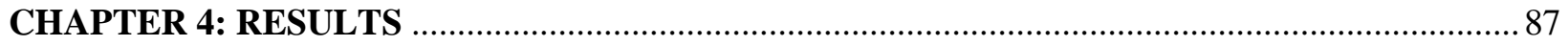

4.1. Impact of Pharmaceuticals on Activated Sludge Microbial Communities ............................. 88

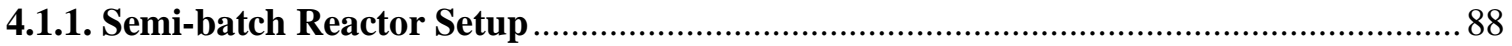

4.2. Impact of Tetracycline on the Bacterial Population in Activated Sludge Reactors................ 90

4.2.1. Tetracycline Semi-Batch Reactor Performance ........................................................ 90

4.2.2. The Impact of Low Concentrations of Tetracycline at Short and Long Retention

Times on the Community Composition and Diversity of Bacteria ....................................... 90

4.2.3. Diversity Comparison Using the Shannon Index …................................................ 91

4.3. Impact of Tetracycline and Ibuprofen on Bacterial and Protozoan Populations in Activated

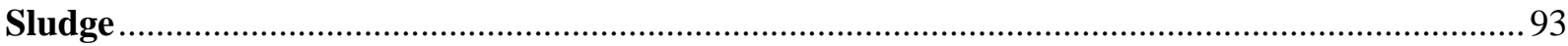

4.3.1. Tetracycline and Ibuprofen Semi-Batch Reactor Performance .................................93

4.3.2. Impact of High Concentrations of Tetracycline and Ibuprofen on Bacterial and Protozoan Diversity and Composition

4.4. Detection of Ammonia Oxidizing Microorganisms in an Full Scale Activated Sludge

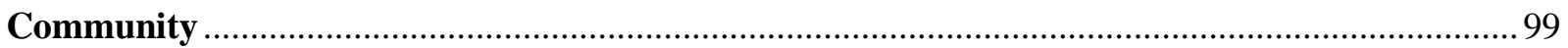

4.4.1. Detection of AOA and AOB in the Activated Sludge Process....................................99

4.4.2. Community Composition of AOA and AOB in the Activated Sludge System ...........103

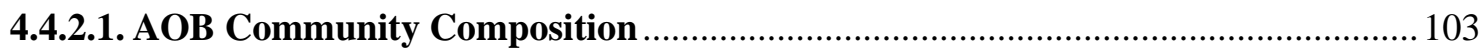

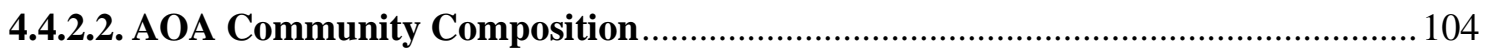

4.4.2.3. Comparison of AOB and AOA Community Composition .................................. 104

4.5. Abundance of Ammonia Oxidizing Microorganisms in an Full Scale Activated Sludge

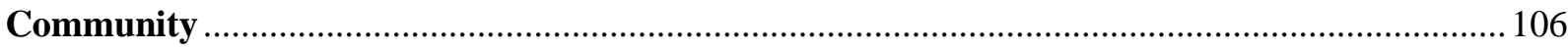

4.5.1. Relative Abundance of AOB and AOA in Activated Sludge Communities............... 106

4.5.2. Absolute Abundance of AOB and AOA Populations............................................. 108

4.6. The Activity of AOA and $A O B$ in an Full Scale Activated Sludge Community.................... 111

4.6.1. Quantification of AOB and AOA amoA Gene Transcription .................................. 111

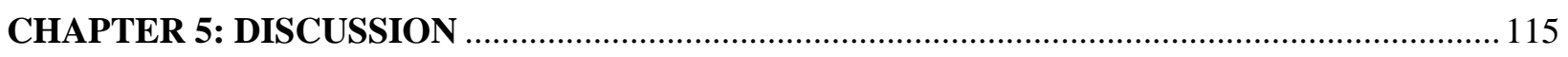

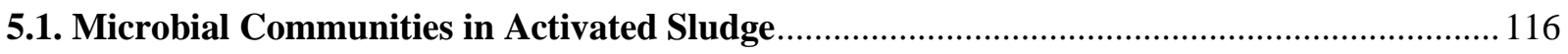

5.1.1. The Impact of Tetracycline on the Community Composition and Functioning of

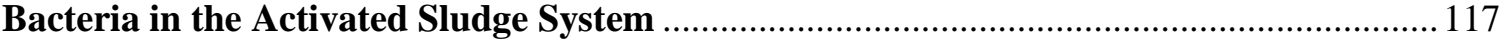

5.2. Impact of Tetracycline and Ibuprofen on Protozoa in Activated Sludge ............................ 122

5.3. Location of Ammonia Oxidizing Bacteria and Archaea in a Full-Scale Wastewater

Treatment Plant 
5.4. Community Composition of AOA and AOB in a Full-Scale Activated Sludge System.

5.5. Quantification of AOA and AOB Abundances in a Full-Scale Activated Sludge System of Municipal Wastewater Treatment Plant 128

5.5.1. Comparing Relative Abundance of Ammonia-Oxidizing Communities. 128

5.5.2. Absolute Abundance of AOA and AOB Populations. 131

5.6. Activity of AOB and AOA in the WWTP 132

5.7. Conclusion and Future Recommendations. 136 APPENDIX 140

APPENDIX A: PCR 140

APPENDIX B: Quantitative PCR and RT-PCR 143

APPENDIX C: Standard Curves 148 


\section{LIST OF TABLES}

Table 1. Influent and effluent characteristics, operational parameters of the activated sludge .........69

Table 2. Primer sets specific for prokaryotes and eukaryotes ...................................................................... 79

Table 3. Primer sets specific for AOB and AOA and total heterotrophs.................................................8 80

Table 4. Shannon indices for bacterial community composition ..........................................................992

Table 5a. Bacterial genera found in the communities exposed to Tetracycline and Ibuprofen......... 96

Table 5b. Protozoan genera found in the communities exposed to Tetracycline and Ibuprofen ...... 97

Table 6. Relative abundance ratios of AOA and AOB communities................................................ 108

Table 7. Abundance of the amoA gene of ammonia oxidizing bacteria and archaea ....................... 109

Table 8. Abundance of the amoA cDNA copies in activated sludge ........................................................ 112 


\section{LIST OF FIGURES}

Figure 1. Humber Wastewater Treatment System ..................................................................... 15

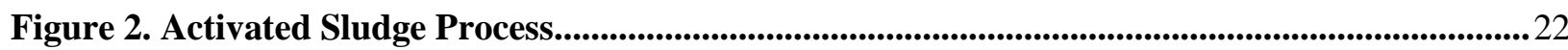

Figure 3. Pharmaceutical compounds from various wastewater streams ...........................................35

Figure 4. Nitrogen Cycle.................................................................. 41

Figure 5. Two major groups of prokaryotes perform ammonia oxidation...............................................44

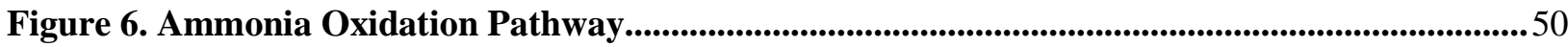

Figure 7. Mechanism of anaerobic ammonia oxidation within the Anammoxosome ..........................53

Figure 8. Microscopic images of AOA. Nitrosopumilus maritimus strain SCM1 ................................55

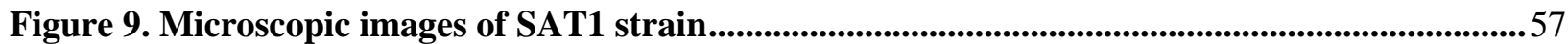

Figure 10. a) Reactor description and design b) Aerated semi-batch reactor system ........................ 73

Figure 11. Dendrogram representing the relationship between bacterial community profiles ..........93

Figure 12. DGGE profiles of the a) bacterial and b) protozoan population in the reactors................96

Figure 13a. PCR product targeting 16S rRNA gene fragment for AOA and AOB ......................... 101

Figure 13b. PCR product targeting amoA gene fragment for AOA and AOB....................106

Figure 14a. Community profile of AOB using 16S rDNA in activated sludge ................................. 105

Figure 14b. Community profile of AOB using amoA gene in activated sludge .................................... 105

Figure 15. Community profile of AOA using the 16S rDNA and amoA gene activated sludge ....... 106

Figure 16. Relative abundance ratios of AOB and AOA to the total heterotrophs ............................ 107

Figure 17. Number of bacterial amoA gene copies in activated sludge ................................................ 110

Figure 18. Number of archaeal amoA gene copies in activated sludge............................................. 110

Figure 19. The expression of bacterial amoA gene in activated sludge ............................................ 113

Figure 20. The expression of archaeal $a m o A$ gene in activated sludge................................................... 114 


\section{LIST OF ABBREVIATIONS}

AMO - ammonia monooxygenase

ANAMMOX - anaerobic ammonia oxidation

AOA - ammonia oxidizing archaea

AOB - ammonia oxidizing bacteria

AT - aeration tank

DGGE - denaturing gradient gel electrophoresis

DIG - digester

HAO - hydroxylamine oxidoreductase

HRT - hydraulic retention time

EPA - environmental protection agency

MWWTP - municipal wastewater treatment plant

PCR - polymerase chain reaction

qPCR - quantitative polymerase chain reaction

RAS - return activate sludge

RBC - rotating biological contactor

RS - recycled sludge

RT-PCR - reverse transcription polymerase chain reaction

SRT - sludge or solid retention time

VFA - volatile fatty acids

WAS - waste activated sludge

WHO - world health organization

WWTP - wastewater treatment plant 


\section{CHAPTER 1: INTRODUCTION}




\subsection{Introduction}

Nitrogen (N) availability in the environment can often be looked at as a doubleedged sword. For instance, the presence of nitrogen in soil is essential for increased productivity in crops. One practical example is seen in the use of nitrogen fertilizers to induce crop growth by improving soil quality and nutrient availability for plants as nitrogen is considered a primary nutrient and is of vital importance to the physiology of plants (Leininger et al., 2006). On the other hand, excessive input of nitrogen due to human activities have dramatically increased the amount of biologically available nitrogen in an ecosystem. When this occurs, nitrogen can become a pollutant. Besides causing undesirable effects on the crop or plants, excess nitrogen can cause problems in the environment such the stimulation of algal blooms in water reservoirs threatening fresh water sources with oxygen depletion and toxicity (Sauder et al., 2012). Because of the importance of nitrogen in all ecosystems, and its significant input from human activities leading to perturbations in the environment, nitrogen and its transformations have received a great deal of attention from ecologists (Bernhard et al., 2010).

Nitrogen can enter the environment from various routes. From excess nitrogen that can run off from agricultural sites into receiving water bodies, to the emission of nitrogenous compounds from burning fossil fuels, numerous human activities can contribute to nitrogen pollution. One of the major pathways of $\mathrm{N}$ into the environment is through wastewater effluent that may be discharged into rivers and lakes. Wastewater contains human waste such as urine that is a source of ammonia, resulting in its high concentrations in wastewater. As a result, one of the important objectives of wastewater 
treatment is to ensure successful removal of nitrogen and phosphorus compounds from the wastewater using secondary treatment or the biological treatment process.

One type of biological treatment of wastewater that is commonly utilized is known as the activated sludge process which is an engineered system employing aerobic microorganisms to reduce the biochemical oxygen demand and eliminate toxicity. The degradation of organic and inorganic compounds is dependent on the activity of distinct groups of microorganisms which are critical for the biological treatment of wastewater.

Ammonia is a major constituent of wastewater because mammals, including humans release the nitrogenous compound ammonia (in the form of urea) as a metabolic waste. Ammonia is the waste produced by the metabolism of nitrogen-containing compounds like proteins and nucleic acids, but then is converted into urea or uric acid before being excreted as urine. Additionally, urea and organic nitrogen in wastewater influents are typically quickly converted to ammonia under aerobic and anaerobic conditions within sewer collection systems via a process called "ammonification" (USEPA, 2015). If ammonia concentrations are not lowered to regulatory levels, problems associated with eutrophication, toxicity and poor discharge quality may arise (Ahn, 2006). To avoid these environmental consequences, the decrease in ammonia concentrations and ultimately the removal of nitrogen from wastewater is the result of natural biological processes which includes uptake, biological nitrification and denitrification (generically termed "biological nitrogen removal"), and anaerobic ammonia oxidation (anammox).

Nitrification and denitrification are major microbial mediated processes responsible for the reduction of nitrogenous compounds in the environment. The nitrification process occurs in two steps and relies on the metabolic activity of two different groups of bacteria. 
Firstly, the ammonia is converted to nitrite by ammonia oxidizing bacteria (AOB) through a process called ammonia oxidation. This step is followed by nitrite oxidation which involves the conversion of nitrite to nitrate by nitrite oxidizing bacteria (NOB) (Ahn, 2006). Ammonia oxidation is generally considered the rate limiting step of nitrification. This process first involves converting ammonia to hydroxylamine, and this reaction is catalyzed by the key enzyme ammonia monooxygenase (AMO). This step is followed by the oxidization of hydroxylamine to nitrite by the enzyme hydroxylamine oxidoreductase (HAO) (Rotthauwe and Witzel, 1997).

The activated sludge process commonly contains ammonia oxidizing bacteria that are considered "the engines" of nitrification which convert ammonia to nitrite and have been previously detected in the secondary wastewater treatment process (Kowalchuk and Stephen, 2001). Most known AOB in wastewater treatment plants are $\beta$-proteobacteria belonging to the genus Nitrosomonas (Park and Noguera, 2004). To date,16 different AOB species have been cultured such as Nitrosomonas europea and Nitrosomonas oligotropha. Understanding the ecology and parameters that affect the physiology of AOBs has become mandatory because nitrification is considered the "Achille's heel" of many wastewater treatment plants (WWTPs) and the causes for nitrification breakdown events are not always obvious (Wagner and Loy, 2002). If nitrifiers have been washed out of a WWTP, the recovery of the nitrification process can take very long with doubling times between $8 \mathrm{~h}$ and several days or weeks, owing to the slow growth rates of the nitrifiers (MartensHabbena et al., 2009; Wagner and Loy, 2002).

To date, ammonia oxidizing bacteria have garnered considerable attention because they were thought to be the only group capable of performing the first and the rate limiting 
step of nitrification (Francis et al., 2005). This all changed when the first ammonia oxidizing archaea (AOA) strain Nitrosopumilis maritimus was isolated using inoculum from the rocky substratum of a tropical marine aquarium tank (Könneke et al., 2005). This member of the newly proposed phylum Thaumarchaeota is also capable of chemolithotrophic ammonia oxidation and thus challenged the proposed mechanisms of biogeochemical cycling of nitrogen. To date, N. maritimus is the only marine ammonia oxidizing archaea that has been cultured. However, using the same enrichment approach other AOA have now been isolated from soils and geothermal environments (Hatzenpichler, 2012; Stahl and de la Torre, 2012). Nitrosotalea devanaterra has been detected in soil samples (Leininger et al., 2006). Candidatus nitrososphaera has also been enriched from the biomass of hot springs (Hatzenpichler et al., 2008).

It was previously thought that archaea mostly inhabit extreme environments. Since then the search for AOAs has resulted in detecting their presence in soil (Leininger et al., 2006), marine habitats (Wuchter et al., 2006) and estuarine sediments (Beman and Francis, 2006). Interestingly, there is evidence that AOA may be more dominant than the AOB population in a variety of these habitats including soils (Leininger et al., 2006), marine habitats (Wuchter et al., 2006) and sediments (Beman and Francis, 2006). These findings also support the notion that the contribution to nitrogen cycling in soil and marine habitats may be more attributable to AOA than AOB.

Although studies have demonstrated that the stoichiometry of bacterial and archaeal ammonia oxidation is indistinguishable (Martens-Habbena et al., 2009), there are differences in the biochemistry of ammonia oxidation performed by both groups. The mechanism is far from being completely understood however there are two important 
distinctions that are currently being investigated. Firstly, it is suggested that AOA utilize copper rather than iron as the major redox active metal in electron transfer reactions. Next, AOA lack any homologs to the bacterial HAO protein that converts hydroxylamine to nitrite in ammonia oxidation (Stahl and De La Torre, 2012). Differences have also been identified in the environments where ammonia oxidizing archaea and bacteria dominate. For example, AOA have been detected in environments with low ammonia concentrations such as open ocean, marine water columns, sediments and hot springs (De La Torre et al., 2008; Hatzenpichler et al., 2008; Wuchter et al., 2006). The ability to survive in such low concentrations was explained by the discovery that AOAs have the highest substrate affinity reported for any microorganisms thus allowing them to outcompete AOB in accessing ammonia (Martens-Habbena et al., 2009).

With the discovery of their presence and dominance in agricultural soils, AOA appear to be potential role players in the global N-cycle (Leininger et al., 2006). However, in municipal wastewater treatment plants, the prevalence of AOA and their role in ammonia oxidation is still unresolved. Park et al. (2006) was the first to report the detection of $\mathrm{AOA}$ in five treatment plants with influent characteristics of low ammonia and low dissolved oxygen. This opened the possibility that AOA can oxidize ammonia with less oxygen demand and consequently lower cost and energy consumption. Park et al. (2006) identified 75 archaeal gene sequences from activated sludge samples demonstrating their presence in manmade systems. However, the role of AOA and their abundance in activated sludge systems has not yet been fully examined.

In municipal wastewater treatment plants, conflict remains regarding the importance of AOA in ammonia oxidation. For instance, in domestic wastewater, the AOB 
were detected at higher numbers in high dissolved oxygen conditions (Park and Noguera, 2004) and when the influent ammonium concentration was high (36.1- $422.3 \mathrm{mg}$ N/L) (Kim et al., 2013). Wells et al. (2009) suggested that AOB outnumber AOA by more than three orders of magnitude, citing that AOA may be minor contributors to ammonia oxidation in highly aerated activated sludge. In comparison, it was also found that in all municipal wastewater treatment plants receiving low ammonium influent (5.6-11.0 mg $\mathrm{N} / \mathrm{L}$ ), the AOA amoA level was higher than that of the AOB amoA level in two of the four municipal wastewater treatment plants examined in Bangkok (Limpiyakorn et al., 2011). These studies mainly focused on the abundance of AOA within the treatment plants, however, the contribution of AOA in ammonia oxidation that occurs during wastewater treatment remains a mystery. Due to inconsistencies regarding the abundance and contribution of ammonia oxidizing microorganisms, this project aims to address the presence and activity of AOA and AOB in the activated sludge treatment system of a fullscale MWTP.

This study aims to investigate the occurrence, distribution and function of AOA and $\mathrm{AOB}$ in a full-scale municipal activated sludge system. The primary focus of this report is to detect and quantify the presence of ammonia oxidizing archaea and bacteria from various stages of a full-scale municipal wastewater activated sludge treatment system using both the 16S rRNA and functional gene amoA as indicators. Secondly, this study will also examine the function of $\mathrm{AOA}$ and $\mathrm{AOB}$ within the activated sludge system. It is hypothesized that population dynamics between ammonia oxidizers may be crucial in municipal wastewater treatment systems to sustain nitrification under dynamic conditions. This research finding on the abundance of ammonia oxidizing archaea and their function 
in all stages of a full-scale activated sludge system will extend the understanding of operational and environmental parameters as influential factors for occurrence and function of AOA in WWTPs.

\subsection{Purpose}

During the treatment of wastewater, if ammonia concentrations are not lowered to safe levels, then problems associated with eutrophication and toxicity is inevitable in receiving water bodies. Ammonia concentration in wastewater is decreased through a microbial mediated process called ammonia oxidation where only aerobic ammonia oxidizing bacteria were thought to play a major role. However, recent evidence suggests that ammonia oxidizing archaea are also present in activated sludge systems but their contribution to the reduction of ammonia concentrations has not yet been fully understood. The role of nitrification in wastewater treatment is paramount for the reduction of nitrogen in municipal wastewater because the release of nitrogen in the effluent can impact the overall health of ecosystems, yet there is a lack of complete understanding of the ecology of the microbes that mediate this process and the impacts of human disturbances on their activity and growth. Thus, the purpose of this research is to determine the contribution of $\mathrm{AOB}$ and $\mathrm{AOA}$ in ammonia oxidation in a municipal wastewater treatment process. The overall goal is to quantify the abundance of each group through the wastewater treatment process, assess the activity of each group and determine whether the system supports redundancy for ammonia removal. This research will examine the nature of functional redundancy between $\mathrm{AOA}$ and $\mathrm{AOB}$ and how this relationship can impact the ammonia oxidation process under various conditions in activated sludge systems. 


\subsection{Hypothesis and Objectives}

In this research the working hypothesis was that, in the activated sludge process of a full-scale municipal wastewater treatment plant, there is functional redundancy between ammonia oxidizing bacteria and ammonia oxidizing archaea populations enabling the oxidation of ammonia to be a stable process.

To test this hypothesis the following objectives of the study were established as follows:

1. To determine if the presence of pharmaceutical compounds Tetracycline and Ibuprofen will have any effects on the community composition and diversity of microorganisms present in activated sludge.

2. To determine the abundance of $\mathrm{AOA}$ and $\mathrm{AOB}$ in all stages of a full-scale activated sludge system being utilized in a municipal wastewater treatment plant. The ratio of each group relative to the total heterotrophic population will be determined using $\mathrm{qPCR}$ to quantify the $16 \mathrm{~S}$ rRNA gene in each group relative to the total heterotrophic population.

3. To determine the absolute abundance of each ammonia oxidizing population in the activated sludge treatment system. The abundance ratios will be determined using qPCR to quantify the $a m o A$ functional gene in each group.

4. To determine AOA and AOB contributions to the overall nitrification potentials in activated sludge systems by using the RT-qPCR assay to target and quantify the amoA gene in transcriptionally active ammonia oxidizing organisms in each population

5. To monitor the AOB and AOA community diversity in activated sludge systems and identify members of the AOA community using DGGE, cloning and Sanger Sequencing. 
CHAPTER 2: BACKGROUND 


\section{Background}

\subsection{The Importance of Wastewater Treatment}

As the global population continues to increase, the availability of fresh water resources becomes more significant. The world is nearly surpassing a population of 9 billion people that will continue to put severe pressure on the world's water systems. Statistically worldwide, 2.5 billion people are living without proper sanitation (Unicef, 2015). Over $70 \%$ of the people who lack sanitation, or 1.8 billion people, live in Asia. For instance, China has a rapidly growing economy where water is a scarce resource as just $8 \%$ of the world's fresh water is available to meet the needs of $22 \%$ of the world's population (Geissen et al., 2015). What was once thought of an as endlessly renewable source, is now reaching a tipping point that may lead to irreversible catastrophic consequences. Due to a wide range of human activities such as industrialization, globalization, population growth, urbanization and with warfare, numerous threats such as climate change, overuse of water resources and pollution are on the horizon. In comparison, the strategies and advancement in water conservation and maintenance are lagging behind. Climate change has the potential to cause an increase in the frequency of severe droughts, heat waves, floods and storms that may severely impact the water cycle. Many countries also are using improper techniques and cheap technologies to withdraw water from ground resources and rivers due to demand for irrigation and/or industrial purposes. And lastly pollution, from anthropogenic sources, is one of the main contributors that impacts water quality and causes detriment to fresh water resources. According to the world health organization (WHO), industrialized countries have extensive experience of the problems caused by water pollution and the strategies and technologies available to control it (WHO, 2014). 
However, in the developing world, although pollution is increasing rapidly with urbanization and industrialization, most countries have very limited experience in pollution control measures or with the institutional and legislative frameworks needed to make such measures effective (Enderlein and Williams, 1997).

Water pollution can lead to numerous detrimental effects and burden a society's health, safety, economy and destruction of the environment. Firstly, pathogenic microorganisms that may be present in drinking water can cause a significant amount of disease. Diarrheal disease alone amounts to an estimated 3.6\% of the total DAILY global burden of disease and is responsible for the deaths of 1.5 million people every year (WHO, 2014). It is estimated that $58 \%$ of that burden, or 842,000 deaths per year, is attributable to unsafe water supply, sanitation and hygiene and includes 361,000 deaths of children under age five, mostly in low-income countries (Geissen et al., 2015).

Human activities are resulting in accelerated waste production and that is also a major source of pollution and is responsible for excessive inputs of phosphorus, nitrogen and pesticides from non-point sources into water bodies threatening biodiversity and human health. This is called nutrient pollution and according to the environmental protection agency (EPA) is one of America's most widespread, costly and challenging environmental problems, caused by excess nitrogen and phosphorus in the air and water (USEPA, 2015). Nutrient pollution has impacted many streams, rivers, lakes, bays and coastal waters for the past several decades, resulting in serious environmental and human health issues, and impacting the economy (EPA, 2017). Both nitrogen and phosphorus are nutrients that are natural parts of ecosystems required by all living organisms and are essential for life. For example, nitrogen and phosphorus support the growth of algae and 
aquatic plants, which provide food and habitat for fish, shellfish and smaller organisms that live in water. Additionally, agricultural plants require nitrogen to have proper growth and their productivity is usually limited by the availability of nitrogen in the soil. To combat this, farmers supply nitrogen in available forms such as nitrate and particularly ammonia fertilizers to maintain crop production (Bernhard, 2010). This results in the release of excess nitrogen and phosphorus into receiving waters that may lead to eutrophication of downstream water bodies causing photosynthetic algae to grow significantly faster than ecosystems can handle. Significant increases in algae harm water quality, food resources and habitats, and decrease the oxygen that fish and other aquatic life need to survive. Large growths of algae are called algal blooms and they can severely reduce or eliminate oxygen in the water, leading to illnesses and death in fish. This can have severe effects on the fishing and aquaculture industries (Bernhard, 2010). Some algal blooms are also harmful to humans because they produce elevated toxins and bacterial growth causing illness and toxicity and thus decrease the recreational value of major lakes and rivers.

In addition to agricultural input, one major source of pollution arises from huge volumes of wastewater discharge that is pumped into lakes and river systems. Wastewater is known as "used" water that is a mixture of liquid and solid materials that is expelled as waste from residential, industrial and agricultural activities (City of Toronto, 2010). Every day, 2 million tons of sewage, industrial and agricultural waste are discharged into the world's water (UN WWAP, 2003). The UN estimates that the amount of wastewater produced annually is about $1.5 \times 10^{15} \mathrm{~L}$, six times more water than exists in all the rivers of the world (UN WWAP, 2003). If the necessity of reducing the amount of pollutants in used water being discharged into the environment is not understood soon, then the world 
might be heading backwards where societies lived in foul smelling streets, had little understanding of water preservations and maintenance and be susceptible to outbreaks of life threatening diseases due to pathogenic bacteria in the polluted water.

Biological wastewater treatment is one of the most important contributions to maintaining the wellbeing of the global population and protection and preservation of natural water resources. Wastewater treatment ensures that water quality meets standards that will not affect aquatic communities, fisheries, drinking-water supply, irrigation, and recreation. Specifically, in Canada, wastewater treatment is a huge benefit to Canadian citizens since it allows all Canadians access to clean, non-contaminated and pollutant free lakes and river systems. Often overlooked and undermined due to the high quality and standards of wastewater treatment programs in Canada, the significance of wastewater treatment is not always prioritized. The overall water management objectives of wastewater treatment are associated with the removal of pollutants in the used water and the protection and preservation of natural water resources. Additionally, of specific concern is the protection of human health by the destruction of pathogenic organisms present in wastewater prior to treated effluent being discharged to receiving waters. Nature has an amazing ability to cope with small amounts of water wastes and pollution due to the existence of large supplies of fresh water and the natural ability of surface waters to cleanse themselves over time. However, if billions of gallons of wastewater and sewage produced every day are not treated before being released back into the environment, the expected outcome will be catastrophic damages beyond a level nature can handle. 


\subsection{The Wastewater Treatment Process}

Wastewater treatment begins when WWTPs receive influent wastewater from the sewage system. The wastewater is subjected to a procedural step by step method which contains various stages (Figure 1). The goal of wastewater treatment is to provide safe and effective reduction of contaminants in wastewater and to operate under strict regulations and meet or exceed standards set by the province and federal government to protect public health and the environment.

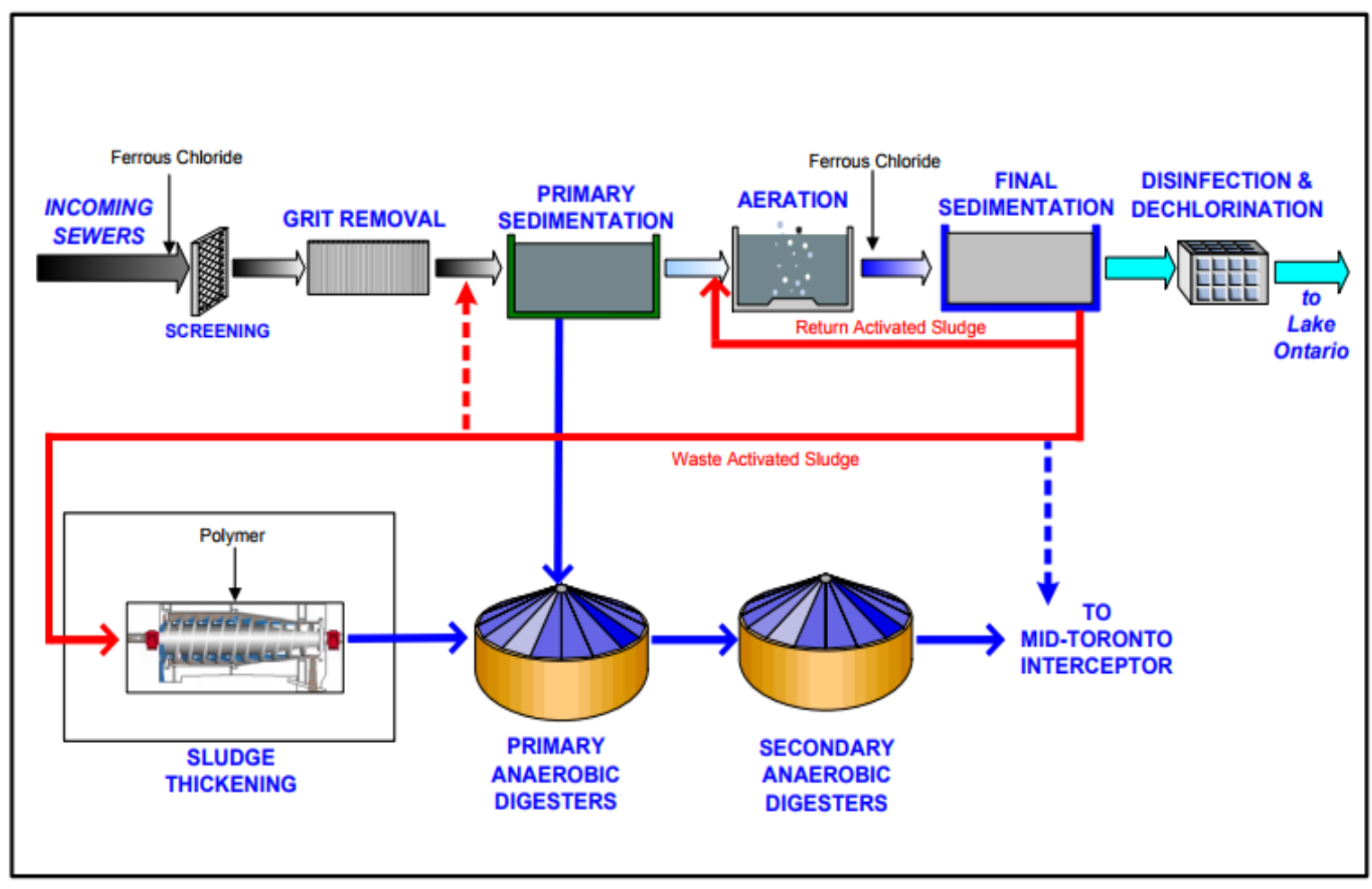

Figure 1. Humber Wastewater Treatment System Process Flow Diagram (City of Toronto, 2010)

The first step of wastewater treatment is also known as the preliminary stage. This process is designed to mechanically remove large debris from the influent wastewater using a series of screens or mechanical rakes. Ferrous chloride is often added as a coagulant that 
can convert soluble phosphorus into insoluble phosphorus that can be removed by precipitation. Ferric ions combine to form ferric phosphate which is insoluble for example.

Next, the primary clarification treatment step is utilized to physically separate solids from the wastewater. Using a slow velocity flow rate, the wastewater is pumped into the primary settling tanks and kept for several hours allowing the solid particles to settle. The separation of heavy solid organic material from the liquid, which settles near the bottom of these tanks, results in the formation of a raw or primary sludge. This sludge is collected and discharged to other processing operations for further treatment such as anaerobic digestion. Lighter materials such as fats and oils that float to the surface are usually skimmed off and extracted for further treatment. The remaining liquid which contains non-dissolving solids and other suspended material is called primary effluent that is pumped into the secondary treatment stage (City of Toronto, 2010).

The secondary treatment stage is called the biological treatment of wastewater. Microbial communities are crucial to the biological treatment process due to their ability to metabolize and degrade organic and inorganic materials. In biological treatment, oxygen is often required to provide an optimal condition for the growth of these microorganisms. There are various types of biological treatment processes that are employed worldwide such as the activated sludge process, biofiltration, rotating biological contactors or constructed aerated lagoons (Gogate and Pandit, 2004). Several factors such as wastewater characteristics, total inflow, cost etc., can determine which strategy is most applicable.

After mixing the wastewater with microorganisms and allowing flocculation to occur, the wastewater is directed into a secondary clarification tank, where again the wastewater is retained at a low velocity for several hours. This process is used as a 
solid/liquid separation step. During this retention period, the heavier suspended solids such as bacterial flocs settle to the bottom of the tank forming a material called raw sludge or settled sludge. The settled sludge is pumped into anaerobic digestion for further treatment (City of Toronto, 2010). The anaerobic process reduces the sludge volume, mitigates odours and destroys pathogens, thereby stabilizing the sludge. Also, by using anaerobic digestion in the treatment of wastewater sludge, methane gas is produced that may be important to offset energy demands. Methane is a known as biogas which is a renewable energy source and one of the promising solutions to the large environmental problem concerning waste handling, water pollution, $\mathrm{CO}_{2}$ emission, etc. (Berktay and Nas, 2008).

Municipal wastewater treatment plants generate sludge as a by-product of the physical, chemical and biological processes used in the treatment of wastewater. One of two things will happen to the settled sludge. Most of it will be returned to the aeration basins to keep enough activated solids in the tanks to maintain steady supply of biodegrading microorganisms and avoid a washout. This is known as the return activated sludge or RAS. A small portion of the sludge will be removed from the system. It is referred to as waste activated sludge or WAS. The remaining liquid is pumped into the disinfection tanks where the wastewater may be treated with chlorine or other means of disinfection. At the end of disinfection process, the treated effluent is released into the environment (City of Toronto, 2013).

If necessary, tertiary treatment is employed by some WWTPs to ensure further treatment. In some cases, tertiary treatment is required to lower concentrations of phosphorus and nitrogen from the wastewater. Rotating biological contactors for example may be a form of tertiary treatment. Although the strategy of wastewater treatment can 
vary among various locales worldwide, conventional wastewater treatment consisting of primary, secondary and disinfection remains one of the most utilized and stable methods and biological treatment remains its most significant component.

\subsection{Wastewater in Toronto}

Home to four major wastewater treatment plants (WWTPs) that serve a population of nearly 2.8 million citizens, the city of Toronto has a highly concentrated urban population that is responsible for contributing excessive organic, inorganic material and pathogenic bacteria to the sewer system. The practice of wastewater collection and treatment has been developed and perfected, using some of the most technically sound biological, physical, chemical and mechanical techniques available. As a result, public health and water quality are protected better today than ever before (City of Toronto, 2010). Consequently, the treatment of wastewater is an essential process to treat sewage so that final effluent does not contaminate the fresh and natural water resources that it is discharged into.

Wastewater is produced from residential and commercial activities such as taking showers, flushing a toilet, using the washing machine, cooking and cleaning. Next, the raw wastewater from various sources enters the sewer system or the collection system. This is a network of pipes specifically designed to transport millions of gallons of wastewater that are generated each day. Wastewater is characterized and identified based upon the source it arrives from. The term "domestic wastewater" is wastewater that is discharged from residential sources. This wastewater is commonly generated by activities such as food preparation, laundry, cleaning and personal hygiene (City of Toronto, 2010). Wastewater from the toilet is termed "black" and the wastewater from the kitchen and bathroom is 
termed "grey". They can be disposed of separately or they can be combined (WHO, 2014). In the city of Toronto, there are three types of sewer designs. Sanitary sewers carry wastewater that is released from a drain, toilet, sink or appliances such as washing machines or dishwasher. This wastewater from residences and businesses flows to treatment plants where it is cleaned before being released into Lake Ontario. The second type of sewage system is called the storm sewers that capture rainwater or snowmelt. Much of this is captured through catch basins that are the visible square grates on the side of the road. This water flows directly into nearby waterways including streams, rivers and Lake Ontario. The third type is known as combined sewers which transport both sanitary and storm water sewage to the wastewater treatment plant for processing (City of Toronto, 2010). Industrial/commercial wastewater is flow that is discharged from manufacturing and commercial activities such as printing, food and beverage processing.

\subsubsection{Humber Wastewater Treatment Plant}

The Humber wastewater treatment plant located in Toronto, began operating in 1960 with a starting capacity for treating wastewater of up to 227,000 cubic metres. The current capacity is 473,000 cubic metres which serves a population of approximately 651,000 (Etobicoke, York, portion of the west end of North York, and Toronto). Major treatment processes and equipment include screening and grit removal, primary treatment, secondary treatment, phosphorus removal, effluent disinfection and de-chlorination, final effluent pumping, waste activated sludge thickening, anaerobic sludge digestion and odour control. The plant uses a total of eight aeration tanks which use ceramic tile bubble diffusers to provide air and mix activated return sludge with primary effluent. The return sludge comes from sludge collectors in the tanks that sweep the settled sludge (primary sludge or 
raw sludge) into sludge hoppers located on the bottom of the tank at one end, from where the sludge is pumped to anaerobic digestion tanks. A two-stage, anaerobic, mesophilic sludge digestion process is utilized at the Humber Treatment Plant. This process reduces the sludge volume, mitigates odours and destroys pathogens, thereby stabilizing the sludge (City of Toronto, 2010). Treated effluent is discharged to Lake Ontario.

\subsection{Different Types of Biological Wastewater Treatment}

The occurrence of eutrophication is becoming a serious environmental issue. Nutrients such as nitrogen $(\mathrm{N})$ and phosphorus $(\mathrm{P})$ compounds present in wastewater are major factors because their presence at high concentrations can lead to problems associated with eutrophication in downstream water bodies. Not only that, the focus on waste minimization and water conservation in recent years has also resulted in the production of concentrated or toxic residues. It is of utmost importance to dispose off these residues in a proper manner as well as to keep the concentration of chemicals in the effluent stream to a certain minimum level in order to comply with the environmental laws, which are becoming more stringent these days (Gogate and Pandit, 2004). Thus, biological wastewater treatment or biological nutrient removal (BNR) is the primary focus of wastewater treatment.

There are numerous wastewater treatment processes based on the physical and chemical removal of contaminants at low operational costs, providing easy handling and have comparatively less harmful effects on the corresponding environment. There are different types of biological treatment systems that are applied such as rotating biological contactors (RBCs), oxidation lagoons and activated sludge systems. But these techniques rely on two fundamental processing options based on the structural configuration of the 
biomass. Firstly, the type of system can be based on traditional suspended growth in which the biomass grows in suspended or dispersed form in liquid medium without any attachment to the surface. The second type is called the fixed film and attached growth system, this system usually requires a medium that provides the surface area for the development of biofilms. During operation, the media carriers of the biofilms are kept in constant circulation. In an aerobic reactor the circulation is induced through the action of the air bubbles injected into the tank by a fine or coarse bubble diffuser system. In an anoxic reactor, a submerged mixer is typically supplied (Williams, 2002).

\subsubsection{Activated Sludge System}

The activated sludge system is one of the most common and most efficient methods used to degrade organic matter in wastewater especially with municipal wastewater (Pholchan et al., 2010). It has advantages over other methods due to its low operational cost and low maintenance requirements (NESC, 2003). Activated sludge systems comprise a multi-chamber reactor unit in which aerobic microorganisms are used to degrade organic components of wastewater to produce a high-quality effluent (Bocchiaro and Zamperini, 2016). In the activated sludge process, effluent from primary treatment is pumped into an aeration tank and is mixed with bacteria rich slurry known as activated sludge. These microorganisms can be considered the "engines" of wastewater treatment systems that oxidize the organic carbon present in wastewater to produce carbon dioxide, water and new cells that form small clusters or flocs during the aeration and mixing process (Bocchiaro and Zamperini, 2016). Constant supply of oxygen is required to maintain aerobic conditions in an aeration tank. Besides aerobic bacteria, anaerobic and/or nitrifying bacteria along with higher organisms can be present. Air or pure oxygen is pumped through the 
mixture and promotes bacterial growth, flocculation and decomposition of the organic and inorganic material. After aeration, the mixture is transferred to a secondary clarifier for settling of floc particles and the effluent free of solids can proceed for further treatment or discharge. A portion of the sludge is then recycled back to the aeration tank, where the process is repeated (Bocchiaro and Zamperini, 2016). A schematic of the entire process is shown in Figure 2.

To retain the growth of desired microorganisms which are significant to waste reduction and degradation of organic content, operational parameters for niche development, such as temperature, $\mathrm{pH}$, dissolved oxygen and solids retention time (SRT) also known as sludge age and mean cell retention must be optimized. This parameter is traditionally used in the design and operation of biological nutrient removal (BNR) systems to control for the presence or absence of desired microbial populations (e.g. nitrifiers) (Ahn, 2006).

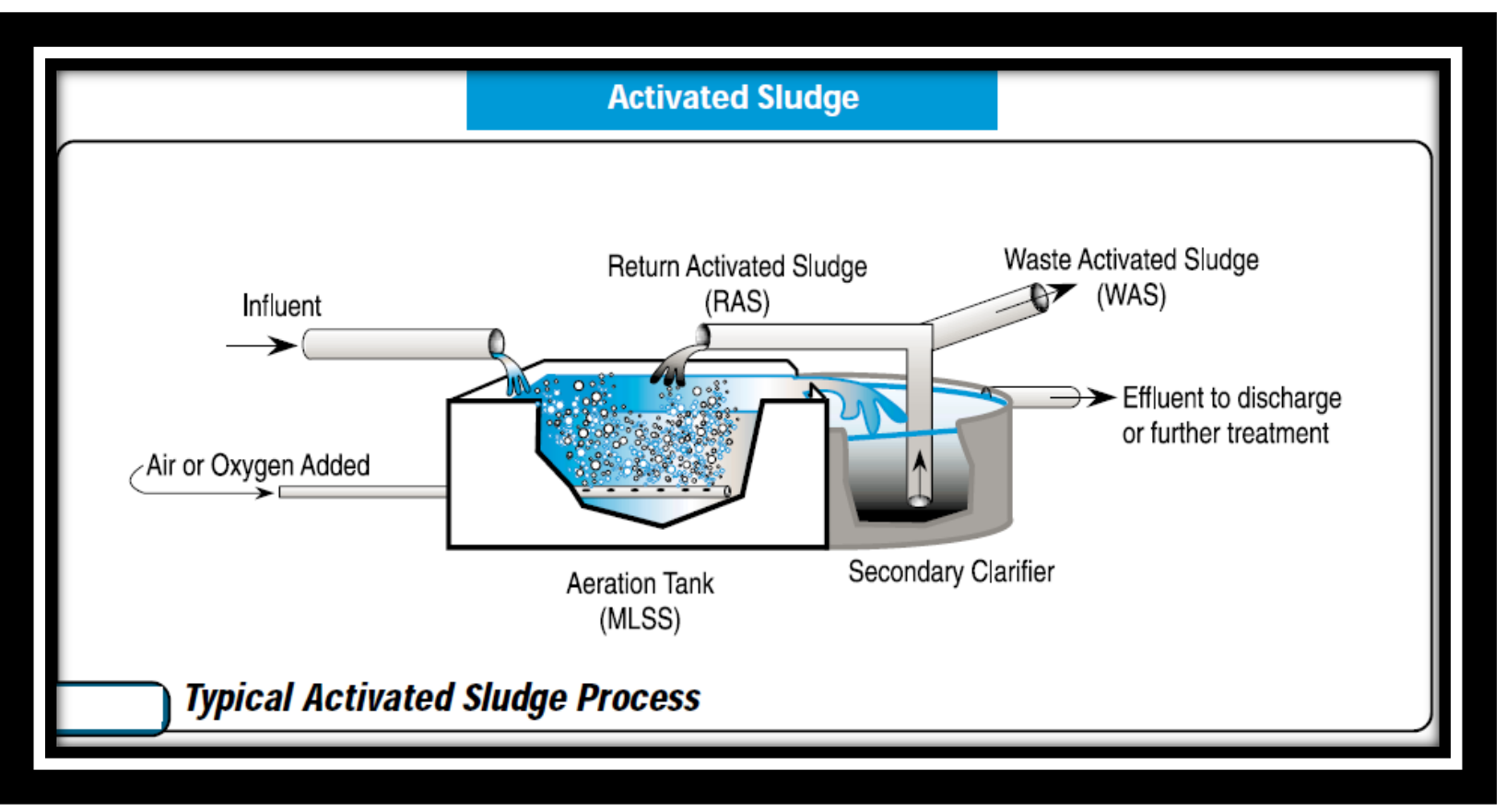

Figure 2. Activated Sludge Process (NESC, 2003) 


\subsubsection{Anaerobic Digestion}

The sludge produced during primary settling is directed to large enclosed tanks void of free molecular oxygen, known as anaerobic digester tanks. In these tanks, the presence of anaerobic bacteria can utilize the organic material present in the sludge as an energy source and produce carbon dioxide and methane gas. Anaerobic digestion is critical to achieve four major goals. First and foremost, fermentable organic from the influent wastewater are mixed with the return-activated sludge (RAS) and converted to volatile fatty acids (VFA) by heterotrophic organisms. Secondly, anaerobic digestion enables the reduction of sludge volume which is important in stabilizing the raw or primary sludge for post processing operations and ultimate disposal. Next, methane produced from anaerobic digestion can be used to offset the energy demand of the wastewater treatment plant ultimately reduce operating costs. And last but not the least, anaerobic digesters may contain anoxic zones, where the $\mathrm{NO}_{3}{ }^{-}$which is recycled from the aeration tank is converted to dinitrogen gas by facultative heterotrophic organisms (Ge et al., 2010). This results in the loss of $\mathrm{N}$ into the atmosphere and leads to the overall reduction of $\mathrm{N}$ from the wastewater. During the digestion period, typically 15 to 28 days, conditions suitable to maximize the biological activity of the anaerobic bacteria are maintained. The digester tank contents are heated to maintain a temperature of $35-37^{\circ} \mathrm{C}$, mixed to provide contact of organic material with bacteria and prevent the formation of a scum blanket (City of Guelph, 2012).

Conventional anaerobic digestion technology is based on a two-stage process, namely, a first thermophilic step with a short hydraulic retention time (HRT), acting as a pre-treatment to improve the hydrolysis rate, followed by a longer mesophilic step, aimed 
at achieving effective organic matter removal. The two-stage process may permit the separation of the hydrolytic and acidogenic steps from the methanogenesis; in the first stage, presenting faster kinetics, the organic matter degradation and the production of Volatile fatty acids are achieved via the action of a synergistic community of microorganisms, while in the second stage, acetoclastic methanogenesis can occur more effectively under higher pH conditions (Ge et al., 2010). Primary digesters have concrete roofs and are equipped with digester gas mixers, while secondary digesters have no mixers and are equipped with steel floating covers which accommodate changes in volume of stored gas and sludge. The wastewater contained in the second stage digestion tanks are periodically allowed to rest unmixed to encourage settling of the stabilized digested biosolids. Solids are withdrawn and directed to solids handling operations for excess water removal and further processing (Ge et al., 2010).

\subsection{Activated Sludge Microbial Community}

The goal of the activated sludge process is to convert non-dissolvable, colloidal and suspended particles into settled sludge that can be removed from the liquid component. However, the term "activated" arrives from the fact that activated sludge contains live aerobic microorganisms such as algae, bacteria, fungi and protozoa and the presence and syntrophic activity of these microbial communities belonging to different functional groups remain the central and most significant component of the activated sludge process (Xu et al., 2017). Activated sludge consists of a mixed community of microorganisms, approximately $95 \%$ bacteria and 5\% higher order organisms (protozoa, rotifers and invertebrates). The most predominant microorganisms are aerobic bacteria, but there are also substantial populations of fungi and protozoa. Rotifers and nematodes are most 
frequently found in systems with long aeration periods (Bitton, 2005). The functions of these microbial communities can lead to the reduction of not only excess $\mathrm{N}, \mathrm{C}$ and $\mathrm{P}$ compounds but other organic and inorganic contaminants that are present as well.

The metabolic activity of the microorganisms must be maintained to guarantee proper breakdown and reduction of undesirable compounds. Specific conditions must be met to ensure that the microorganisms present in the floc or activated sludge are in a state of proper growth and, therefore, working at maximum efficiency (Russell, 2006). The following conditions need to be met to ensure maximal benefit from the microbial community:

- First, the microbial community should be continuously supplied with sewage with a uniform and nutritionally adequate organic content. Too many variations in the organic load will lead to undesirable results.

- Second, the complete mixing of incoming wastewater and the microorganisms present in the aeration basin is necessary and should be achieved through aeration techniques.

- Third, oxygen must continually be supplied through diffused aeration to maintain a dissolved oxygen concentration of at least $1-2 \mathrm{mg} / \mathrm{L}$.

- Fourth, the effluent from the biological treatment tanks must be pumped forward into settling tanks (clarifiers) where separation of mixed liquor solids from the liquid can be completed (Metcalf and Eddy, 2003).

To ensure optimum operation, the operator may change the environment or process to encourage or discourage the growth of specific microorganisms. Changes in $\mathrm{pH}$, dissolved oxygen, temperature, dissolved solids and sludge age directly affects 
microorganisms and consequently, treatment efficiency. Although new technologies such as advanced oxidation and chemical oxidation are in development, the activated sludge system using the above conditions remains popular and economical choice. It is a process that is used by large communities that produce large volumes of wastewater. It has low construction cost and a relatively small land requirement (NESC, 2003).

\subsection{Methods to Study the Composition of the Microbial Community}

Prokaryotic microbial communities that are present in activated sludge or biofilm reactor systems are responsible for most of the carbon and nutrient removal from sewage and thus represent the core component of every biological wastewater treatment plant (WWTP) (Wagner and Loy, 2002).

The insights into ecophysiology and community composition of prokaryotes in wastewater poses various challenges because most microorganisms that are responsible for key processes in WWTPs are often not culturable. However, the advent of molecular techniques, that requires no culturing, has advanced our knowledge of the structure, composition and functioning of microbial communities in WWTPs (Malik et al., 2008). Molecular methods rely on the characterization of cellular constituents such as nucleic acids, proteins, fatty acids and other taxa-specific compounds. Such molecules can be extracted directly from environmental samples without the need for culturing and analysis of the molecular composition can be used to elucidate the composition of the microbial community. The next sections will discuss a few molecular techniques that are commonly used to study the physiology and characteristics of the wastewater microbial community. 


\subsubsection{Polymerase Chain Reaction (PCR)}

Polymerase chain reaction is an essential molecular technique due to its ability to produce millions of copies of a portion of a desired gene or the entire gene with high fidelity (Malik et al., 2008). This method has been widely used to detect, characterize and quantify microorganisms in soil and water. It is a commonly used method to amplify 16S rRNA, or its gene, prior to fingerprinting techniques. Simple PCR uses a pair of primers in a single amplification reaction. The primers are designed towards a target gene of interest. Another variant of the PCR technique which can simultaneously detect and quantify the amplified product while the reaction is occurring is a real-time PCR. This approach enables the detection and quantification of PCR amplicons during the early exponential phase of the reaction (Heid et al., 1996; Higuchi et al., 1993). Real-time PCR has an increased capability for quantifying gene copy numbers present in a given sample. It involves the use of fluorescent markers to quantify the product at the end of each amplification cycle and the amount of fluorescence is directly related to the amount of product at the end of each cycle in the PCR reaction. The above two variations are only useful for detection and quantification of genes; but provides no information regarding gene expression or microbial activity and function. Reverse-Transcription PCR or RT-PCR allows the quantification of gene expression using cDNA as the template. While the concept remains largely similar, RNA is first synthesized to cDNA by reverse transcriptase, and then qPCR is performed on the cDNA template (Espy et al., 2006).

According to Malik et al (2008), PCR can provide many advantages such as speed, accuracy and provide significant information on unculturable microbial species identification and community diversity. However, it is also affected by many factors. 
Firstly, the sufficient yields and quality of extraction and purification of DNA from environmental samples can be a major concern. Insufficient lysis of cells could result in the preferential extraction of DNA from gram-negative bacteria, while excessively harsh treatments may result in the shearing of DNA from readily lysed cells (Wintzingerode et al., 1997). Next, PCR amplification efficiency is susceptible to the presence of inhibitory substances that are co-extracted with nucleic acids which include humic acids, organic matter and clay particles (Malik et al., 2008).

Another factor is PCR bias that may be introduced at several points during the experiment. From sample collection, to transport and to storage, each step may introduce bias into subsequent microbial analysis. Thus, to avoid major alterations to the microbial compositions, samples must be extracted rapidly after collection.

Although like all other techniques PCR may have its short comings, it is still one of the most reliable molecular methods used for the detection and quantification of nonculturable microorganisms which make up $99 \%$ of unculturable bacteria present in environmental samples such as soil and water (Kowalchuk and Stephen, 2001).

\subsubsection{Denaturing Gradient Gel Electrophoresis}

The ability to monitor community diversity and microbial identification by denaturing gradient gel electrophoresis (DGGE) has been integral in molecular microbiology. All bacteria contain a 16S rRNA gene, which is highly conserved and is ubiquitous. The amplification of the 16S rRNA gene using PCR and specific primers can be used that target different taxonomic groups (from kingdom to genus) since they are conserved yet variable enough to provide phylogenetic comparisons of microbial communities (Muyzer and Ramsing, 1995). Once the amplicon is generated through PCR, 
microbial community compositions can be analyzed based on profiles generated from the physical separation of rRNA or DNA sequences on a gel (Muyzer and Ramsing, 1995). Denaturing gradient gel electrophoresis is a technique that can separate amplified rDNA fragments of the same length but with different base pair (Guanine and Cytosine) compositions (Fischer and Lerman, 1983). The separation of bands in DGGE is dependent on the decreased electrophoretic mobility of partially melted double stranded DNA molecules in polyacrylamide gels containing a linear gradient of DNA denaturants or a linear temperature gradient (Muyzer and Smalla, 1998). The PCR-amplified DNA fragments are generally limited in size to $500 \mathrm{bp}$ and are separated on the basis of sequence differences, not variation in length. The number of bands produced during DGGE is proportional to the number of dominant species in the sample. This is a method of choice when the desired information does not have to be as phylogenetically exhaustive as that provided by $16 \mathrm{~S}$ rRNA gene clone libraries, but is still precise enough determine the dominant members of microbial communities with medium phylogenetic resolution (Malik et al., 2008). For environmental or contaminated source samples where the microbial diversity is largely unknown, DGGE/TGGE technique provides the opportunity for the identification of the microbial population through the excision and sequencing of bands. This is particularly useful when working with soil and wastewater samples, where the sample contains various types of contaminants and inhibitors that may not make it suitable for other methods (Piterina and Pembroke, 2013).

\subsection{Structure and Composition of Microbial Communities in Activated Sludge}

Understanding the microbial ecology of wastewater treatment plants in situ allows the identification of microorganisms that function to remove carbon and nutrients from 
sewage. The development of molecular approaches has helped to study bacterial diversity in WWTPs in a cultivation-independent manner. For example, fluorescent in situ hybridization (FISH) can be used to visualize and study the microbial community structure (Wagner and Loy, 2002). The coexistence of nitrifying and denitrifying bacteria was also recently discovered using PCR coupled with DGGE that examined community diversity of nitrifiers (Chen et al., 2017). Recently, high throughput 454 pyrosequencing of microbial communities of activated sludge samples from oxic and anoxic zones has determined the microbial composition of each niche (Wang et al., 2009)

The organisms most directly involved in wastewater treatment are the bacteria. They dominate all other groups, in number and biomass, and affect the process of mineralization and elimination of organic and inorganic nutrients (Madoni, 2011). Based on early studies focusing on the $16 \mathrm{~S}$ ribosomal ribonucleic acid (rRNA) gene library analysis, it is found that activated sludge is dominated by Beta-, Alpha- and Gammaproteobacteria a well as the Bacteroidetes and the Actinobacteria (Wagner and Loy, 2002). Recently, this has been supported by Xu et al. (2017) who state Proteobacteria, Chloroflexi, Bacteridetes, Actinobacteria, Verrucomicrobia Acidobacteria and Nitrospirae are the most common phyla found in activated sludge from full scale municipal WWTPs. Proteobacteria is observed to dominate all phyla (21-65\%) with the $\beta$ proteobacteria being the most abundant class and mainly responsible for the organic and nutrient removal (Cydzik-Kwiatkowska and Zielińska, 2016).

Considerable attention must also be given towards bacteria responsible for nitrogen removal because nitrification is considered the Achille's heel of many WWTPs. Once nitrifiers suffer from a washout or a breakdown event, the causality is not obvious and due 
to their extremely slow growth rate, their recovery is time consuming and may be costly (Wagner and Loy, 2002). Nitrogen removal in the activated sludge system is achieved by the microbial mediated processes nitrification and denitrification. In nitrification two major groups of bacteria called the ammonia oxidizing bacteria (AOB) and nitrite oxidizing bacteria (NOB) play a major role. Most known AOB in wastewater treatment plants are $\beta$ proteobacteria (Park and Noguera, 2004). The genera within family Nitrosomonadaceae such as Nitrosomonas and Nitrosospira are the most detected AOB in WWTPs. The actual picture became far more complex when molecular tools used for diversity analysis became based on the amoA gene which encodes for the active site subunit of the ammonia monooxygenase present in all ammonia oxidisers. The amoA approach revealed that ammonia oxidisers of the genus Nitrosospira, in contrast to other ecosystems (Kowalchuk and Stephen, 2001), are not important in those full-scale nitrifying WWTPs analysed so far (Daims, 2001; Park and Noguera, 2004). To date 16 different AOB species have been cultured such as Nitrosomonas europea and Nitrosomonas oligotropha. The predominant NOB phylum in activated sludge from WWTPs belong to Nitrospirae (Nielsen et al., 2010) with the most ubiquitous and abundant genus being the Nitrospira. The advent of molecular techniques has rapidly advanced the understanding of microbial community structure and function that was previously deemed impossible to know (Xu et al., 2017).

Protozoan populations also play an important role and are commonly found in the mixed liquor of activated sludge tanks. The parameter of low organic load and high sludge retention time in the current systems of wastewater treatment can lead to the proliferation of protozoa such as ciliates, flagellates, amoebae and even small metazoa (Madoni, 2011). It is believed that protozoa contribute to wastewater treatment by clarifying the effluent, 
which is accomplished by their ability to graze on bacteria (Madoni, 2011). Some protozoa such as crawling ciliates and other forms, can eat flocculated bacteria, but most protozoa are ciliates that can only graze on suspended bacteria and particles resulting in a clearer effluent. Studies have also been performed on the role of protozoa predation in nitrogen cycling in activated sludge (Pogue and Gilbride, 2007). It has been determined that the presence of protozoa can increase the per-cell nitrification activity of the activated sludge microbial community.

There are 228 protozoa species listed for the activated-sludge plants, about 160 belong to the phylum Ciliophora, but only a limited number of these have been observed frequently. The ciliate community of the activated sludge is slightly different from that of the other systems such as percolating filters, but some species, such as Acineria uncinata, Vorticella convallaria, Vorticella microstoma, Opercularia coarctata and Aspidisca cicada, are commonly observed in both processes (Madoni et al., 2011). In a study devoted to reconstructing the species structure of the ciliate community in activated-sludge processes, it was found that of the 45 species present in 39 different plants, five were recurrent and representative of the principal community (Aspidisca cicada, Vorticella convallaria, V. striata octava, Epistylis plicatilis and Trochilia minuta) (Madoni et al., 2011).

Although dominant phyla and genera are often shared among activated sludge samples from different WWTPs, it is evident that the microbial structure and abundance ratios are quite dissimilar. Xu et al. (2017) observed discrepancies in microbial abundance and structure distribution from six WWTPs. They report 37 microbial clades with seven bacterial phyla of Nitrospira, Planctomycetes, Gemmatimonadales, Chloroflexi, 
Acidobacteria and Proteobacteria presented statistically significant differences. They also observed differences in the distribution of $\mathrm{AOB}, \mathrm{NOB}$ and denitrifiers among the six WWTPs. The common explanation of such discrepancies is that environmental parameters and operating conditions have strong selective pressure on the microbial community structure and overall efficiency of the activated sludge process. That is why information about microbial community diversity and its functions along with parameters that affect their growth and biochemical activities can be very useful.

\subsection{Factors Affecting the Composition and Function of Activated Sludge}

Typically, a mainstream biological nutrient removal process consists of anaerobic, anoxic and aerobic zones and a secondary settler with multiple recycle streams (Lee et al., 2006). In the aerobic zone, oxygen is vital to the activated sludge process because it promotes the growth of aerobic bacteria that metabolize waste. In the aerated activated sludge tanks, the oxygen concentration is maintained from 1 to $2 \mathrm{mg} / \mathrm{L}$. In the presence of dissolved oxygen, aerobic microorganisms degrade organic material and remove ammonia via nitrification. The heterotrophic bacteria obtain their oxygen using the following sequence: free and dissolved oxygen, nitrate, and then sulfate. An anoxic zone is established when the dissolved oxygen levels are kept below $1 \mathrm{mg} / \mathrm{l}$ and must be as close, without reaching $0 \mathrm{mg} / \mathrm{l}$, as possible in the unaerated basin. A target would be 0.2 to 0.5 $\mathrm{mg} / \mathrm{l}$ (ANUA, 2011). In the anaerobic zone, fermentable organic matter from the influent wastewater is mixed with the return-activated sludge (RAS) and converted to volatile fatty acids (VFA) by heterotrophic organisms. Denitrification is also performed by denitrifying bacteria under these conditions and is responsible for the reduction of nitrogen by producing $\mathrm{N}_{2}$ gas as the end product (Lee et al., 2006). If the zone has no free or dissolved 
oxygen, the microbes will obtain their oxygen source by breaking down the nitrates that are returned to the anoxic zone in the activated sludge.

Temperature and $\mathrm{pH}$ affect the microbial community present in the activated sludge process. Reports indicate that the optimal temperature range should fall in the range of 15$25{ }^{\circ} \mathrm{C}$ and the $\mathrm{pH}$ should be maintained at 6.5 to 8.5 to support most groups of functionally active microbes (Viessman and Hammer, 1998).

The SRT is another design parameter that can have significant impact on the structure and function of the activated sludge microbial community. This parameter affects not only the performance of nutrient removal and sludge characteristics but also the production of secondary pollutants such as nitrous oxides (Gao et al., 2013). Increasing the resident time of activated sludge systems can allow important microorganisms that have an extremely slow growth rates and doubling times to establish themselves within the system. For example, lots of wastewater treatment plants are operated at long SRTs both to enhance nitrification and to reduce excess sludge production. Autotrophic nitrifiers are extremely slow growing, thus a long SRT is needed to maintain a certain amount of nitrifiers and ensure nitrification. Pai et al. (2010) reported that ammonia removal efficiency was reduced from $90 \%$ to $26 \%$ when the SRT was decreased from 15 to 5 days. In contrast, having a long SRT may affect phosphorus removal efficiency. Therefore, it is important to examine the effect of SRT on the biological nutrient removal (BNR). Besides operational parameters, the microbial community composition, abundance and ecophysiology may also be affected by the presence of contaminants in wastewater. Many classes of contaminants are present in wastewater and that is heavily dependent on the 
source it arrives from. The next sections will cover two major groups, pharmaceuticals and the nutrient nitrogen and their effects on biological wastewater treatment.

\subsection{Types of Contaminants in Activated Sludge}

The presence of various classes of contaminants is also important to consider when monitoring active microbial populations in the activated sludge process. Pharmaceuticals are a new class of "emerging contaminants" that are being released into the environment daily through the wastewater stream (Figure 3). It is observed that the majority (30-90\%) of pharmaceutical compounds ingested by humans are excreted in the urine or feces and can enter the wastewater as pseudo-persistent compounds because of the continuous influx (Ternes et al., 2004). Additionally, other streams of pharmaceutical waste can arrive from various waste streams such as hospital wastewaters.

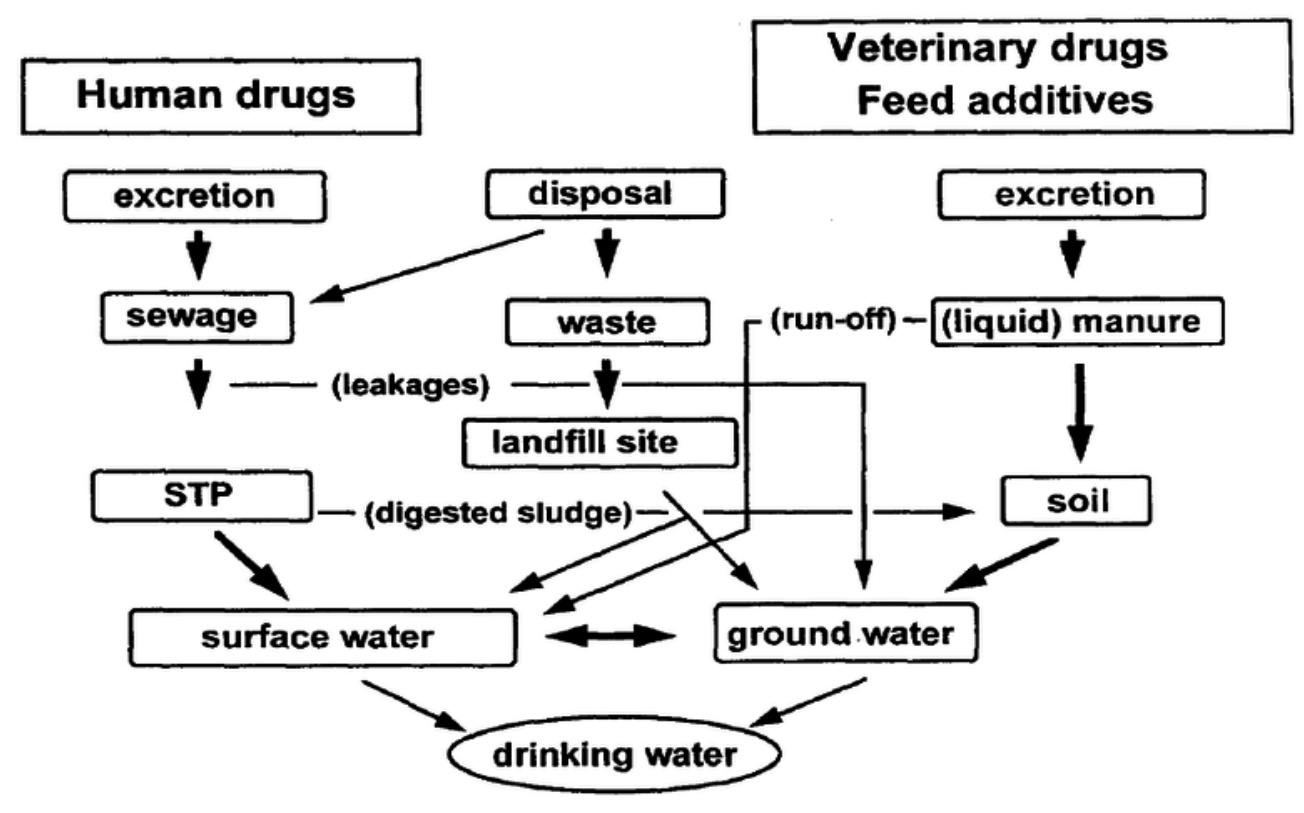

Figure 3. Pharmaceutical compounds from various wastewater streams (Ternes et al., 2004) 


\subsection{Antibiotics}

Antibiotics are a class of naturally-occurring, semi synthetic and/or fully synthesized compounds with antimicrobial activity. These compounds are used to combat bacterial infections and are consumed in large volumes by humans and animals to treat and prevent diseases. One major class of antibiotics found in wastewater are Tetracyclines. Tetracyclines are a group of broad-spectrum antibiotics first discovered in the early 1940s and later approved by the FDA in 1948. Tetracyclines also have sub-classifications such as short acting (i.e. tetracycline), intermediate-acting (i.e. demeclocycline) and long-acting compounds (i.e. minocycline and doxycycline). Specifically, Tetracyclines inhibit protein synthesis by blocking aminoacyl tRNA and preventing it from binding to the $30 \mathrm{~S}$ ribosome (Cetecioglu et al., 2014). Tetracyclines have been commonly used for both human and animal care, however, the majority of it's use today is in veterinary medicine and animal husbandry, such as growth promotion and prevention of bacterial infections in livestock (Gujarathi et al., 2005). Tetracyclines have been detected in various environments such as soil, water, wastewater and activated sludge (Toth et al., 2011; Zhang et al., 2013) with concentrations ranging from a 2 ng/L to more than 4 ug/L (Ma et al., 2015).

The presence of antibiotics such as tetracycline in wastewater poses two major risks. Firstly, these compounds are designed to inhibit or kill the target microorganisms. Thus, their presence may cause deleterious effects on established microbial communities responsible for the degradation of $\mathrm{C}$ and minimization of $\mathrm{N}$ and $\mathrm{P}$ compounds. For example, nitrification which is a crucial process for the oxidation of ammonia, may be more susceptible to antibiotics because autotrophic nitrifiers are less abundant and have a slower growth rate. This results in the presence of lower numbers of autotrophic bacteria 
than heterotrophic bacteria. One study demonstrated that a mixture of antibiotics ciproflaxin (CIP), gentamycin (GM), sulfamethoxaole (SMZ), trimethoprim (TMP) and vancomycin (VA) at a concentration of $30 \mathrm{mg} / \mathrm{L}$ inhibited nitrification at the nitrite oxidation step resulting in accumulation of nitrite (Schmidt et al., 2012). In another study, Watkinson et al. (2004) found that three antibiotics, erythromycin, clarithromycin, and amoxicillin at $1000 \mu \mathrm{g} / \mathrm{L}$ concentrations significantly decreased denitrification rates by benthic bacteria. Other studies have also supported that changes in the microbial community composition from salt marsh sediment (Córdova-Kreylos and Scow, 2007), and agricultural soil amended with (Kotzerke et al., 2008) and without manure (Hammesfahr et al., 2008; Li et al., 2011; Yang et al., 2009) occurred when exposed to antibiotics or pharmaceuticals.

Secondly, wastewater treatment plants can provide an environment for the establishment and propagation of antibiotic resistance bacteria (Watkinson et al., 2007). The nutrient rich environment that is found in biological treatment may provide ideal conditions for the spread of antibiotic resistance due to rapid growth of bacterial generations. Natural antibiotic producers are already resistant to the antibiotics they produce (Jury et al., 2011). Other bacteria develop resistance by developing or acquiring antibiotic resistance gene using mechanism such as horizontal gene transfer. Bacteria can demonstrate resistance by altering permeability barriers across bacterial (Jury et al., 2011) outer membranes, preventing uptake of the compound by inhibiting its corresponding transport carrier, modifying the target's binding sites so that it no longer can recognize the antibiotic and by chemically or with the use of enzymes degrade the antibiotic (Jury et al., 2011). 


\subsection{Non-Steroidal Anti-Inflammatory Drugs (NSAID)}

There are many classes of contaminants that make their way into wastewater influent. One group is the non-steroidal anti-inflammatory drugs (NSAID) such as ibuprofen. Ibuprofen is an antipyretic and analgesic drug that is commonly used by children and adults (Aslam et al., 2010). It exerts anti-inflammatory and analgesic effects by nonselective inhibition of the cyclooxygenase enzymes COX-1 and COX-2 which are required in the synthesis of prostaglandins (Bushra and Aslam, 2010). Although this drug continues to enter the urban wastewater treatment system in increasing amounts each year, studies on the severity of its effects on non-human eukaryotic organisms is limited (Pasquini et al., 2014). Ibuprofen at concentrations as low as $1 \mathrm{mg} / \mathrm{L}$ have been shown to cause a significant reduction in attachment and hydranth number in the cnidarian, Hydra attenuate (Quinn et al., 2008). In prokaryotes, previous work has shown that Ibuprofen induced a decrease in extra polymeric substances (EPS) production which may result in an overall decrease in bacterial activity (Pasquini et al., 2013).

\subsection{Nitrogenous Compounds in Wastewater}

Nitrogen in wastewater can come from multiple sources and is one of the major nutrients that requires removal before the wastewater effluent can be discharged. Mammals, including humans release the nitrogenous compound ammonia (in the form of urea) as a metabolic waste. For instance, ammonia is the approximately waste produced by metabolism of nitrogen-containing compounds like proteins and nucleic acids, but then is converted into urea or uric acid before being excreted. As a result, ammonia is a major constituent and nitrogen is one of the major nutrients that are found in excessive concentrations. Nitrogen contributions from municipal wastewater treatment plants are 
much greater than those from industrial facilities. This is because municipal wastewater has much higher nitrogen concentrations than industrial effluent and there are many more wastewater treatment plants than there are industrial facilities. The effluent from all these facilities is treated and regulated, but it still contains nitrogen. Effluent nitrogen concentrations vary between facilities depending on the type of treatment technology and other factors. Nutrient contamination remains a serious environmental issue and a threat to sustainable development worldwide. Since wastewater discharges containing nitrogen can be toxic to aquatic life, cause oxygen depletion and eutrophication in receiving water, and affect chlorine disinfection efficiency, reducing nitrogen levels from the discharges is necessary (Metcalf and Eddy, 2003). The impact of eutrophication varies case by case, but the results are severe nonetheless. One example is shown by "The Puget Sound Dissolved Oxygen Study" performed in Washington, D.C. which compiled flows for municipal wastewater treatment and industrial plants discharging to the marine waters of Puget Sound, Washington. Approximately 78 U.S. municipal wastewater treatment plants, nine Canadian municipal wastewater treatment plants, five oil refineries, four active pulp/paper mills, and one aluminum facility discharge effluent directly into the marine waters of Puget Sound or the Straits. Based on a 2006-2007 monitoring effort by the Discharge Monitoring Permit (Department of Ecology, Washington, D.C.), the estimated dissolved inorganic nitrogen (DIN) concentrations from all facilities discharging to Puget Sound was obtained. Wastewater treatment plants have a median concentration of $22 \mathrm{mg} / \mathrm{L}$ of DIN in treated effluent, which is 10 to 100 times more concentrated than levels in rivers (Mohamedali et al., 2011). Nitrogen compounds can be removed from wastewater by variety of physicochemical and biological processes. As the world faces stringent nutrient discharge 
regulations, it is imperative that successful reduction of nitrogen is accomplished during the wastewater treatment process.

To understand the reduction of ammonia and eventual loss of $\mathrm{N}$ into the atmosphere, the nitrogen cycle must be understood. The nitrogen cycle is the biogeochemical cycle which follows nitrogen compounds as it circulates around the atmosphere, terrestrial and marine ecosystems.

\subsection{Nitrogen Cycle}

Nitrogen is a primary nutrient required by all living organisms for survival. It is a component of many different biomolecules including proteins, DNA, and even chlorophyll. The transformation of nitrogen into its many oxidation states is key to productivity in the biosphere and is highly dependent on the activities of a diverse assemblage of microorganisms, such as bacteria, archaea, and fungi (Bernhard, 2010). Nitrogen is the $4^{\text {th }}$ most common element and can be present in various oxidation states such as organic form, as $\mathrm{NH}^{4+}$, nitrite $\left(\mathrm{NO}_{2}^{-}\right)$, nitrate $\left(\mathrm{NO}_{3}^{-}\right)$, nitrogen dioxide $\left(\mathrm{NO}_{2}\right)$, nitrous oxide $\left(\mathrm{N}_{2} \mathrm{O}\right)$, nitric oxide $(\mathrm{NO})$, and the most abundant form, dinitrogen gas $\left(\mathrm{N}_{2}\right)$. Being existent in various forms allows nitrogen to be a dynamic element that can act as an electron acceptor and donor and participate in numerous metabolic pathways. The transformation of nitrogen and nitrogenous compounds on earth is illustrated by the nitrogen cycle (Figure 4). The major transformations of nitrogen are nitrogen fixation, nitrification, denitrification, anammox, and ammonification (Ahn, 2006). 


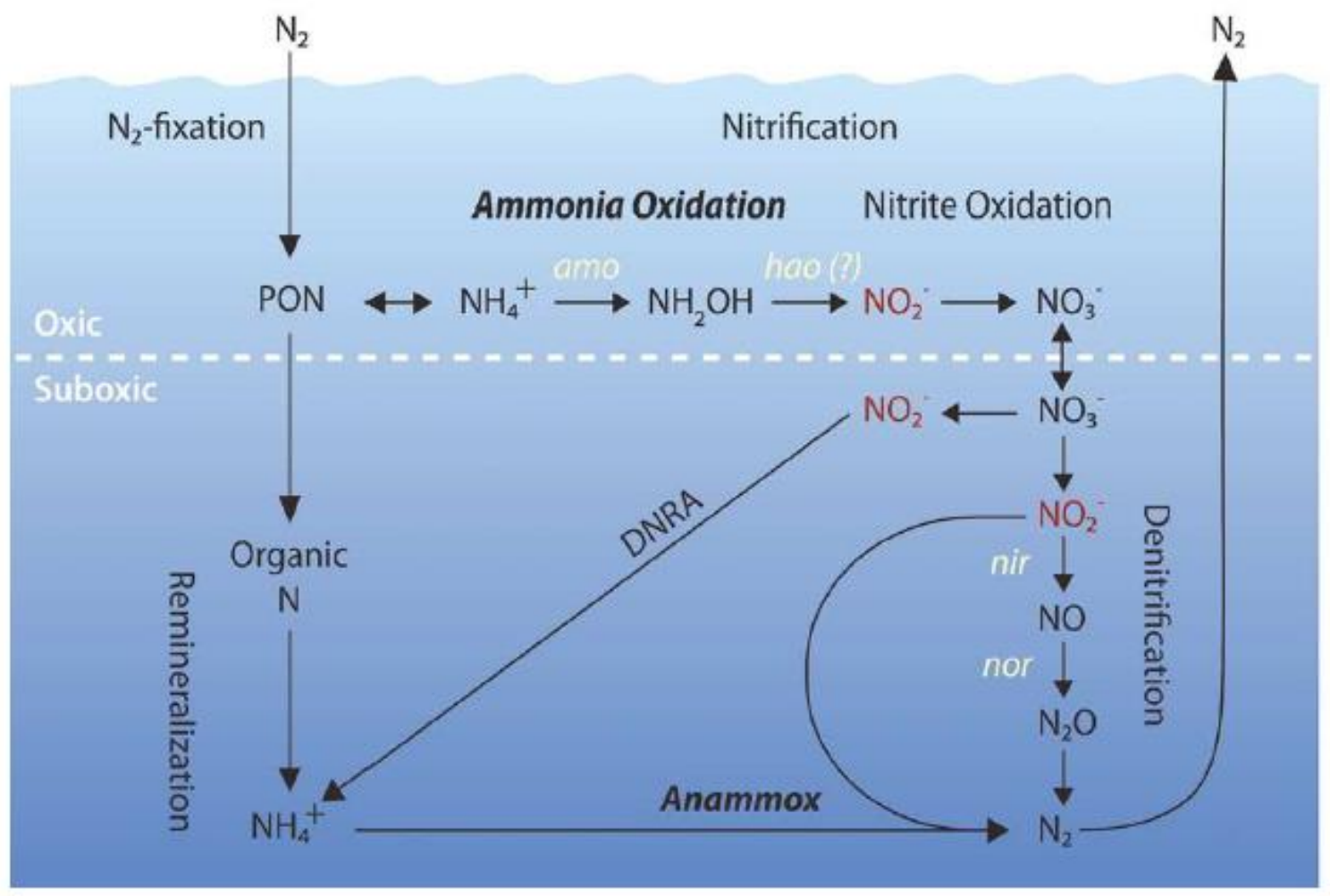

Figure 4. Nitrogen Cycle (Francis et al., 2007)

Across the globe, primary productivity is nitrogen limited, thus nitrogen gas must first be fixed from the atmosphere by a mutualistic nitrogen fixing microorganisms called diazotrophs or cyanobacteria to be utilized in physiological or metabolic processes. The fixed form of nitrogen is required by all living organisms on earth and thus it is not surprising to find nitrogen fixing bacteria and cyanobacteria to be ubiquitous in major environments. For example, nitrogen fixing bacteria called Rhizobia found in the root nodules of plants, through symbiotic nitrogen fixation makes vegetation such as legumes rich in protein and an important component of the human diet (Bernhard, 2010). The unique ability of these microorganisms is gained by the presence of a nitrogenase enzyme complex, comprising two protein components, the iron protein dinitrogenase reductase and 
the molybdenum iron protein dinitrogenase. The activity of this enzyme allows nitrogen and hydrogen to produce ammonia in an energy intensive process (Dixon and Kahn, 2004; Cheng, 2008). Due to the strength of the triple bond between the nitrogen atoms in $\mathrm{N}_{2}$ gas, and it requires a large amount of energy to break this bond. The whole process requires eight electrons and at least sixteen ATP molecules. As a result, only a select group of prokaryotes can carry out this energetically demanding process (Bernhard, 2010). Although most nitrogen fixation is carried out by prokaryotes, some nitrogen can be fixed abiotically by lightning or certain industrial processes, including the combustion of fossil fuels. The ammonium produced from nitrogen fixation is then assimilated by the cells of these microorganisms into amino acids, protein cell wall components such as $N$-acetyl muramic acid, as well as nucleic acids. This process in the nitrogen cycle is referred to as ammonia assimilation.

\section{$\mathrm{N}_{2}+8 \mathrm{H}^{+}+8 \mathrm{e}^{-} \longrightarrow 2 \mathrm{NH}_{3}+\mathrm{H}_{2}$}

Once $\mathrm{N}$ has entered the cycle, the reverse mechanism is the process is known as ammonification or mineralization. This results in the release of ammonia into the environment from dead or decaying cells. The degradation of proteins, nucleic acids, peptidoglycan, which all contain $\mathrm{N}$ is achieved by lysozymes and ureases (Moir, 2011; Bernhard, 2012).

Nitrification is a chemolithoautotrophic oxidation of ammonia to nitrate under strict aerobic conditions. This process occurs in two separate stages. Firstly, the $\mathrm{NH}_{3}$ is converted 
into $\mathrm{NO}_{2}^{-}$(ammonia oxidation) followed by the $\mathrm{NO}_{2}^{-}$being converted into $\mathrm{NO}_{3}^{-}$(nitrite oxidation). Each stage is performed by distinct bacterial genera that use ammonia or nitrite as an energy source and oxygen as an electron acceptor, while carbon dioxide is used as a carbon source (Ahn et al., 2006). Both these processes yield a very low amount of energy in the form of ATP, which leads to the microorganisms responsible for these processes to have a notoriously slow growth rate (Bernhard, 2012). Due to the excess ammonia concentrations found in wastewater, nitrification is an integral part of biological wastewater treatment.

Denitrification is the second component of the nitrogen cycle and ultimately results in the return of $\mathrm{N}$ back into the atmosphere. This process is considered a heterotrophic bioconversion process under anoxic conditions. The oxidized nitrogen compounds $\left(\mathrm{NO}_{2}{ }^{-}\right.$ and $\mathrm{NO}_{3}{ }^{-}$) are reduced to gaseous dinitrogen by heterotrophic microorganisms that use $\mathrm{NO}_{2}{ }^{-}$and/or $\mathrm{NO}_{3}{ }^{-}$instead of oxygen as electron acceptors and organic matter as the carbon source (Ahn, 2006).

The discovery of anaerobic ammonia oxidation (anammox) was a surprise to the notion that all nitrification was carried out under strictly aerobic conditions. Strous et al. (1999) discovered prokaryotes belonging to the Planctomycetes phyla that can oxidize ammonia using nitrite as the electron acceptor to produce gaseous $\mathrm{N}_{2}$. However, ammonia first must be pre-oxidized to nitrite before feeding it into the ANAMMOX process. Several studies investigating a variety of aquatic ecosystems demonstrate that anammox may be responsible for majority of nitrogen loss (Kuypers et al., 2005). For wastewater treatment, where nitrogen removal is of utmost importance, it is suggested that a combined system for nitrogen removal should be based on partial nitritation /Anammox. This will provide 
several advantages such as no requirement for external carbon addition, negligible sludge production and less energy and oxygen requirement than the conventional process (Jetten et al., 2002).

\subsubsection{Nitrification and Denitrification}

Nitrification occurs in two steps by the function two different groups of bacteria. The ammonia is converted to nitrite by ammonia oxidizing microorganisms through a process called ammonia oxidation. This process is essentially an aerobic process, occurring in aphotic environments, because ammonia oxidation has been found to be inhibited by light (Church et al., 2010; French et al., 2012; Merbt et al., 2012). This step is followed by nitrite oxidation which involves the conversion of nitrite to nitrate by nitrite oxidizing bacteria.

Ammonia oxidation is the first and rate limiting step of nitrification and is a very critical aspect of wastewater treatment. Ammonia oxidation involves converting ammonia to hydroxylamine which is a reaction catalyzed by AMO (Rotthauwe et al., 1997). This step is followed by the oxidization of hydroxylamine to nitrite by the enzyme hydroxylamine oxidoreductase. Aerobic ammonium oxidizing bacteria (AOB) and more recently discovered ammonia oxidizing archaea (AOA) play an important role in performing ammonia oxidation on a global scale (Figure 5).

$$
\begin{aligned}
& \mathrm{NH}_{3}+\mathrm{O}_{2}+2 \mathrm{e}^{-} \longrightarrow \mathrm{NH}_{2} \mathrm{OH}+\mathrm{H}_{2} \mathrm{O} \\
& \mathrm{NH}_{2} \mathrm{OH}+\mathrm{H}_{2} \mathrm{O} \longrightarrow \mathrm{NO}_{2}^{-}+5 \mathrm{H}^{+}+4 \mathrm{e}^{-}
\end{aligned}
$$




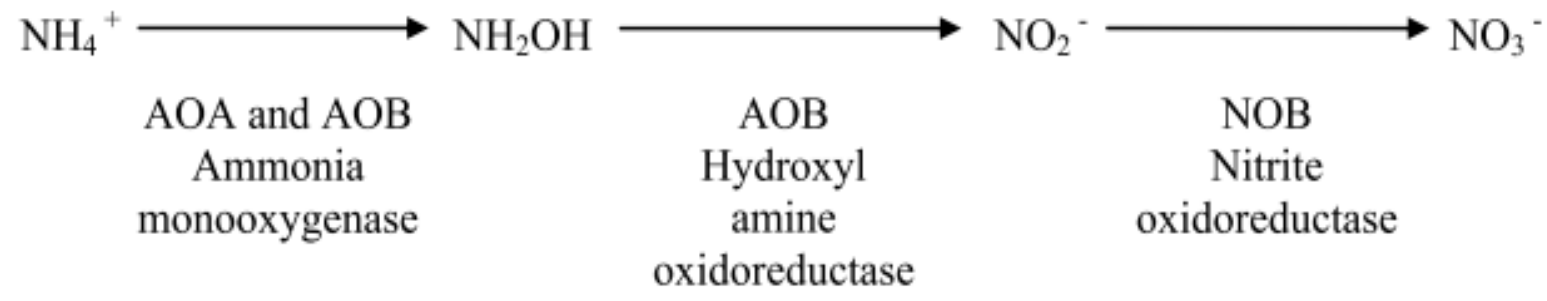

Figure 5. Two major groups of prokaryotes perform ammonia oxidation

Nitrite oxidation is the second stage of nitrification. In this reaction, nitrite oxidizing bacteria use the enzyme nitrite oxidoreductase to convert nitrite into nitrate (Kowalchuk et al., 2001).

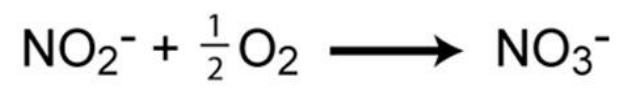

Ammonia oxidizers and nitrite oxidizers are ubiquitous in aerobic environments. They have been extensively studied in natural environments such as soils, estuaries, lakes, and open-ocean environments. However, ammonia- and nitrite-oxidizers also play a very important role in wastewater treatment facilities by removing potentially harmful levels of ammonium that could lead to the pollution of the receiving waters. Much research has focused on how to maintain stable populations of these important microbes in wastewater treatment plants (Bernhard et al., 2012).

Denitrification and nitrification are linked processes where the denitrifying bacteria use $\mathrm{NO}_{3}{ }^{-}$produced from nitrification by reducing it under low oxygen or anoxic conditions. 
$\mathrm{The} \mathrm{NO}_{3}{ }^{-}$is used as an electron acceptor in the absence of oxygen. Thus, denitrification is performed by facultative heterotrophic bacteria that also require a carbon source and $\mathrm{NO}_{3}{ }^{-}$ as their oxygen source (Ahn, 2006). In this process, several enzymes are used to convert the $\mathrm{NO}_{3}{ }^{-}$to nitrite, nitric oxide, nitrous oxide and ultimately to dinitrogen gas. Dinitrogen gas $\left(\mathrm{N}_{2}\right)$ is the ultimate end-product of denitrification, and as a result this process is responsible for removing bioavailable nitrogen and returning it to the atmosphere. In wastewater treatment, denitrification is a beneficial process because it can remove unwanted nitrates from the wastewater effluent, thereby reducing the chances that the water discharged from the treatment plants will cause undesirable consequences (Bernhard, 2012). The presence of nitrates can cause massive algal blooms causing eutrophication of an entire aquatic system. Also, the presence of high nitrate levels in water poses concerns to human health due to the risks of conditions such as methanoglobinemia and formation of nitrosamines (Fewtrell et al., 2004; Kleinjans et al., 1991).

Nitrification and denitrification are dependent processes that ensure the $\mathrm{N}$ flux entering and leaving the environment remains balanced. This balance is essential to the "double edge" sword effect that involves nitrogen. In the case where there is too little N present in soil, the production of crops in agriculture would not be as productive. On the other hand, too much flux of $\mathrm{N}$ into water bodies can cause massive damage through toxicity and eutrophication. A balance is provided by the nitrogen cycle and the microorganisms that can carry out these unique metabolic processes. 


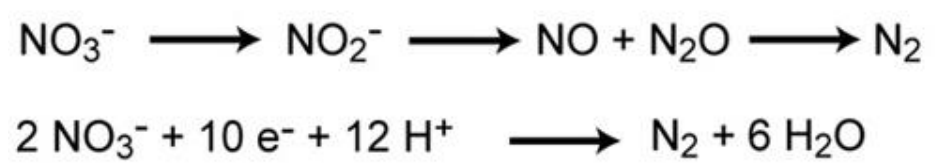

\subsection{Chemolithotrophy}

Winogradsky (1887) was the first to describe the term "inorganic oxidizers" to describe chemolithotrophs. Today, chemolithotrophy refers to the collection of energy for cell maintenance and biosynthesis from the oxidation of inorganic compounds (Kelly and Wood, 2006). The inorganic compounds are the source of electrons and this process does not require the availability of light (Kelly and Wood, 2006). Chemolithotrophs use carbon dioxide as their carbon source. This process is usually dependent on oxygen, where oxygen acts as the final electron acceptor.

Most commonly, bacteria and archaea are classified as chemolithotrophs exhibiting extraordinary diversity of substrates, modes of carbon nutrition, morphology, and habitat. The established sources of chemlithotrophic energy are oxidation of hydrogen, ammonia, nitrite, sulfur and its reduced compounds, ferrous iron and possibly cuprous copper (Kelly and Wood, 2013). Thus, chemolithotrophs play an essential role in the global biogeochemical cycles of major elements. Specially, the $\mathrm{N}$ cycle is dependent on the activity of chemolithotrophs.

The pathway for the energy production of chemolithotrophs involves a reduced inorganic electron donor, e.g., ammonium, nitrite, hydrogen sulfide, or ferrous iron $\left(\mathrm{Fe}^{+2}\right)$ to donate electrons into an electron transport chain in the membrane of the chemolithotroph. In most cases, specialized enzymes present in membranes of 
chemolithotrophs e.g., rusticyanin in iron oxidizers, hydrogenase in hydrogen oxidizers, ammonia monooxygenase in ammonia oxidizers, sulphite oxidase or a reversed APS reductase in sulfate oxidizers) help facilitate this process. Electron(s) are then transferred through membrane bound proteins that bind quinones, iron sulphur centers and hemes (cytochromes) depending on the type of chemolithotrophy, before reduction of oxygen, as the terminal electron acceptor. During this process, a proton gradient is generated between the outside and inside of the cell, driving production of ATP through ATP synthase in the membrane of the organism. During this process, reducing power NADH is also formed from NAD+ either through direct electron donation or by reverse electron flow depending on the reduction potential of the inorganic ion pair concerned (Stahl and De La Torre, 2012). For example, due to low reduction potential of $\mathrm{H}_{2}$, no energy requiring reverse electron flow is needed in hydrogen oxidizing organisms, whereas in sulphur oxidation and ammonia oxidation a reverse electron flow is needed due to the comparatively high redox potential of the electron donors involved (Kowalchuk and Stephen, 2001).

\subsection{The Nitrifiers}

Nitrifying microorganisms are classified as chemolithotrophs that can convert ammonium into nitrite. They consist of two types of microorganisms: those that convert ammonia to nitrite called the ammonia oxidizing microorganisms, and the ones that converts nitrite to nitrate known as the nitrite-oxidizing microorganisms. The most commonly recognized genus of bacteria that carries out ammonia oxidation is Nitrosomonas; however, Nitrosococcus, Nitrosopira, Nitrosovibrio, and Nitrosolobus are also able to oxidize ammonium to nitrite. These ammonium oxidizers are genetically diverse, but related to each other in the beta subdivision of the Proteobacteria. In the nitrite 
oxidation stage, several genera such as Nitrospira, Nitrospina, Nitrococcus, and Nitrocystis are known to be involved. However, the most famous nitrite oxidizer genus is Nitrobacter. Ammonia oxidizing bacteria have garnered considerable attention because they were thought to be the only group capable of performing the first and the rate limiting step of nitrification (Beman and Francis, 2006).

The member of the newly proposed phylum Thaumarchaeota is also capable of chemolithotropic ammonia oxidation and thus challenged the proposed mechanisms of biogeochemical cycling of nitrogen. It may be possible that these chemolithotrophic Thaumarchaeota are central players in the global nitrogen cycle (Leininger et al., 2006).

\subsubsection{Ammonia Oxidizing Bacteria}

Approximately $40 \%$ of the nitrogen present in wastewater is in the form of ammonia (Viessman and Hammer, 1998). The need to remove ammonia from waste is quite significant because of the severity of its impact in the environment. An ideal and inexpensive way of ammonia removal is achieved by nitrification in the biological treatment reactors using AOB. According to Kowalchuk and Stephen (2001), wastewater treatment is by far the most important biotechnological application of AOB and this biological treatment to remove nutrients from wastewater has been adopted worldwide as a secondary step in most wastewater treatment plants. Because of the importance of the function of $\mathrm{AOB}$, understanding their ecology and physiology has become a subject of intense research over recent years (Kowalchuk and Stephen, 2001).

The oxidation of ammonia into nitrate is a two-step process (Figure 6). Firstly, the ammonia is converted into hydroxylamine by the key enzyme AMO which controls the rate limiting step of nitrification (ammonia oxidation). This is a two-electron process 
consuming one mole of $\mathrm{O}_{2}$. Next, hydroxylamine is converted into nitrite by the enzyme called hydroxylamine oxidoreductase (HAO).

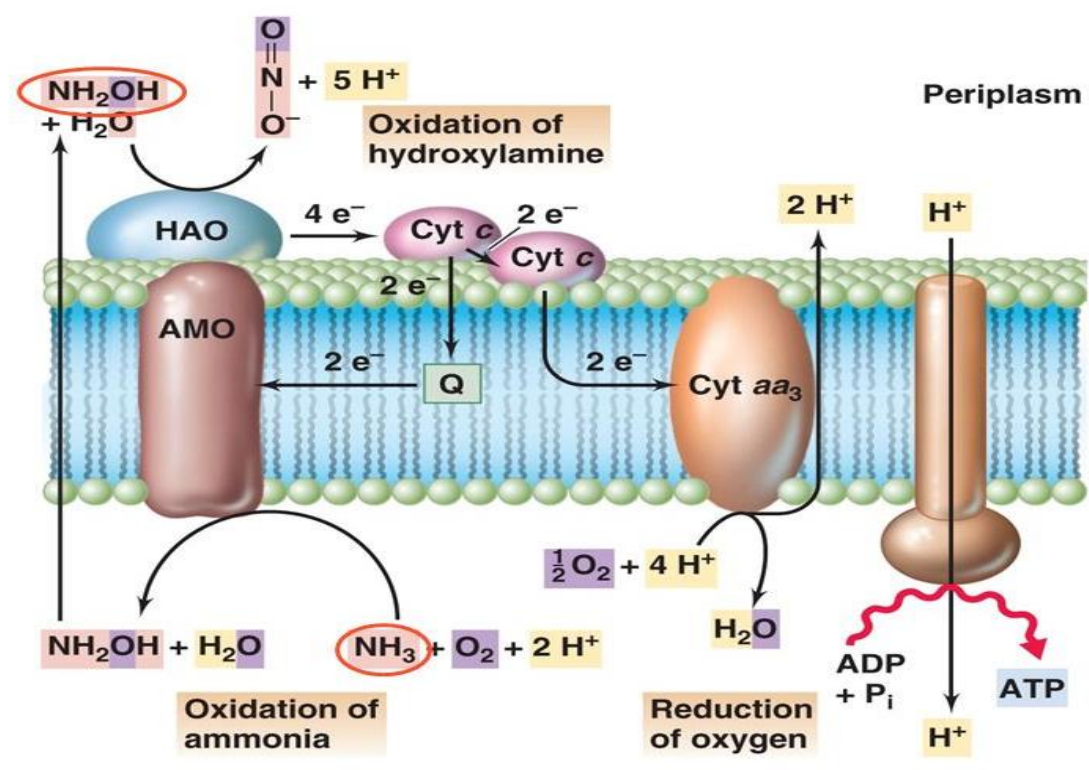

Cytoplasm

Figure 20.32

Figure 6. Bacterial Ammonia Oxidation Pathway (Madigan and Martinko, 2006)

The AMO enzyme is made up of 3 subunits encoded by 3 different amo genes $(a m o A, a m o B, a m o C)$. The amoA gene which encodes for the catalytic $\alpha$-subunit of AMO has been used as a molecular marker for culture independent analysis of AOB communities because it is highly conserved and required by all AOB (Francis et al., 2005). In this process, primers specific to the AMO gene regions are amplified and quantified. Several primers were designed based on the alignment of publicly available amoA sequences to amplify a partial stretch of the amoA gene from a wide range of autotrophic ammonia oxidizers belonging to the $\mathrm{b}$ subclass of the Proteobacteria. The primers were tested in different combinations by using both template DNA from cultured strains and template DNA from environmental samples. The primer combination consisting of amoA-1F and 
amoA-2R provided the most reliable performance in these studies and, consequently, was used in all further studies (Rotthauwe and Witzel, 1997). The assay resulted in a specific 491-bp PCR product for all of the ammonia oxidizers tested except Nitrosococcus oceanus, an ammonia-oxidizing member of the g subclass of the Proteobacteria. Using this technique, it was found that most $\mathrm{AOB}$ found within wastewater treatment plants are $\beta$ proteobacteria in the genera Nitrosomonas (Park and Noguera, 2004; Siripong and Rittmann, 2007).

The activated sludge treatment system is one method used for the reduction of ammonia concentrations in wastewater. It has been assumed that ammonia oxidizing bacteria are dominant in manmade systems such as the activated sludge reactors found in municipal wastewater treatment plants (Zhang et al., 2011).

Distinct AOB species in environments are linked with the eco-physiological properties such as oxygen concentrations, ammonia concentrations and $\mathrm{pH}$. Nitrosomonas europaea has been observed to be associated with environments that contain high concentrations of ammonium while Nitrosomonas oligotropha is found in low ammonia settings (Lydmark et al., 2007). Ammonia levels in domestic wastewater are normally between 10 to $40 \mathrm{mg} / \mathrm{L}$ (Ragsdale, 2005). Several studies indicated that AOBs were present in higher abundance under various environments in the wastewater treatment systems. Wells et al. (2009) found that the AOB amoA gene outnumbering AOA by three orders of magnitude in all activated sludge samples collected for aeration basins. Others have also supported this claim by analyzing the abundance of bacterial and archaeal amoA gene in a lab-scale nitrogen removal reactor. They found that the gene copy number for AOB remained 60 times higher than the AOA level and stated that AOB likely play a major role 
in nitrification process during wastewater treatment (Zhang et al., 2009). It is suggested that two major environmental parameters favour the presence and abundance of $\mathrm{AOB}$ in WWTPs. High ammonium concentrations (Ye and Zhang, 2011; Limpiyakorn et al., 2011; Bai et al., 2012) and higher dissolved oxygen (DO) concentrations showed higher abundances of AOB in reactors seeded with sludge from nine springs WWTP (Park and Nogeura, 2004) which employed a higher DO concentration in their nitrification reactors.

\subsubsection{Anaerobic Ammonium Oxidizers}

The anaerobic ammonium oxidation process (referred to as anammox) is a chemolithotrophic process achieved by anammox bacteria (Ahn, 2006). Since its discovery by Mulder et al., (1995) there have been numerous reports of the occurrence and contributions of anammox bacteria found in different types of ecosystems (Dang et al., 2016; Hao et al., 2009). The discovery of anammox has completely changed the outlook of the nitrogen cycle. Their role in efficient nitrogen removal is evident in numerous reports. For example, they are responsible for $\sim 50 \%$ nitrogen removal in marine systems (Thamdrup and Dalsgaard, 2008) and $~ 40 \%$ in contaminated groundwater (Moore et al., 2011).

The anammox bacteria are characterized to have a highly unusual physiology because surprisingly these bacteria can survive by metabolizing ammonia without the need for oxygen. The process involves the oxidation of ammonia directly into nitrogen gas $\mathrm{N}_{2}$ by using nitrite as a final electron acceptor to yield gaseous nitrogen (Wuchter et al., 2006). Jetten et al (2009) determined the structures of key enzymes in this process, with a view to elucidating the mechanism of anaerobic ammonium oxidation (Figure 7). 


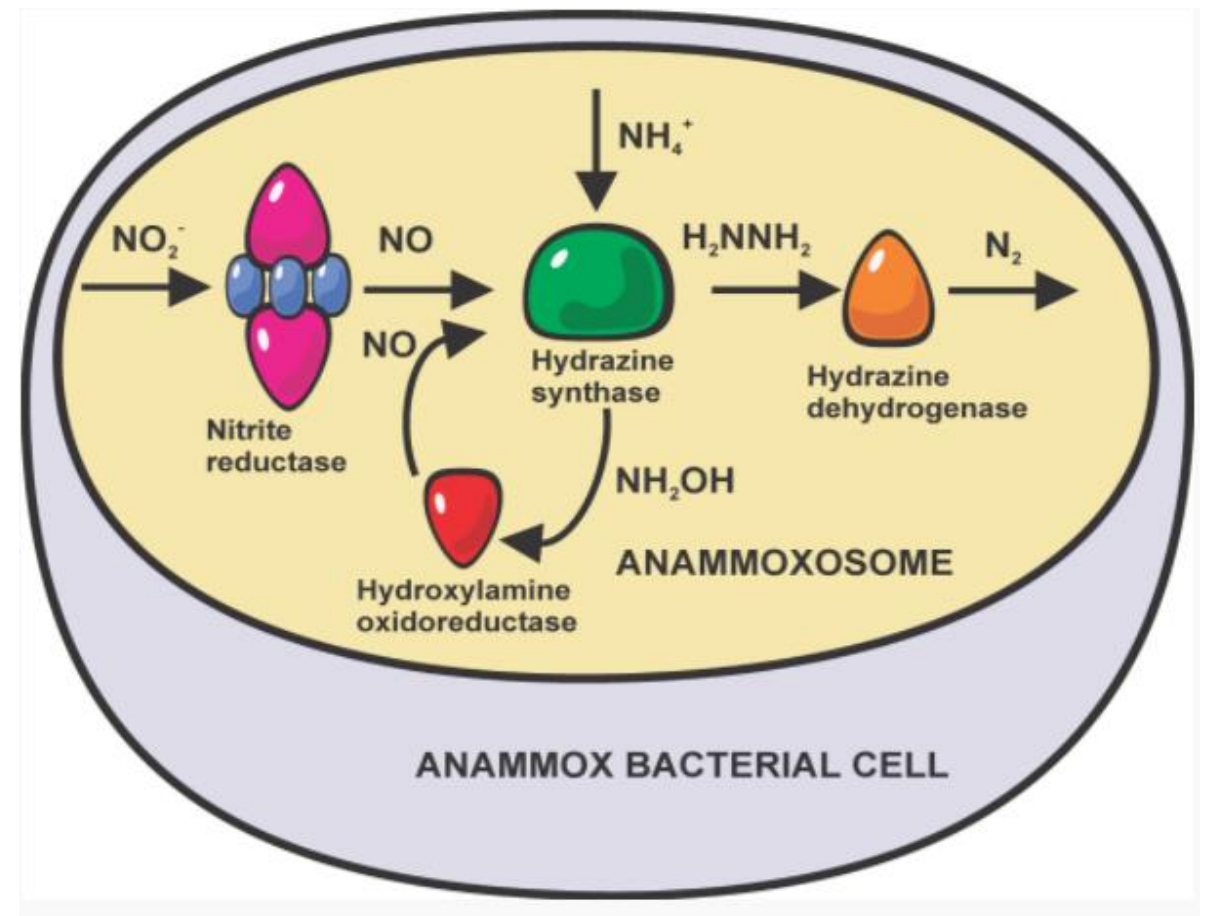

Figure 7. Mechanism of anaerobic ammonia oxidation within the Anammoxosome (Jetten et al., 2009)

Their unique metabolic ability is provided by the presence on of a specific organelle in their cell called the anammoxosome where the anammox reaction occurs. Studying the model anammox organism Brocardia anammoxidans, it is found that these organisms fall into the unique group of organisms (bacteria) called the Planctomycetes, which contain membrane bound cellular organelles, including a membrane-bound nucleoid similar to a nucleus (Kartal et al., 2011). The 16S rRNA genes of known anammox bacteria show several phylogenetically distinct Candidatus genera including Ca. Brocadia, Ca. Scalindua, Ca. Kuenenia, Ca. Anammoxyglobus and Ca. Jettenia. The average sequence similarity between Ca. Scalindua and Ca. Brocadia or Ca. Kuenenia clusters is only $85 \%$ (Jetten et al., 2005). Conventional wastewater treatment using nitrification followed by denitrification can be expensive. The anammox process has the potential to be a cost- 
effective alternative for ammonia removal because it eliminates problems associated with conventional treatment such as high sludge production, high oxygen demand and the need for an external carbon source (Jetten et al., 2009). It is suggested that the application of anammox bacteria with partial nitrification accomplished by aerobic ammonium oxidizing bacteria can be a promising alternative for efficient nitrogen removal in WWTPs (Ahn, 2006). The nitrifiers convert ammonia to nitrite and consume oxygen producing anoxic conditions the anammox process needs. Additionally, the anammox organisms obtain their nitrate or nitrite source from aerobic ammonia oxidizers such as Nitrosomonas, and hence they have been found inhabit environments together with these organisms. The presence of aerobic-anaerobic micro-zones in flocs, sediment or soil environments, so both these groups can coexist. Although the anammox process has a lot of promise, there is still information withstanding regarding the diversity, physiology and function of anammox bacteria. Challenges are faced with the fact that some of these bacteria do not grow well in laboratory conditions due to their slow growth rate (doubling time 11-20 days) and their sensitivity to small temperature fluctuations and low oxygen concentrations (Awata et al., 2012). The advancement of culture independent molecular techniques becomes a quintessential approach to gain insight into the detection and characterization of anammox bacteria. The microbial communities of anammox, denitrification, and nitrification appear to be either mutualistic or competitive. Thus, the environmental parameters such as the availabilities of DOC, $\mathrm{NH}_{4}^{+}, \mathrm{NO}_{2}^{-}, \mathrm{Fe}^{+3}$, and $\mathrm{Mn}^{+2}$ are considered to have impacts on anammox rates in anoxic sediments (Song and Tobias, 2011). 


\subsubsection{Ammonia Oxidizing Archaea}

Ammonia oxidation is the first step in nitrification and a key process in the global nitrogen cycle. This process was thought to be exclusively mediated by the ammonia oxidizing bacteria until a chemolithoautotrophic, marine ammonia oxidizing archaea strain which used ammonia as sole energy source and produced nitrite was discovered (Konneke et al., 2005). It was previously thought that archaea only inhabited extreme environments. However, the search for AOAs has resulted in detecting their presence in soils (Leininger et al., 2006), marine habitats (Wuchter et al., 2006) and estuarine sediments (Beman and Francis, 2006). Additionally, there is evidence that AOAs are found to be more dominant than the AOB population in a variety of habitats including soils (Leininger., 2006), marine habitats (Wuchter et al., 2006) and sediments (Beman and Francis, 2006). These findings provided evidence that the contribution to nitrogen cycling in soil and marine habitats may be attributable to $\mathrm{AOA}$ as well as $\mathrm{AOB}$, and in some cases, there is evidence that $\mathrm{AOA}$ may be the major contributor.

The isolation of the first ammonia oxidizing archeon Nitrosopumilus maritimus strain SCM1 as a pure culture was from a marine aquarium (Könneke et al., 2005). Candidatus "Nitrosopumilus maritimus", was capable of performing ammonia oxidation and contained putative genes for all three subunits ( $a m o A, a m o B$, and $a m o C)$ of ammonia monooxygenase, the enzyme responsible for ammonia oxidation. This opened the doors to the possibilities of studying the genetics, biochemical activities and ecology of these organisms, and the possibilities of isolation and characterization of more such nitrifiers from various other environments (Tourna et al., 2011; Hatzenpichler et al., 2008; Jung et al., 2011). Up to now, $N$. maritimus is the only marine ammonia oxidizing archaea that has 
been cultured. However, using the same enrichment approach other AOA have now been isolated from soils and geothermal environments (De la Torre et al., 2008; Hatzenpichler et al., 2008). Nitrosotalea devanaterra and Nitrososphaera viennensis are recent AOA enrichment cultures detected and enriched from soil samples (Leininger et al., 2006; Tourna et al., 2011). Joining the representatives from soil and sediments is the moderately thermophilic cultured representative Nitrososphaera gargensis (Hatzenpichler et al., 2008). While Candidatus nitrososphaera is one of many AOAs that have been enriched from the biomass of hot springs, Nitrososphaera gargensis was first enriched from a hot spring in Siberia in 2008 (Hatzenpichler et al., 2008).

The size of an archaea ranges from 0.1 to $15 \mathrm{~mm}$ in diameter. Individual archaeon have various shapes, such as spheres, rods, spirals and plates (Garrity and Boone, 2001). Candidatus "N. maritimus" appears as straight rods with a diameter of $0.17-0.22 \mathrm{~mm}$ and a length of $0.5-0.9 \mathrm{~mm}$ (Figure 8) (Konneke et al., 2005). The culture of SCM1 grows up to $1.4 \times 10^{7}$ cells $/ \mathrm{mL}$ at $28^{\circ} \mathrm{C}$ when grown at a concentration of $500 \mu \mathrm{M}$ ammonium. The SCM1 strain grows only at the temperature range of $20^{\circ} \mathrm{C}-30^{\circ} \mathrm{C}$. The optimum $\mathrm{pH}$ for its growth is found to be between 7.0 and 7.8 , and it exhibits no ammonia-oxidation activity at pH lower than 6.7 (Könneke et al., 2005; Urakawa et al., 2011). The pure culture SCM1 has a low tolerance for higher ammonium concentrations, its growth ceases at an ammonium concentration between $2 \mathrm{mM}$ and $3 \mathrm{mM}$. 


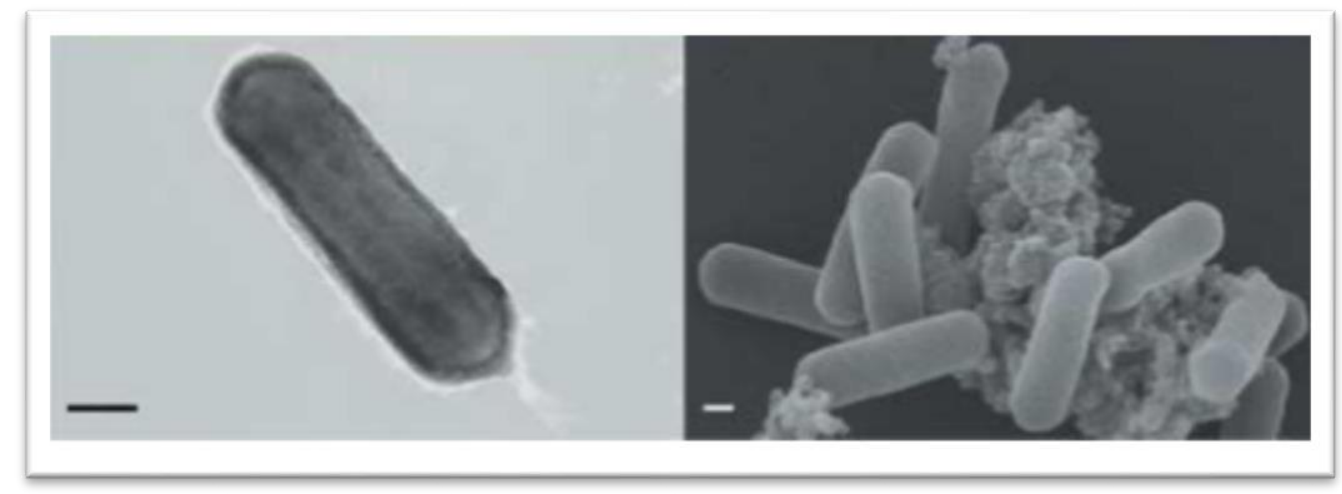

Figure 8. Microscopic images of AOA. Nitrosopumilus maritimus strain SCM1 (Könneke et al., 2005).
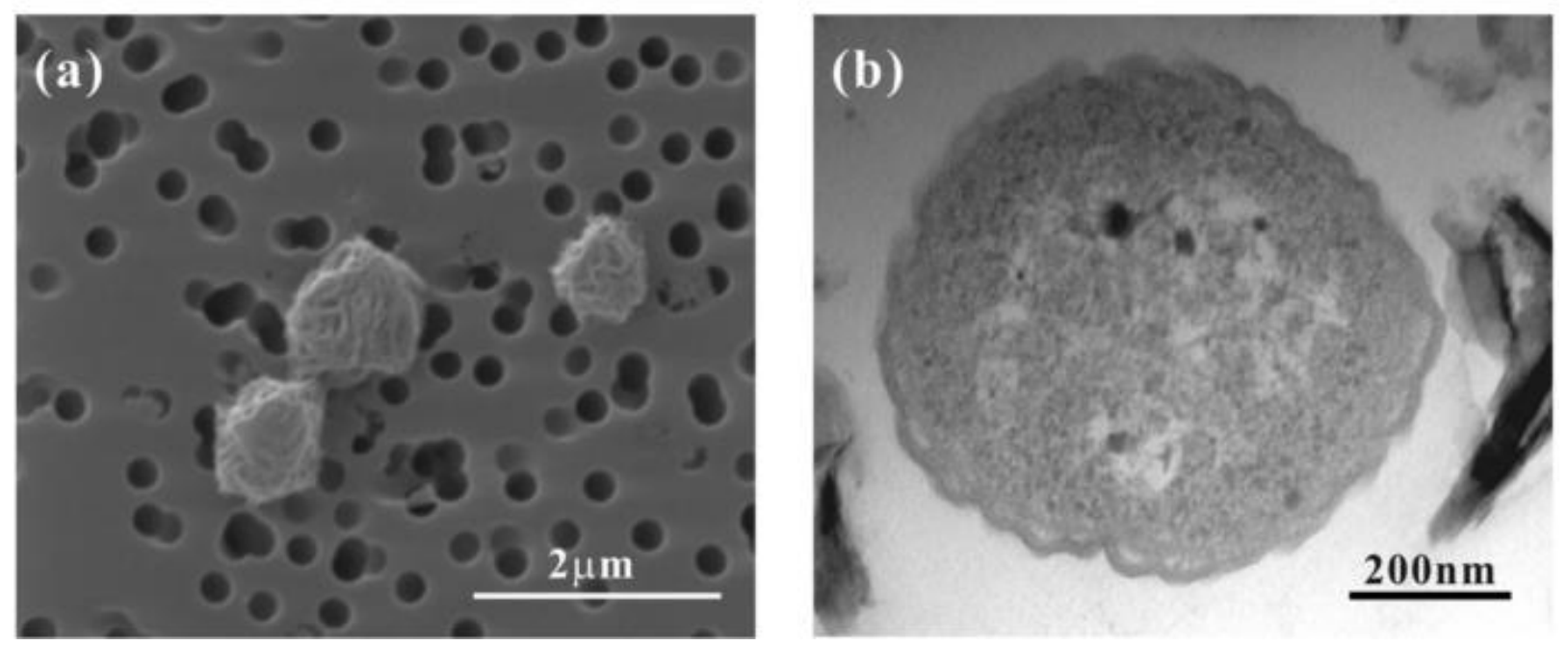

Figure 9. Microscopic images of SAT1 enrichment culture. a) Scanning electron microscopy image b) Transmission electron microscopy (Li et al., 2016).

The recent discovery of AOA in natural systems demonstrated AOA may play a role in $\mathrm{N}$ removal and global $\mathrm{N}$ cycling. Due to excess ammonia concentrations in wastewater, the ammonia oxidation process becomes a critical part of the biological wastewater treatment and should demand attention. The ability of Thaumarchaeota to be 
able to perform chemolithotropic ammonia oxidation has increased the requirement to understand their behaviour and function in biological nitrogen removal in WWTPs.

The enrichment of AOA from a full-scale WWTP has led to significant information regarding its physiological characteristics like cell morphology, growth rate, mode of nutrition, and influence factors. The first successful enrichment of a novel ammoniaoxidizing archaeon strain SAT1 was from reactors which used activated sludge from WWTP as initial inoculum (Figure 9) (Li et al., 2016). They discovered environmental factors had an influence on the SAT1 strain by comparing the specific growth rates of AOA under gradient conditions. It was shown that the strain SAT1 could adapt only to salinity no higher than $0.03 \%$, which was much lower than that of Nitrosopumilus maritimus and considered a strain a non-halophile. Additionally, the growth of stain SAT1 was inhibited by ammonia or nitrite higher than $3 \mathrm{mM}$. These tolerant limits were comparable with Nitrosopumilus maritimus (Könneke et al., 2005) and "Ca. Nitrososphaera gargensis" (Erguder et al., 2009), but lower than that of the soil AOA Nitrosotalea devanaterra (up to $50 \mathrm{mM}$ ) (Lehtovirta-Morley et al., 2011). The strain SAT1 was adapted to temperature from $25^{\circ} \mathrm{C}$ to $33^{\circ} \mathrm{C}$, and the optimum was $29^{\circ} \mathrm{C}$. The $\mathrm{pH}$ range was 5.0 to 7.0 , with the optimum $\mathrm{pH}$ at 6.0. These properties indicated that the strain SAT1 was mesophilic and neutrophilic (Li et al., 2016).

Recently, another AOA culture was enriched from wastewater called the S1 strain containing a single AOA strain from the filtering materials of biological aerated filter in a WWTP (Chen et al., 2017). The optimum growth conditions for the SC1 were obtained while the ammonia concentration was $1 \mathrm{mM}$, temperature was at $30^{\circ} \mathrm{C}, \mathrm{pH}$ was at 7.5 and DO concentration was $2.65 \mathrm{mg} / \mathrm{L}$, respectively. Under the optimum condition, the AOA 
abundance was $3.51 \times 10^{7}$ copies $/ \mathrm{mL}$ (Chen et al., 2017). The above finding demonstrated that there are specific environmental parameters that are required in order for the AOA to grow optimally.

\subsection{Factors Affecting Ammonia Oxidation by Archaea}

Physical and chemical parameter differences in the environments where both ammonia oxidizing archaea and bacteria are found may contribute to which phylum dominates. Environmental factors, such as $\mathrm{pH}$, oxygen concentration and temperature, will affect the compositions of microbial communities responsible for nitrification. Nitrifying bacteria are susceptible to inhibition because of their slow intrinsic growth rates and their sensitivity to many environmental conditions (Jonsson et al., 2000; Hu et al., 2002; Kelly et al., 2004). Five factors may influence ammonia oxidation by archaea including ammonia concentrations, temperature, $\mathrm{pH}, \mathrm{DO}$ and total organic carbon (TOC) concentrations and AOA also appear sensitive to these environmental factors, particularly ammonia concentrations, oxygen and temperature (Park et al., 2006; Urakawa et al., 2008). It is also suggested that AOA may be more adaptable to survive a broad range of growth conditions and therefore may have a more versatile metabolism than their AOB counterparts. For example, while $\mathrm{AOB}$ dominate in ammonia rich environments, AOA have been detected in environments with very low ammonia concentrations such as open ocean, marine water columns, sediments and hot springs (Wuchter et al., 2006; Hatzenpichler et al., 2008; Reigstad et al., 2008). The ability to survive in such low concentrations was explained by the discovery that AOA have the highest substrate affinity for ammonia reported for any microorganisms thus allowing them to outcompete $\mathrm{AOB}$ in accessing this substrate (Martens Habbena et al., 2009). It appears that characterized AOB have Km values that are 
more than 200-fold higher than the Km value of N. maritimus (Martens Habbena et al., 2009). The extremely low apparent $\mathrm{Km}$ and high maximum activity of $N$. maritimus contribute to a specific affinity for ammonia $(\operatorname{Vmax} \cdot \mathrm{Km}-1)$ of approximately $69,000 \mathrm{~L} / \mathrm{g}$ ${ }^{-1} \mathrm{~h}^{-1}$. This is among the highest substrate affinity reported for any microorganism, not only for organic substrates but also for assimilation of ammonia by bacterial heterotrophs and marine phytoplankton for cellular growth (Martens Habbena et al., 2009).

Few studies have looked at the role of ammonia availability in manmade systems such as the aeration tanks found in wastewater treatment plants. Neufeld et al., (2012) investigated $\mathrm{AOA}$ and $\mathrm{AOB}$ abundances in engineered water treatment systems that used rotating biological contactors (RBCs) as a method of treatment. The major discovery was that as the ammonium concentrations decreased along the flow-path of RBCs, the abundance of AOA populations increased (negative correlation with high statistical significance between ammonia concentrations and AOA abundance $\mathrm{r}=0.6887, \mathrm{P}>0.0001$ ). Due to high substrate affinity of AOA for ammonia, they can survive and dominate low ammonia conditions (Neufeld et al., 2012). This implied niche adaptation of AOA to low ammonia conditions and deemed ammonia availability as important factor in determining relative proportions of ammonia oxidizers (Neufeld et al., 2012). In contrast, archaeal amoA genes and gene expression has also been detected at higher ammonium concentrations as Candidatus nitrososphaera was enriched from the biomass of hot springs with ammonium concentrations reaching $5.9 \mathrm{mM}$ (Hatzenpichler et al., 2008) and even at $10 \mathrm{mM} \mathrm{NH}_{4}{ }^{+}$(Treusch et al., 2005). These findings demonstrate the versatility of AOA in diverse ecological niches because of their ability to survive in environments varying in ammonia concentrations. 
Temperature and $\mathrm{pH}$ can also play an important role in providing a niche for AOA. The archaeal amoA genes have been retrieved from a broad range of temperatures (Erguder et al.,2008). The archaeal $a m o A$ genes have been found in aquarium biofilm systems with water temperatures as low as $5.5^{\circ} \mathrm{C}$ (Urakawa et al., 2009) and in hot spring sediments and microbial mats with temperatures reaching $42-97^{\circ} \mathrm{C}$ (Hatzenpichler et al., 2008; Reigstad et al., 2008). These findings demonstrate that AOAs have a broad habitat range and survive in diverse environments.

The $\mathrm{pH}$ values of the environments where archaeal amoA genes have been detected also show a similar trend. Archaeal genes have been found over a wide range of $\mathrm{pH}$, starting from 3.67 (He et al., 2007) to 8.65 (Urakawa et al., 2008). In acidic to neutral pristine and fertilized soil samples, Leininger et al. (2006) detected archaeal amoA gene copy numbers were 1.5-230 time more abundant than the bacterial $a m o A$ genes in topsoil $(0-10 \mathrm{~cm})$. This demonstrated that in acidic environments archaea may be able to dominate bacterial populations. Additionally, a more recently described AOA enriched from low $\mathrm{pH}$ soils, Nitrosotalea devanaterra can optimally grow between $\mathrm{pH} 4$ and 5. The ability of $N$. devanaterra to grow at extremely low $\mathrm{pH}$ values is also suggestive that ammonium, rather than un-ionized ammonia, is the substrate for growth. One explanation for the failure of $\mathrm{AOB}$ to grow at $\mathrm{pH}$ values significantly below $\mathrm{pH} 7$ is their requirement for the un-ionized form as growth substrate. Because the concentration of the unionized ammonia form decreases 10 -fold for every 1 -unit reduction in $\mathrm{pH}$, the $\mathrm{AOB}$ would become rapidly substrate limited as $\mathrm{pH}$ is lowered. This suggested that AOA ecotypes are more tolerant to acidic environments than their AOB counterparts. 


\subsection{Detecting Ammonia Oxidizing Microorganisms in Activated Sludge}

It is found that the AOA and ammonia oxidizing bacteria use the enzyme AMO, to catalyze the rate limiting step of bacterial ammonia oxidation (Francis et al., 2005). The amoA gene which encodes for the catalytic asubunit of AMO has been used as a molecular marker for culture independent analysis of ammonia oxidizers. The presence of the amoA gene has also been confirmed to be associated with archaeal ammonia oxidation by Crenarchaeota. Although highly similar, the amoA genes from $\mathrm{AOB}$ and AOA are divergent enough to use molecular techniques to determine the relative abundance of each group (Leininger et al., 2006). The qPCR technique has been essential in providing information regarding the ecology of AOA. The relative abundance of ammonia-oxidizing organisms can be expressed assuming that there are 2.5 and 1 amoA gene copies per AOB and AOA, respectively (Herrmann et al., 2008). Leininger and associates (2006) were the first to compare the abundances of bacterial and archaeal ammonia oxidizers by qPCR amplification of the amoA genes. Leininger et al., (2006) deduced that AOA associated amoA genes dominated the $\mathrm{AOB}$ associated amoA genes in all soil samples they had tested. Leininger's study states that AOA are more abundant in all soil ecosystems on earth.

Although, studies have demonstrated that the stoichiometry of bacterial and archaeal ammonia oxidation is indistinguishable (Martens Habbena et al., 2009), there are differences in the biochemistry of ammonia oxidation performed by both groups. The mechanism is far from being completely understood however there are two important distinctions that are currently being investigated. Firstly, it is suggested that AOA utilize copper rather than iron as the major redox active metal in electron transfer reactions. Next, 
AOA lack any homologs to the bacterial hydroxylamine oxidoreductase (HAO) protein that converts hydroxylamine to nitrite in ammonia oxidation (Stahl and De la Torre, 2012).

In municipal wastewater treatment systems, there is still a lack of understanding on the prevalence and role of AOAs in ammonia oxidation in manmade systems such as bioreactors used in secondary treatment of wastewater. Park et al., (2006) identified 75 archaeal gene sequences from activated sludge samples demonstrating their presence in man-made systems. The presence of AOA appears to be dependent upon oxygen concentration and SRT in WWTPs since all of the archaeal amoA positive sludge samples were collected from Orbal WWTPs operating at low DO concentrations for simultaneous nitrification and denitrification (Park et al., 2006). However, the role of AOA and their abundance in activated sludge systems have not yet been fully elucidated.

Ammonia availability, temperature and $\mathrm{pH}$ are important environmental factors that must be investigated to understand the presence of AOA in activated sludge systems and explain the synergy between AOA and AOB. Due to the continuous flux of wastewater influent into municipal WWTPs, the parameters or characteristics of the wastewater can fluctuate monthly, daily, even hourly. Studies have demonstrated that AOAs are versatile and can survive in a wide range of environmental conditions. However, the question of why AOA were dominant compared with $\mathrm{AOB}$ in majority of the studied environments and what parameters are effective in their occurrence and abundance remain unclear. The biochemistry of ammonia oxidation performed by AOAs is still unresolved as well.

Wastewater microbial communities are essential to the success and efficiency of the biological treatment process and much knowledge regarding their ecology and community composition is desired. There are various classes of contaminants present in 
wastewater effluent and the acute effects of these compounds on wastewater microorganisms remains a mystery. Thus, this study will aim to investigate the effect of Tetracycline and Ibuprofen on the community composition of bacteria and protozoa in activated sludge. Additionally, this study will characterize the role of AOA in nitrification that occurs in activated sludge systems which will be essential to understanding their contribution to nitrogen removal in those systems. This may also lead to the discovery of cheaper and more efficient alternatives to $\mathrm{N}$ removal. This project aims to investigate community composition of activated sludge microbial communities, while focusing specifically on the ammonia oxidizers that are present in the activated sludge system. The overall goal is to quantify the abundance of each group through the wastewater treatment process, assess the activity of each group and determine whether the system supports redundancy for ammonia removal. This will provide significant insight regarding the ecophysiology of ammonia oxidizers in wastewater treatment. Using a developed and reliable method (e.g., a PCR-based method), the abundance and composition of AOB and AOA communities will be determined using real-time PCR assays and denaturing gradient gel electrophoresis (DGGE). The gene copy numbers determined from q-PCR are converted to cell numbers based on a relationship between the total microbial counts and the total amount of extracted DNA.

It is hypothesized that during the secondary treatment of municipal wastewater treatment plants, there is functional redundancy between ammonia oxidizing bacteria and ammonia oxidizing archaea populations enabling the oxidation of ammonia to be a stable process. 


\section{CHAPTER 3: MATERIALS AND METHODS}




\subsection{Wastewater Treatment Plant Description}

\subsubsection{Wastewater Treatment Plants (WWTPs)}

The samples used in this study were composed of activated sludge (grab samples) collected from two WWTPs located in Toronto, ON. The North Toronto Wastewater Treatment Plant (NTWTP) is the smallest plant of the four wastewater treatment facilities owned and operated by the City of Toronto. It is in the Don Valley at 21 Redway Rd. The plant covers an area of 27 hectares and serves a population of approximately 80,000 residents in the East York community and surrounding area by treating more than 7.5 million gallons per day. The Humber Wastewater Treatment Plant (HWTP) is a larger plant located in West Toronto, ON, and began operating in 1960 with a starting capacity for treating wastewater of up to 227,000 cubic metres. The current capacity is 473,000 cubic metres which serves a population of approximately 651,000 in Etobicoke, York, a portion of the west end of North York, and Toronto.

Both WWTPs employ primary clarification followed by the conventional activated sludge process for organic compound removal and nitrification. In this process, secondary treatment is achieved when effluent from the primary clarifier tank is mixed with return activated sludge (RAS) from the final clarifiers and aerated with ceramic fine bubble dome diffusers. Secondary treatment is followed by the anaerobic digestion of the sludge produced. The excess is removed as waste activated sludge (WAS) and is thickened and anaerobically digested prior to transfer to the Ashbridges Bay Treatment Plant (ABTP) for further treatment. 
The first grab sample obtained from NTWTP was used in lab scale semi-batch reactors to determine the effect of Tetracycline on the community composition of microorganisms present in activated sludge.

The next activated sludge samples were obtained from the HWTP and utilized for two separate experiments. Samples were collected from the secondary treatment (aeration tanks), recycled sludge tank, and anaerobic digester tanks of the Humber treatment plant. The aeration tank samples were utilized as inoculum for lab scale semi-batch reactors to determine the effect of Tetracycline and Ibuprofen on the community composition of bacteria and protozoa present in activated sludge. Additionally, all samples from the aeration tanks, recycled sludge and digesters were also investigated for the presence, abundance and activity of ammonia oxidizing bacteria and archaea. The next section will discuss the sample collection and processing techniques in detail.

\subsection{Sample Collection}

\subsubsection{Samples for Lab Scale Reactors to Investigate the Impact of Tetracycline on Community Composition of Activated Sludge}

Samples of activated sludge were collected from a full-scale aeration tank of the activated sludge system in North Toronto Wastewater Treatment Plant. Approximately 12 $\mathrm{L}$ of activated sludge was collected and transported on ice $\left(4^{\circ} \mathrm{C}\right)$ from the plant to the lab in two sterilized plastic containers, each with a capacity of $6 \mathrm{~L}$. An aliquot of the activated sludge was centrifuged, and the pellet was stored at $-20^{\circ} \mathrm{C}$ as a source of DNA from the original sample for later use. 


\subsubsection{Samples for Lab Scale Reactors to Investigate the Impact of Tetracycline and Ibuprofen on Community Composition}

Activated sludge samples from the aeration tanks (AT) of secondary treatment were obtained from the Humber WWTP. For this experiment, one litre samples were obtained from AT 2, 4, 6, and 8 and transported on ice $\left(4^{\circ} \mathrm{C}\right)$ from the plant to the lab in sterilized plastic containers, each with a capacity of one litre. Within $2 \mathrm{~h}$, the aeration tank activated sludge sample was mixed into a sterile $4 \mathrm{~L}$ glass Erlenmeyer flask. An aliquot of the activated sludge was centrifuged, and the pellet was stored at $-20^{\circ} \mathrm{C}$ as a source of DNA from the original sample for later use.

\subsubsection{Samples for the Presence and Function of AOA and AOB in the Activated Sludge System}

Samples of activated sludge was collected from stages of the full-scale activated sludge system from HWTP. Humber wastewater treatment plant contains a total of eight aeration tanks, each equipped with ceramic fine bubble dome diffusers: five in the South Plant treatment process, and three in the North Plant treatment process. Each of the eight aeration tanks (ATs) are in series, fed from one common primary effluent channel in the north, and one common primary effluent channel in the south, although some mixing of the flow from the north and south primary effluent channels is possible and common in order to balance flows. For anaerobic digestion (DIG), Humber WWTP also contains eight tanks. These are also parallel process trains. The sludge enters the tanks (intermittently) from the thickening building or the primary pumping stations. Digested sludge from tanks $1,2,3,5,7,8,9$, and 10 flows to 4 and 6 , which are basically holding tanks. 
For this experiment, one litre samples were obtained from aeration tanks 2, 4, 6 and 8 , the recycled sludge flow path and anaerobic digesters tanks 1 and 2 . The samples were collected and transported on ice $\left(4^{\circ} \mathrm{C}\right)$ in sterilized one L plastic bottles and immediately wastewater pellets were prepared by the centrifugation of two $\mathrm{mL}$ aliquots of activated sludge from each of the four aeration tanks, recycled sludge and two anaerobic digester tanks at $1900 \times \mathrm{g}$ for 2 minutes. The pellets were stored at $-20^{\circ} \mathrm{C}$ as sources of DNA and at $-80^{\circ} \mathrm{C}$ for RNA from the original samples for later use.

Analysis of the characteristics and parameters of the wastewater was not performed during the experiment, however, the yearly averages for significant parameters of the activated sludge samples were obtained directly from the annual report published by the North Toronto and Humber wastewater treatment plants (City of Toronto, 2016). Influent and effluent characteristics are listed in Table 1 below.

Table 1. Influent and effluent characteristics, operational parameters of the activated sludge system from the full-scale Humber wastewater treatment plant (City of Toronto, 2016).

\begin{tabular}{|c|c|c|c|c|c|c|}
\hline Wastewater & $\mathrm{pH}$ & Biochemical & Carbonaceous & $\mathrm{NH}_{3}-\mathrm{N}$ & Total & Total \\
& (SU) & Oxygen & Biochemical & (mg/L) & Kjeldahl & Suspended \\
& & Demand & Oxygen & & Solids \\
& & $(\mathrm{BOD})$ & Demand & & & $(\mathrm{mSS})$ \\
& & $(\mathrm{mg} / \mathrm{L})$ & $(\mathrm{CBOD})$ & & & \\
& & & $(\mathrm{mg} / \mathrm{L})$ & & & \\
\hline Influent & 7.35 & 297 & 154.24 & 28.19 & 44.94 & 308.74 \\
\hline Effluent & 7.57 & - & 5.95 & 1.24 & 2.62 & 13.27 \\
\hline
\end{tabular}


Other relevant parameters and descriptions were as follows: For the aeration tanks, the DO was $>2 \mathrm{mg} / \mathrm{L}$. The DO for the anaerobic digesters could not be obtained due to the thickness and viscosity of the sample which did not permit a proper investigation. The hydraulic retention time (HRT) for the aeration tanks ranged from 3.5 hours for aeration tanks 2 and 4, $5.5 \mathrm{~h}$ for aeration tank 6, and $6.9 \mathrm{~h}$ for aeration tank 8. Humber treatment plant maintained a mean cell resident time (MCRT) of approximately 10.8 days for digesters and 5 days for aeration tank 2 and 4, and 7 days for aeration tanks 6 and 8 (City of Toronto, 2016).

\subsection{Pharmaceutical Stock Solutions}

A stock solution of Tetracycline (50 mg/L) (Sigma, USA) was made by the addition of $1000 \mathrm{~mL}$ sterile water to $50 \mathrm{mg}$ of Tetracycline. The antibiotic solution was stored at $4{ }^{\circ} \mathrm{C}$ in foil until needed to protect it from degradation. Appropriate volumes were added to the reactors to generate final concentrations of $1 \mu \mathrm{g} / \mathrm{L}, 10 \mu \mathrm{g} / \mathrm{L}$ and $500 \mu \mathrm{g} / \mathrm{L}$.

A stock solution of Ibuprofen (1 g/L) was prepared from two 500 mg Advil@ tablets which were crushed into a fine powder. The NSAID solution was stored at $4^{\circ} \mathrm{C}$. Appropriate volumes were added to the reactors to generate a final concentration of 100 $\mu \mathrm{g} / \mathrm{mL}$.

\subsection{Aerated Lab Scale Semi-Batch Reactors}

\subsubsection{Reactor Set-Up to Determine Effect of Tetracycline on Bacterial Community Composition}

Eighteen semi-batch reactors were set up using sterile commercially available $1 \mathrm{~L}$ plastic containers. Each reactor was kept open to the air and inoculated with $500 \mathrm{~mL}$ of activated sludge obtained from a full-scale aeration tank in the North Toronto Wastewater 
Treatment. Commercially available rubber tubing was attached to the lab air supply, then using flow rate limiters or valves, air was supplied to the flasks. To minimize the loss of sample through evaporation, tubing from the central air supply nozzle was circulated through a moisture flask that contained autoclaved water before being delivered to the reactors. Fish aquarium bubbling stones were used to achieve aeration and mixing within the flasks.

The 18 semi-batch reactors classified as the Tetracycline reactors were divided into six groups of three (Figure 10). Groups 1, 3 and 5 were considered low fed rate reactors (mimicking long retention rates of 50 days) and Groups 2, 4 and 6 were considered higher fed rates (mimicking short retention rates of 10 days). Groups 3, 4, 5 and 6 were supplemented with Tetracycline: Groups 3 and 4 with $1 \mu \mathrm{g} / \mathrm{L}$ and Groups 5 and 6 with 10 $\mu \mathrm{g} / \mathrm{L}$. Specifically, Group 1 consisted of 3 reactors that contained no Tetracycline and had $10 \mathrm{~mL}$ samples (2\% of total volume) removed every second day and replaced with synthetic wastewater (Liao et al., 2001). The ratio of chemical oxygen demand (COD): N: $\mathrm{P}$ in the synthetic wastewater was kept at $100: 5: 1$. Group 2 consisted of 3 reactors that contained no Tetracycline but had $50 \mathrm{~mL}$ samples (10\% of total volume) removed every other day and replaced with synthetic wastewater. Group 3 consisted of 3 reactors that contained low levels of Tetracycline $(1 \mu \mathrm{g} / \mathrm{L})$ and had $10 \mathrm{~mL}$ samples removed every second day and replaced with synthetic wastewater containing $1 \mu \mathrm{g} / \mathrm{L}$ of Tetracycline. Group 4 reactors that contained low levels of Tetracycline $(1 \mu \mathrm{g} / \mathrm{L})$ and had $50 \mathrm{~mL}$ samples removed every second day and replaced with synthetic wastewater containing $1 \mu \mathrm{g} / \mathrm{L}$ of Tetracycline. Group 5 consisted of 3 reactors that contained high levels of Tetracycline $(10 \mu \mathrm{g} / \mathrm{L})$ and had $10 \mathrm{~mL}$ samples removed every second day and replaced with synthetic 
wastewater containing $10 \mu \mathrm{g} / \mathrm{L}$ of Tetracycline. Group 6 consisted of 3 reactors that contained high levels of Tetracycline $(10 \mu \mathrm{g} / \mathrm{L})$ and had $50 \mathrm{~mL}$ samples removed every second day and replaced with synthetic wastewater containing $10 \mu \mathrm{g} / \mathrm{L}$ of Tetracycline. The Tetracycline concentrations represented low and high environmentally-relevant concentrations previously reported in environmental water/wastewater samples (Klümerer, K., 2009; Lin et al., 2009). On sampling day 0 and day 14, two millilitres of samples from each reactor were centrifuged at $4600 \times \mathrm{g}$ for 15 minutes and the pellets were frozen at $20^{\circ} \mathrm{C}$ until DNA extraction was carried out.

a)

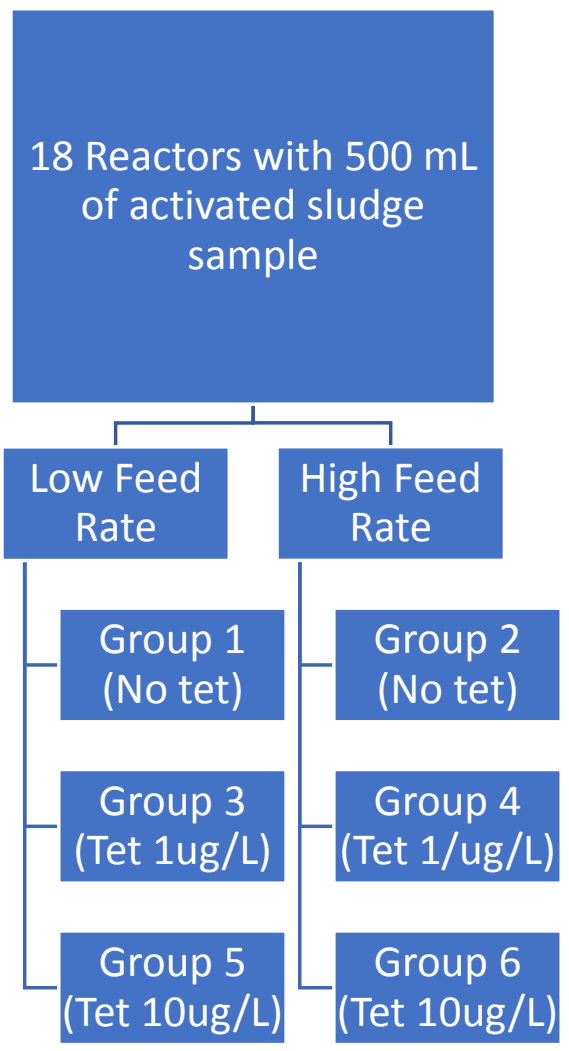


b)

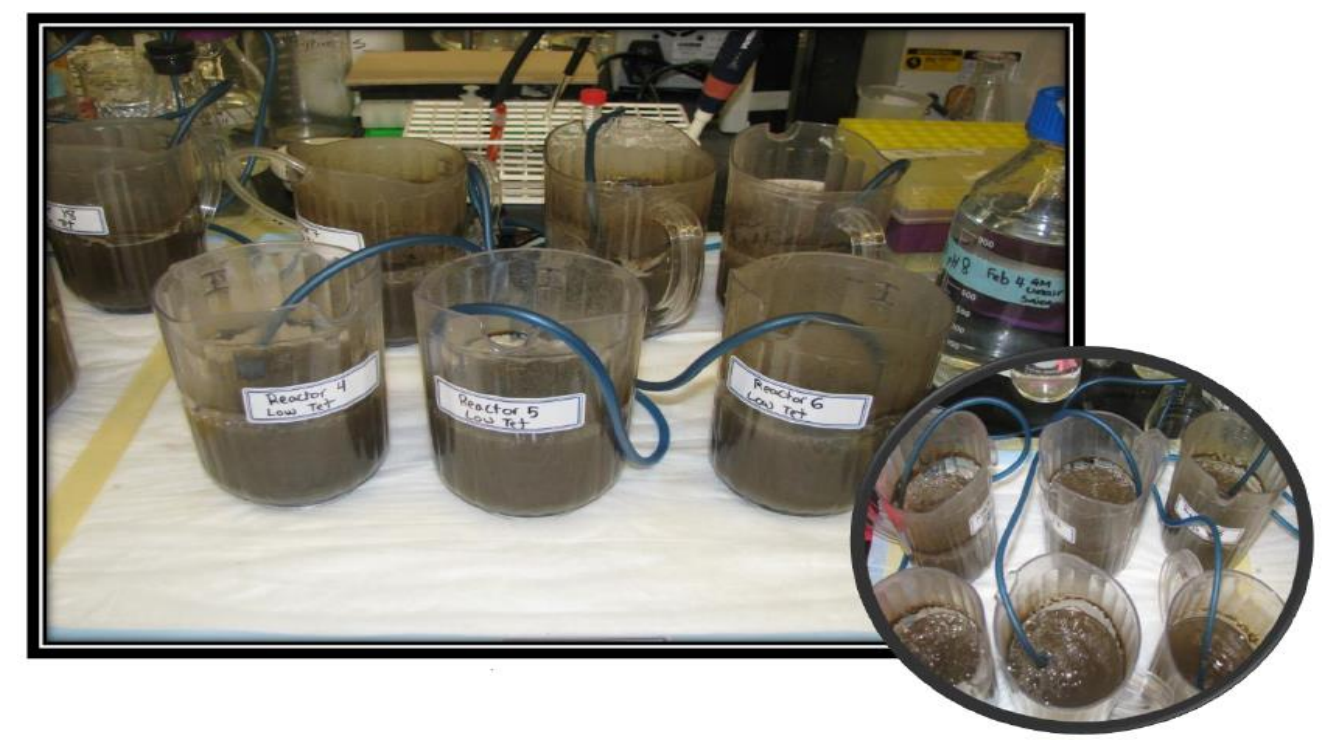

Figure 10. a) Schematic of Reactors b) Aerated semi-batch reactor system

\subsubsection{Reactor Setup to Determine Effect of Ibuprofen and Tetracycline on the Bacterial and Protozoan Composition and Community Structure}

Similar to the reactors setup previously used, $1 \mathrm{~L}$ of activated sludge was obtained from the full-scale aeration tanks 2, 4, 6 and 8 of the HWTP and transported to the lab in 1 $\mathrm{L}$ plastic containers. Within approximately 3 hours, the samples were all mixed in a $4 \mathrm{~L}$ glass Erlenmeyer flask and processed by placing $500 \mathrm{~mL}$ aliquots in six $1 \mathrm{~L}$ plastic reactor vessels. These reactors were classified as the Tetracycline and Ibuprofen reactors and were divided into three groups of 2 . Two reactors contained no added pharmaceuticals and were considered the reference reactors. Two reactors were supplemented with $500 \mu \mathrm{g} / \mathrm{L}$ of Tetracycline, two were supplemented with $100 \mu \mathrm{g} / \mathrm{mL}$ of Ibuprofen. The reactors were oxygenated using the lab air supply that connected aquarium bubblers with rubber tubing and maintained a $\mathrm{DO}>2.0 \mathrm{mg} / \mathrm{L}$ through a flask containing deionized water to minimize moisture loss. During the feed event which occurred on days 0,5 and $10,50 \mathrm{~mL}$ volume 
from each reactor was removed for further analysis and replaced with sterile synthetic wastewater (Liao et al., 2001) to supplement the nutrient level but not add in new microbes. The ratio of chemical oxygen demand (COD): N: $\mathrm{P}$ in the synthetic wastewater was kept at $100: 5: 1$. On sampling days 0,5 and $10,2 \mathrm{~mL}$ aliquots from each duplicate reactor samples were collected in triplicate and used for analysis. The aliquots were centrifuged at $4600 \times \mathrm{g}$ for 15 minutes and the pellets were frozen at $-20^{\circ} \mathrm{C}$ until DNA extraction was carried out.

\subsection{DNA Extraction}

Samples for DNA were collected in triplicate from the initial WWTP samples and from each reactor at time intervals. The samples were centrifuged at $5500 \times \mathrm{g}$ for 15 minutes to obtain visible pellets for DNA extraction. Each sludge pellet contained $0.25 \mathrm{~g}$ of sludge in a pellet form. After discarding the supernatant, the pellet was stored at $-20^{\circ} \mathrm{C}$ until total genomic DNA was extracted using PowerSoil DNA Isolation Kit (MOBIO Laboratories, Carlsbad, CA, USA) following the manufacturer's instructions. The extracted DNA was resuspended in $50 \mu \mathrm{L}$ of DNA free water. One microliter of extracted

DNA was used to measure the concentration by Nanodrop Spectrophotometer ND-1000 (Thermo Fisher Scientific, USA), and remaining DNA was stored at $-20^{\circ} \mathrm{C}$. The presence of DNA was confirmed by gel electrophoresis on a $2 \%(w / v)$ agarose gel.

\subsection{RNA Extraction}

Wastewater pellets for activated sludge from aeration tanks $2,4,6$ and 8 , recycled sludge and digester tanks 1 and 2 were collected in triplicate like previously described for DNA. Total RNA free of DNA and protein contamination was then extracted from the 0.25g of wastewater sludge pellet using the Trizol (Life Technologies Corp, Carlsbad, CA, 
USA) method by following procedure described in the manufacturer's instructions. After homogenizing the sample with $2 \mathrm{~mL}$ of TRIzol ${ }^{\circledR}$ Reagent, the sample was incubated at room temperature for 5 minutes. Next, $200 \mu \mathrm{L}$ chloroform was added and the sample was incubated at room temperature for another 2-3 minutes. The samples were then subjected to centrifugation at 15 minutes at $12,000 \times \mathrm{g}$ at $4^{\circ} \mathrm{C}$ which allowed the homogenate to separate into a clear upper aqueous layer (containing RNA), and interphase and red lower organic layers (containing the DNA and proteins). Total RNA was precipitated from the aqueous layer with the addition $0.5 \mathrm{~mL}$ of ice cold isopropanol $\left(-20^{\circ} \mathrm{C}\right)$ to the aqueous phase per $1 \mathrm{~mL}$ of TRIzol ${ }^{\mathrm{TM}}$ Reagent used for lysis. The samples were again incubated for 10 minutes at room temperature and centrifuged for 10 minutes at $12,000 \times \mathrm{g}$ at $4^{\circ} \mathrm{C}$. Total RNA precipitate formed a small but visible white gel-like pellet at the bottom of the tube. Protein was also precipitated out from the phenol-ethanol supernatant by isopropanol precipitation. The precipitated RNA was washed to remove impurities using ethanol. The pellet was resuspended in $1 \mathrm{~mL}$ of $75 \%$ ethanol per $1 \mathrm{~mL}$ of TRIzol ${ }^{\mathrm{TM}}$ Reagent used for lysis. The suspension was vortexed briefly and then centrifuged for 5 minutes at $7500 \times \mathrm{g}$ at $4^{\circ} \mathrm{C}$. After discarding the supernatant, the pellet was air-dried for 5-10 minutes and stored at $-80^{\circ} \mathrm{C}$ until future use. One microliter of extracted RNA was used to measure the concentration by Nanodrop Spectrophotometer ND-1000 (Thermo Fisher Scientific, USA), and the presence of the RNA was confirmed by gel electrophoresis on a $1 \%(\mathrm{w} / \mathrm{v})$ agarose gel.

\section{7. cDNA Synthesis Using Reverse-Transcriptase}

To generate cDNA, $1 \mu \mathrm{g}$ of total extracted RNA was first treated using the DNASE (ABI) to remove all DNA contamination. One microlitre of DNASE was added per $1 \mu \mathrm{g}$ 
of RNA sample. One microgram of purified cDNA was subsequently produced using the IScript cDNA synthesis (Life Technologies, Foster City, California, USA) by using random primers (Invitrogen NZ) at a concentration of $2.5 \mathrm{nmol}$ per reaction. The reaction was incubated in a thermal cycler (Life Technologies, Foster city, California, USA) using the following protocol. First 5 minutes at $25^{\circ} \mathrm{C}$, followed by 20 minutes at $46^{\circ} \mathrm{C}$, and 1 minute at $95^{\circ} \mathrm{C}$. Two negative controls were performed with all reactions. The first control contained soil RNA template and all DNAse/RT reagents, except for the final addition of the RT enzyme. A second control contained no template (water only) to ensure that all reagents were free from possible contaminants.

\subsection{Polymerase Chain Reaction (PCR) Methods}

To test the effect of Tetracycline and Ibuprofen on the microbial community responsible for biological nutrient removal in the activated sludge system, primer sets were chosen specifically to target two of the dominant groups. Primers for the prokaryotic and eukaryotic $16 \mathrm{~S}$ and $18 \mathrm{~S}$ rRNA genes were used to quantify the amount of each population, respectively. Primer sequences and their references are listed on Table $\mathbf{2}$ below.

The detection of the ammonia-oxidizing bacteria and archaea from the different stages of the activated sludge system were performed using PCR with two different sets of primers. The first set of primers was designed to target the $16 \mathrm{~S}$ rRNA gene sequences from the $\mathrm{AOB}$ and $\mathrm{AOA}$ and the total heterotrophic populations, whereas another set of primer was used to target the amoA (ammonia monooxygenase subunit A) gene of the AOA. Detailed methods and primers used are discussed below. Primer sequences used for the detection of AOA and AOB using PCR and their references are listed in Table 3 below. 


\subsubsection{S rRNA Gene Amplification Using PCR for Bacteria}

For PCR targeting the $16 \mathrm{~S}$ rRNA gene of the total heterotrophic population, the specific primer pair 341F (5'- CCT ACG GGA GGC AGC AG-3') and V3R (5'- ATT ACC GCG GCT GCT GG -3') was used (Muyzer et al., 1995). The amplification was performed in a BIO-RAD T100 (Life Science Research Division, California, USA) PCR thermocycler with an initial denaturation step performed at $94^{\circ} \mathrm{C}$ for 2 minutes, followed by 35 cycles of denaturation at $94^{\circ} \mathrm{C}$ for 1 minute, annealing at $60^{\circ} \mathrm{C} 1$ minute, and elongation at $72^{\circ} \mathrm{C}$ for 1 minute. A final elongation was performed at $72^{\circ} \mathrm{C}$ for 2 minutes. The $25 \mu \mathrm{L}$ final volume PCR reaction included $12.5 \mu \mathrm{L}$ of $2 \mathrm{X}$ PCR mastermix (Thermo Scientific) (containing 0.4 mM dNTPs, 0.05 unit of Taq DNA Polymerase and $\left.4 \mathrm{mM} \mathrm{MgCl}_{2}\right), 0.5 \mu \mathrm{L}$ of forward and reverse primer $(10 \mu \mathrm{M}), 1.25 \mu \mathrm{L}$ of DMSO (Sigma Aldrich), $0.343 \mu \mathrm{L}$ of bovine albumin serum (BSA) (Promega) and $8.9 \mu \mathrm{L}$ of ultra pure Millipore water. Approximately 100ng of template DNA was added.

\subsubsection{S rRNA Gene Amplification Using PCR for Protozoa}

For the 18S rRNA protozoan gene, 3NDF and V4-euk-R2 were used (Lin et al., 2014). Primer sequences and references are listed in Table 2 below. The reagents for PCR amplification with this primer set were the same as those used in the above eubacterial amplification. For the $18 \mathrm{~S}$ rRNA, forward primer 3NDF (5'-GGCAA

GTCTGGTGCCAG-3') and reverse primer V4-euk-R2 (5'-ACGGTATCT(AG)

ATC(AG)TCTTCG-3') were used (Lin et al., 2014). The PCR protocol for $18 \mathrm{~S}$ rRNA gene eukaryotic amplification was as follows $95^{\circ} \mathrm{C}$ for 2 minutes, followed by 25 cycles at $95^{\circ} \mathrm{C}$ for 1 minute, $55^{\circ} \mathrm{C}$ for 45 seconds, $72^{\circ} \mathrm{C}$ for 1 minute with a final extension at $72^{\circ} \mathrm{C}$ for 5 min. To visualize the PCR product $4 \mu \mathrm{L}$ of the product was run on a $1.5 \%$ SYBR safe DNA 
stained agarose gel for 30 minutes at $85 \mathrm{~V}$ constant voltage before visualizing the gel by UV trans-illumination (BIO RAD Life Science Research Division, California, USA).

\subsubsection{S rRNA Gene Amplification for Ammonia Oxidizing Bacteria}

For PCR targeting the 16S rRNA gene of the AOB population, the CTOf189 (5'GGAGRAAAGCAGGGGATCG-3') and CTO654r (5'-CTAGCYTTGTAG

TTTCAAACGC-3') (Kowalchuk et al. 1997) primer set that is specific to ammonia oxidizing bacteria belonging to $\beta$-Proteobacteria was used. The reagents for PCR amplification with this primer set were the same as those used previously with 100ng of template DNA. The amplification was performed in a BIO-RAD T100 (Life Science Research Division, California, USA) PCR thermocycler with an initial denaturation step performed at $93^{\circ} \mathrm{C}$ for 3 minutes, followed by 35 cycles of denaturation at $92^{\circ} \mathrm{C}$ for 30 seconds, annealing at $57^{\circ} \mathrm{C}$ for 1 minute, and elongation at $72^{\circ} \mathrm{C}$ for 45 seconds. A final elongation was performed at $72^{\circ} \mathrm{C}$ for 5 minutes. The PCR product was visualized in a $1.5 \%$ agarose gel.

\subsubsection{S rRNA Gene Amplication for Ammonia Oxidizing Archaea}

For PCR targeting the 16S rRNA gene of the AOA population, the Crenar771F (5'ACGGTGAGGGATGAAAGCT-3') and Crenar957R (5'-CGGCGTTGACTC

CAATTG-3') (Ochsenreiter et al., 2003) primer set that is specific to ammonia oxidizing archaea belonging to Crenarcheota was used. The reagents for PCR amplification with this primer set were the same as those used in the above amplification. The amplification was performed in a BIO-RAD T100 (Life Science Research Division, California, USA) PCR thermocycler with an initial denaturation step performed at $95^{\circ} \mathrm{C}$ for 15 minutes, followed by 35 cycles of denaturation at $95^{\circ} \mathrm{C}$ for 1 minutes, annealing at $55^{\circ} \mathrm{C}$ for 1 minute, and 
elongation at $72^{\circ} \mathrm{C}$ for 1 minute. A final elongation was performed at $72^{\circ} \mathrm{C}$ for 10 minutes. The PCR product was visualized in a $1.5 \%$ agarose gel.

Table 2. Primer sets specific for prokaryotes and eukaryotes

\begin{tabular}{|c|c|c|c|c|}
\hline Primer & $\begin{array}{l}\text { Primer Sequence } \\
\text { (5' to } 3^{\prime} \text { end) }\end{array}$ & $\begin{array}{l}\text { Annealing } \\
\text { Temperature } \\
\left({ }^{\circ} \mathrm{C}\right)\end{array}$ & $\begin{array}{l}\text { Target } \\
\text { Group }\end{array}$ & Reference \\
\hline $341 \mathrm{~F}$ & CCTACGGGAGGCAGCAG & 60 & Bacteria & $\begin{array}{l}\text { Muyzer et } \\
\text { al } \\
(1995)\end{array}$ \\
\hline 534R & ATTACCGCGGCTGCTGGCA & 60 & Bacteria & $\begin{array}{l}\text { Muyzer et } \\
\text { al } \\
(1995)\end{array}$ \\
\hline 3NDF & GGCAAGTCTGGTGCCAG & 55 & Protozoa & $\begin{array}{l}\text { Lin et al } \\
(2014)\end{array}$ \\
\hline $\begin{array}{l}\text { V4- } \\
\text { euk- } \\
\text { R2 }\end{array}$ & ACGGTATCT(AG)ATC(AG)TCTTCG & 55 & Protozoa & $\begin{array}{l}\text { Lin et al } \\
(2014)\end{array}$ \\
\hline
\end{tabular}


Table 3. Primer sets specific for AOB and AOA and total heterotrophs

\begin{tabular}{|c|c|c|c|c|}
\hline Primer & $\begin{array}{l}\text { Primer Sequence } \\
\text { ( } 5^{\prime} \text { to } 3^{\prime} \text { end) }\end{array}$ & $\begin{array}{c}\text { Temperature } \\
\left({ }^{\circ} \mathrm{C}\right)\end{array}$ & $\begin{array}{l}\text { Target } \\
\text { Group }\end{array}$ & Reference \\
\hline $341 \mathrm{~F}$ & CCTACGGGAGGCAGCAG & 60 & Heterotrophs & $\begin{array}{l}\text { Muyzer et al } \\
\text { (1995) }\end{array}$ \\
\hline 534R & ATTACCGCGGCTGCTGGCA & 60 & Heterotrophs & $\begin{array}{l}\text { Muyzer et al } \\
\text { (1995) }\end{array}$ \\
\hline $\begin{array}{l}\text { CTOf189- } \\
\text { GC }\end{array}$ & $\begin{array}{l}\text { CCG CCG GGC GGC GGG } \\
\text { CGG GGC GGG GGC ACG } \\
\text { GGG GGA GRA AAG CAG } \\
\text { GGG ATC G }\end{array}$ & 57 & $\mathrm{AOB}$ & $\begin{array}{l}\text { Kowalchuk et al. } \\
1997\end{array}$ \\
\hline СТ0654r & $\begin{array}{l}\text { CTA GCY TTG TAG TTT CAA } \\
\text { ACG C }\end{array}$ & 57 & $\mathrm{AOB}$ & $\begin{array}{l}\text { Kowalchuk et al. } \\
1997\end{array}$ \\
\hline Crenar771F & ACGGTGAGGGATGAAAGCT & 55 & $\mathrm{AOA}$ & $\begin{array}{l}\text { Ochsenreiter et } \\
\text { al (2003) }\end{array}$ \\
\hline Crenar957R & CGGCGTTGACTCCAATTG & 55 & $\mathrm{AOA}$ & $\begin{array}{l}\text { Ochsenreiter et } \\
\text { al (2003) }\end{array}$ \\
\hline AmoA-1F & $\begin{array}{l}\text { GGG GTT TCT ACT GGT } \\
\text { GGT }\end{array}$ & 53 & $\mathrm{AOB}$ & $\begin{array}{l}\text { Rotthauwe et al. } \\
\text { (1997) }\end{array}$ \\
\hline AmoA-2R & $\begin{array}{l}\text { CCC CTC KGS AAA GCC } \\
\text { TTC TTC }\end{array}$ & 50 & $\mathrm{AOB}$ & $\begin{array}{l}\text { Rotthauwe et al } \\
\text { (1997) }\end{array}$ \\
\hline $\begin{array}{l}\text { Arch- } \\
\text { amoAF }\end{array}$ & $\begin{array}{l}\text { STA ATG GTC TGG CTT AGA } \\
\text { CG }\end{array}$ & $48-58$ & $\mathrm{AOA}$ & $\begin{array}{l}\text { Francis et al. } \\
\text { (2005) }\end{array}$ \\
\hline $\begin{array}{l}\text { Arch- } \\
\text { amoAR }\end{array}$ & $\begin{array}{l}\text { GCG GCC ATC CAT CTG } \\
\text { TAT GT }\end{array}$ & $48-58$ & $\mathrm{AOA}$ & $\begin{array}{l}\text { Francis et al. } \\
(2005)\end{array}$ \\
\hline
\end{tabular}

\section{9. amoA Gene Amplification Using PCR}

Primers amoA-1F (5'-GGGGTTTCTACTGGTGGT-3') and amoA-2R (5'CCCCTCKGSAAAGCCTTCTTC-3') (Rotthauwe et al. 1997) were used to amplify 491 bp fragment of AOB amoA gene with the identical PCR reaction mixture as the previous 
reactions. The PCR amplification was performed by the condition of an initial denaturation step at $94^{\circ} \mathrm{C}$ for 5 minutes, followed by 30 cycles of denaturation at $94^{\circ} \mathrm{C}$ for 1 minute, annealing at $55^{\circ} \mathrm{C}$ for 30 seconds, and elongation at $72^{\circ} \mathrm{C}$ for 1 minute. Cycling was completed by a final elongation step at $72^{\circ} \mathrm{C}$ for 1 minute.

The amoA gene fragment (635 bp) of AOA was PCR-amplified using the primers Arch-amoAF (5'-STAATGGTCTGGCTTAGACG-3') and Arch-amoAR (5'-GCGGC CATCCATCTGTATGT-3') (Francis et al. 2005). The PCR reaction mixture was identical to the previous reactions. The PCR amplification protocol were as follows: a 10-minute initial denaturation at $95^{\circ} \mathrm{C}$, followed by 30 cycles of $94^{\circ} \mathrm{C}$ for 45 seconds, $53^{\circ} \mathrm{C}$ for 1 minute, and $72^{\circ} \mathrm{C}$ for 1 minute, with a final extension at $72^{\circ} \mathrm{C}$ for 15 minutes (Francis et al. 2005).

\subsection{Quantitative PCR}

Archaeal and bacterial 16S rRNA genes as well as archaeal and bacterial amoA were quantified using a Lightcycler 480 qPCR thermocycler (Roche Diagnostics Roche Applied Science 68298 Mannheim Germany). Quantitative real time PCR was performed in triplicate sets on the extracted sets of DNA and cDNA. The qPCR reaction included a total volume of $20 \mu \mathrm{L}$, containing $2 \mu \mathrm{L}$ (10x) SYBR green master mix (Roche, Mannheim, Germany), $0.2 \mu \mathrm{L}$ of the specific forward and reverse primer at a concentration of $10 \mu \mathrm{M}$, $2 \mu \mathrm{L}$ BSA (Ambion Ultrapure BSA; $5 \mathrm{mg} \mathrm{ml}-1$ ), $2 \mu$ l of template DNA (100 ng) and $5.6 \mu \mathrm{L}$ of water. The qPCR reaction mix was identical for both AOA and AOB qPCR mix. The negative control was performed with Milli-Q water as the template instead of the extracted DNA to detect the existence of a contaminant. 
Gene copy number for total heterotrophs were quantified using the primer set $341 \mathrm{~F}$ (5'-CCTACGGGAGGCAGCAG-3') and V3R (5'-ATTACCGCGGCTGCTGGCA-3') (Muyzer et al., 1995). Bacterial 16S genes specific for $\beta$-proteobacterial AOB were quantified using 16S rDNA primer sets CTO189f (5'-GGAGRAAAGCAGGGGATCG-3') and CTO654r (5'-CTAGCYTTGTAGTTTCAAAC GC-3') as previously described (Kowalchuk and Stephen, 1997). For PCR targeting the 16S rRNA gene of the AOA population, the Crenar771F (5'-ACGGTGAGGGATGAAAGCT-3') and Crenar957R (5'CGGCGTTGACTCCAATTG-3') (Ochsenreiter et al., 2003) primer set that is specific to ammonia oxidizing archaea belonging to Crenarcheota was used.

The qPCR thermocycling steps for 16S rRNA AOB gene were as follows: an initial denaturation step at $95^{\circ} \mathrm{C}$ for 10 minutes, $96^{\circ} \mathrm{C}$ for 2 minutes; 40 cycles of 45 seconds at $96^{\circ} \mathrm{C}, 1$ minute at $57^{\circ} \mathrm{C}$, and 1 minute at $72^{\circ} \mathrm{C}$. The qPCR thermocycling steps for $16 \mathrm{~S}$ AOA gene were as follows: an initial denaturation step performed at $95^{\circ} \mathrm{C}$ for 15 minutes, followed by 35 cycles of denaturation at $95^{\circ} \mathrm{C}$ for 1 minutes, annealing at $55^{\circ} \mathrm{C}$ for 1 minute, and elongation at $72^{\circ} \mathrm{C}$ for 1 minute. A final elongation was performed at $72^{\circ} \mathrm{C}$ for 10 minutes.

Bacterial amoA genes were quantified in each sample using primers amoA $1 \mathrm{~F}$ (GGGGTTTCTACTGGTGGT) and amoA 2R (CCCCTCKGSAAAGCCTTCTTC)

(Rotthauwe et al., 1997). The qPCR thermocycling steps for AOB amoA were as follows: $96^{\circ} \mathrm{C}$ for 2 minutes, 40 cycles of 5 seconds at $96^{\circ} \mathrm{C}, 1$ minute at $57^{\circ} \mathrm{C}$, and 1 minute at $72^{\circ} \mathrm{C}$. Archaeal $a m o A$ genes were quantified by using primers Arch-amoAF (5'STAATGGTCTGGCTTAGACG-3') and Arch-amoAR (5'-GCGGC CATCCATCTGTATGT-3') (Francis et al., 2005). The qPCR conditions were set as 
follows: $96^{\circ} \mathrm{C}$ for 2 minutes; 40 cycles of 5 seconds at $96^{\circ} \mathrm{C}, 1$ minute at $53^{\circ} \mathrm{C}$, and 1 minute at $72^{\circ} \mathrm{C}$. Following the qPCR protocol, the LightCycler software was used to analyze the results and provided information such as amplification curves, melting curves, and $\mathrm{Cp}$ values for each sample. The $\mathrm{Cp}$ values were obtained and averaged for the same samples and the standard deviations were calculated for the triplicate sets of the $\mathrm{Cp}$ values for both the $16 \mathrm{~S}$ rRNA and $18 \mathrm{~S}$ rRNA genes. The $\mathrm{Cp}$ value of each population was an indication of the absolute abundance of that group. The presence and sizes of the amplification of the products were determined by agarose (1\%) gel electrophoresis.

\subsection{Preparation of the Standard Curve Using Cloning and Transformation}

\subsubsection{Cloning and Transformation:}

To develop a standard curve for qPCR, the bacterial and archaeal amoA genes were PCR amplified from extracted DNA with the primers amoA1F/amoA2R and ArchamoAF/Arch-amoAR, respectively. The PCR products were cloned using the PGEM Teasy II vector system cloning Kit from PROMEGA (Madison, WI. Catalog No. A1360). The standard cloning procedure in the kit was followed. An appropriate volume that is in a 3:1 ratio of PCR product inserts to Vector was combined with $5 \mu \mathrm{L} 2 \mathrm{X}$ rapid ligation buffer, $1 \mu \mathrm{L}$ of PGEM T-Easy Vector, $1 \mu \mathrm{L}$ of T4 DNA Ligase and nuclease free water to a final volume of $10 \mu \mathrm{L}$. The reaction was incubated at room temperature for 5 minutes at room temperature and incubated for 24 hours at $4{ }^{\circ} \mathrm{C}$ to achieve maximum number of transformants. Two microlitre of this cloned vector containing the PCR product as an insert was then transformed into one $50 \mu \mathrm{L}$ vial of Escherichia coli JM109 High Efficiency Competent Cells. The mixture was placed on ice for 20 minutes and then heat-shocked for $45-50$ seconds in a water bath at exactly $42^{\circ} \mathrm{C}$. Next, $950 \mu \mathrm{L}$ of S.O.C. medium was added, 
followed by incubation at $37^{\circ} \mathrm{C}$ with shaking at $200 \mathrm{rpm}$ for 1.5 hours. The cells were then spread onto LB agar media containing ampicillin at a working concentration of $100 \mu \mathrm{g}$ $/ \mathrm{mL}$. The plates were incubated at $37^{\circ} \mathrm{C}$ for $18-24$ hours depending on the appearance and size of colonies on the plate. White colonies were indicated as positive colonies, which confirmed that amoA genes were successfully ligated into the pGEM-T Easy Vector and were selected and re-streaked on fresh LB plates.

\subsubsection{Plasmid Extraction}

Pure cultures of each transformant white colonies were transferred to Eppendorf tube containing $1.5 \mathrm{~mL}$ of sterile $0.9 \%$ solution. Sufficient bacteria was added to the suspension until the solution appeared semi turbid. The suspension was centrifuged at 14,000-16,000 $\mathrm{x} g$ for 1 minute. The supernatant was discarded, and the harvested bacterial pellet $(0.25 \mathrm{~g})$ was subjected to plasmid extraction using the GENEAID High Speed Plasmid Mini Kit (Cat. \# PD100. Geneaid Biotech Ltd. New Taipei City, Taiwan) according to manufacturer's instructions. Plasmids were eluted in $30 \mu \mathrm{L}$ of sterile milli-pore water. One microliter of extracted plasmid was used to measure the concentration by Nanodrop Spectrophotometer ND-1000 (Thermo Fisher Scientific, USA).

\subsubsection{Standard Curve}

Plasmids used as standards for quantitative analyses were extracted from the correct insert clones of each target gene and sent for sequencing. The plasmid DNA concentration was determined on a Nanophotometer (IMPLEN, Munich, Germany) and the copy numbers of target genes were calculated directly from the concentration of the extracted plasmid DNA. Tenfold serial dilutions of a known copy number of the plasmid DNA were subjected to a real-time PCR assay in triplicate to generate an external standard curve and 
to check the amplification efficiency. High efficiencies of $99 \%$ were obtained for AOB amoA amplification, with the $\mathrm{R}$ value ranging between 0.997 and 0.999 , and efficiencies of 99\% were obtained for AOA amoA amplification, with the $\mathrm{R}$ value ranging between 0.998 and 0.999 .

\subsection{Community Composition and Diversity Profiles and Identification Using Denaturing Gradient Gel Electrophoresis (DGGE)}

\subsubsection{DGGE}

For PCR-DGGE, two gene fragments with sizes $491 \mathrm{bp}$ and $635 \mathrm{bp}$ of bacterial and archaeal $a m o A$ genes were amplified using the same primer sets used previously for qPCR. Denaturing gradient gel electrophoresis was performed with $8 \%$ (wt / vol) acrylamide gel containing a linear chemical gradient ranging from 30 to $65 \%$ denaturant (10O\% denaturant, $7 \mathrm{M}$ urea and 40\% (vol/vol) formamide) (Yang and Crowley, 2000). Approximately $45 \mathrm{uL}$ of each PCR product was loaded into individual lanes of the polyacrylamide gel. The gel was subjected to electrophoresis for 16 hours at $60^{\circ} \mathrm{C}$ at 100 $\mathrm{V}$ in $1 \mathrm{X}$ TAE buffer using the DCode universal mutation detection system (Bio Rad Laboratories, Hercules, CA, USA). After the electrophoresis, the gel was soaked in SYBR Gold nucleic acid gel stain solution (ThermoFisher) for 30 minutes and then de-stained in 1X TAE buffer for 15 minutes, and was photographed under UV illumination.

\subsubsection{Sequence of DGGE Bands}

Characteristic DGGE bands were visualized with Safe ImagerTM 2.0 Blue Light Transilluminator (ThermoFisher Scientific, USA) and select bands were excised from the DGGE gels using a sterilized scalpel. The excised bands were then placed into $1.5 \mathrm{~mL}$ Eppendorf microtubes. Thirty microliters of sterile ultra-pure water was added to each 
microcentrifuge tube, which was kept at $4{ }^{\circ} \mathrm{C}$ overnight to enable DNA to diffuse from the gel strips into the water phase. One microliter of the DNA solution was used as a template to amplify the DNA fragment from the excised DGGE band with the primer sets for AOB and AOA used previously. The amplicon was sequenced with sequencing primers at ACTG Corp (Toronto). The resultant DNA sequences were inputted into the BLAST search program from NCBI to obtain possible matches. 
CHAPTER 4: RESULTS 


\subsection{Impact of Pharmaceuticals on Activated Sludge Microbial Communities}

\subsubsection{Semi-batch Reactor Setup}

It is very difficult to obtain experimental data on the impact of contaminants on the wastewater microbial community in a full-scale system due to the unknown and constant variations of wastewater characteristics such as concentrations of the contaminants, temperature, $\mathrm{pH}$, dissolved organic materials etc., and the inability to add potentially deleterious compounds to the system to study their effect. Thus, the use of laboratory scale bioreactors is ideal to study the effect of particular compounds on the composition and function of microorganisms in activated sludge. This experiment involved the use of semibatch reactors which are very similar to batch reactors but have the supplementary feature of the addition of one or more components at various intervals. In a semi-batch reactor, fresh media is continuous or sometimes periodically added to the bioreactor but unlike a continuous reactor, there is no continuous removal. Using this method, different feeding rates (that mirrored short and long sludge retention times) in the presence and absence of a known pharmaceutical were tested on the microbial communities present in activated sludge. This semi-batch reactor also provided the opportunity to monitor the microbial community in activated sludge in the presence of Tetracycline and Ibuprofen by sampling at various time intervals. Thus, the semi-batch reactor system provided a method of studying the composition and function of the microbial community under various controlled environmental conditions.

Over the duration of this project, two separate reactor experiments were established. The initial experiment involved reactors supplemented with and without Tetracycline, these reactors were established to test the impact of environmentally relevant 
concentrations of Tetracycline $(1 \mu \mathrm{g} / \mathrm{L})$ and $(10 \mu \mathrm{g} / \mathrm{L})$ under two different feeding rates mimicking short and long retention times. This was achieved by the addition of sterile synthetic wastewater supplemented with the Tetracycline following sampling. For low feed reactors that represented an SRT of 52 days, $10 \mathrm{~mL}$ of the $500 \mathrm{~mL}$ total volume of activated sludge was removed and replaced with $10 \mathrm{~mL}$ of sterile synthetic wastewater. For the high feed reactors that represented an SRT of 10 days, $50 \mathrm{~mL}$ of the $500 \mathrm{~mL}$ total volume of activated sludge was removed and replaced with $50 \mathrm{~mL}$ of sterile synthetic wastewater. The feed was supplemented with Tetracycline at the required doses. The sludge retention times were calculated using the following formula:

\section{SRT (days) $=\quad \underline{\text { Lbs/day of suspended solids in aeration basin }}$ Lbs/day of suspended solids wasted from the system}

Using this equation, the volumes of the total wastewater within the reactors and the volume of wastewater that was removed was converted to lbs and divided by two days, which was the sampling interval throughout the duration of the experiment. Calculations can be found in the appendix.

The second experiment involved reactors supplemented with either Tetracycline or Ibuprofen. This experiment was performed to test the impact of Tetracycline and Ibuprofen on the abundance and community composition of the bacterial and protozoan communities present in the activated sludge system. In this case the retention time of 10 days was maintained and held at a constant rate but the pharmaceuticals were added at higher concentrations (Tetracycline $500 \mu \mathrm{g} / \mathrm{L}$ and Ibuprofen at $100 \mu \mathrm{g} / \mathrm{mL}$ ). These reactors were 
sampled on day 5,10 and 15 where $50 \mathrm{~mL}$ was extracted from the total volume of $500 \mathrm{~mL}$ and replaced with synthetic feed containing the pharmaceuticals.

\subsection{Impact of Tetracycline on the Bacterial Population in Activated Sludge Reactors}

\subsubsection{Tetracycline Semi-Batch Reactor Performance}

The Tetracycline semi-batch reactors were operated with constant aeration that kept the dissolved oxygen concentrations above $2 \mathrm{mg} / \mathrm{L}$ throughout the duration of the experiment. The wastewater was replaced at $2 \%$ and $10 \%$ volume rate every two days using synthetic wastewater containing $1500 \mu \mathrm{g} / \mathrm{mL}$ of carbon. Dissolved carbon measurements (DOC) were taken at day 1 and then again at the end each week during the operating period and it was found that carbon removal was $99 \%$ efficient or better in all the reactors independent of Tetracycline concentrations or feed rate. Parameters such as temperature, $\mathrm{pH}$ and dissolved oxygen (DO) were not monitored because a previous study using a similar reactor setup demonstrated that these conditions were stable in the reactor system and remained at desired levels for microbial growth in activated sludge (Pogue, 2001).

\subsubsection{The Impact of Low Concentrations of Tetracycline at Short and Long Retention Times on the Community Composition and Diversity of Bacteria}

In order to mimic short and long sludge retention times, two different feeding rates were implemented. The short SRT (10 days) was established by extraction and replacement of $50 \mathrm{~mL}$ sample from the total $500 \mathrm{~mL}$ reactor. While the long SRT (50 days) was established when $10 \mathrm{~mL}$ was extracted and replaced from the reactors every 2 days. To evaluate the effects of varying SRT in combination with Tetracycline on the microbial community, the samples were subjected to DNA extraction and amplification of the V3 
region of the 16S rDNA sequence to generate a 193 bp PCR amplicon. The PCR amplicon for each sample was quantified and approximately $1500 \mathrm{ng}$ of PCR product was loaded onto a DGGE gel. Figure 11a illustrates the community profile for the reactors with low concentrations of Tetracycline after 14 days. Each DGGE molecular profile contained numerous bands regardless of Tetracycline concentration or the SRT. It was observed that the profiles from all reactors showed community composition differences in band appearance and intensity over time including the profiles from the control reactors. Similarity analysis of the composition of the populations under the different conditions was conducted using GelCompar software. The DICE analysis clustered the reactors into two main groups based on SRTs rather than Tetracycline concentration since the control reactors of each SRT clustered together with the reactors subjected to the same SRT regardless of the Tetracycline concentrations. This indicated that the shifts observed in the community profiles are more influenced by the retention times than the presence of the pharmaceutical.

The bacterial community profile after being exposed to very high concentrations of Tetracycline is shown in Figure 11b. The community at day 0 represented the initial community profile without the addition of the Tetracycline antibiotic. Although, some differences in band intensity was observed, overall it appeared that the profiles were similar between treatments and showed little to no change in composition.

\subsubsection{Diversity Comparison Using the Shannon Index}

The diversity of the community profiles was compared using the Shannon-Weiner Index. The diversity indices for each group of reactors are shown in Table 4. The indices decreased slightly when the SRT was shorter and Tetracycline concentrations were low, 
and increased slightly when Tetracycline concentrations were very high. However, the indices suggest that the community remained diverse under all conditions. Overall, the composition of the community appeared to have shift which is shown by the increase and decrease in the intensity of specific bands in the gel (change in population abundance) however the overall diversity did not change significantly suggesting that the diversity of a complex robust community can be maintained under changing environmental conditions.

Table 4. Shannon indices for bacterial community exposed to various concentrations of Tetracycline, a) at the environmental concentrations and b) at the synthetically high concentration.

a)

\begin{tabular}{|l|l|l|l|}
\hline \multirow{2}{*}{$\begin{array}{l}\text { Wastewater } \\
\text { replacement rate }\end{array}$} & \multicolumn{3}{|l|}{ Tetracycline concentration* } \\
\cline { 2 - 4 } & $0 \mu \mathrm{g} / \mathrm{L}$ & $1 \mu \mathrm{g} / \mathrm{L}$ & $10 \mu \mathrm{g} / \mathrm{L}$ \\
\hline Initial - day 0 & $1.16 \pm 0.001$ & $1.16 \pm 0.001$ & $1.16 \pm 0.001$ \\
\hline Low - day 14 & $1.36 \pm 0.08$ & $1.13 \pm 0.07$ & $1.25 \pm 0.08$ \\
\hline High - day 14 & $0.98 \pm 0.05$ & $1.14 \pm 0.04$ & $1.11 \pm 0.06$ \\
\hline
\end{tabular}

* represents an average of the three replicate reactors

b)

\begin{tabular}{|l|l|l|}
\hline \multirow{2}{*}{$\begin{array}{l}\text { Wastewater } \\
\text { replacement rate }\end{array}$} & \multicolumn{2}{|l|}{ Tetracycline concentration* } \\
\cline { 2 - 3 } & $0 \mu \mathrm{g} / \mathrm{L}$ & $500 \mu \mathrm{g} / \mathrm{L}$ \\
\hline Initial - day 0 & $1.44 \pm 0.005$ & $1.44 \pm 0.005$ \\
\hline High - day 14 & $1.52 \pm 0.011$ & $1.55 \pm 0.012$ \\
\hline
\end{tabular}

* represents an average of the three replicate reactors 
a)

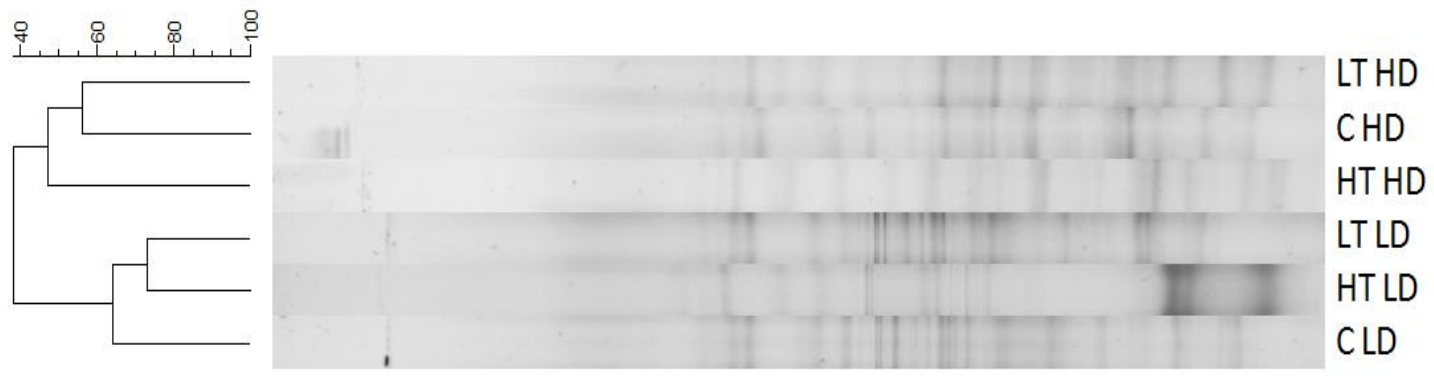

b)
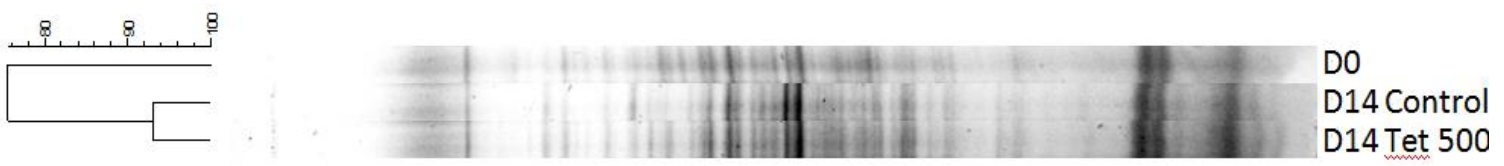

Figure 11. Dendrogram representing the relationship between bacterial community profiles under the different conditions. a) DGGE of profiles from day 14 under the 2 environmentally relevant concentrations (1 (low) and 10 (high) $\mu \mathrm{g} / \mathrm{L}$ ), b) DGGE profiles from day 14 under the very high Tetracycline concentration $(500 \mu \mathrm{g} / \mathrm{L}) . \mathrm{HD}=\mathrm{SRT}$ of 10 days and $\mathrm{LD}=\mathrm{SRT}$ of 50 days.

4.3. Impact of Tetracycline and Ibuprofen on Bacterial and Protozoan Populations in Activated Sludge

\subsubsection{Tetracycline and Ibuprofen Semi-Batch Reactor Performance}

The Ibuprofen/Tetracycline semi-batch reactors were operated with constant aeration throughout the duration of the experiment to maintain a DO $>2 \mathrm{mg} / \mathrm{L}$. The wastewater was replaced at $10 \%$ volume rate every two days using synthetic wastewater containing $1500 \mu \mathrm{g} / \mathrm{mL}$ of carbon as previously described. The reactors supplemented with Ibuprofen or both Tetracycline and Ibuprofen, and the temperature was maintained for 15 days at a range between 20 and $22^{\circ} \mathrm{C}$. 


\subsubsection{Impact of High Concentrations of Tetracycline and Ibuprofen on Bacterial and Protozoan Diversity and Composition}

The community profiles for bacteria and protozoa were generated as previously described and the DGGE images are shown in Figure 12. The profiles from reference and experimental conditions for both the bacterial (Fig. 12a) and protozoan populations (Fig. 12b) are illustrated. For the $16 \mathrm{~S}$ rDNA gene, primers used for the previous experiment were once again utilized. For the $18 \mathrm{~S}$ rRNA protozoan gene, forward primer 3NDF and reverse primer V4-euk-R2 were used (Lin et al., 2014) to generate the amplicon.

In Figure 12a, lane 1 the control community profile after 14 days is shown and represented the WWTP sample without the addition of the pharmaceutical compounds. It reflected the community composition of the wastewater plant inoculum. Lane 2 represented the experimental reactor supplemented with $500 \mu \mathrm{g} / \mathrm{L}$ Tetracycline and lane 3 shows the community exposed to $100 \mu \mathrm{g} / \mathrm{mL}$ Ibuprofen. Fourteen bands were extracted and sequenced and identities of some of the major bacterial members of the population were found by sequencing several of the bands (Table 5a). Overall, there were a few differences in the profiles indicating that high concentrations of these two pharmaceuticals may have some effect on the abundance and composition of the most prominent species of bacteria in the community. Uncultured Polaromonas (band 1), Xanthomonas sacchari (band 6) groups of uncultured proteobacteria and uncultured bacterium (bands 3, 4, 5, 10 11,12, 13, 14) were present in both reference and experimental reactors amended with Tetracycline and Ibuprofen. It appears that uncultured Raoultella (band 2) was affected by Tetracycline and Ibuprofen which led to the disappearance of this band from the experimental reactor profiles along with other uncultured prokaryotes (bands 7 and 8). However, uncultured 
Dokdonella (band 9) started to appear after the samples were treated with both pharmaceuticals. Since the wastewater community contains hundreds of bacterial species, there are limitations to the DGGE method where minor species that may be affected by the pharmaceutical would not be accounted for on the DGGE gel. This indicates that Tetracycline even at very high concentrations does not appear to affect the most dominant species of the bacterial community, but may have some effect on lesser abundant members. Any effects from antibiotics in wastewater that are found at levels below the minimum inhibitory concentrations (MICs) of resistant phenotypes also appear not to affect the most abundant bacterial species in the communities. It is possible that the effects of the compounds may be masked by the vast diversity of the activated sludge system which supports the robustness of mixed populations.

A)

\section{Bacteria}

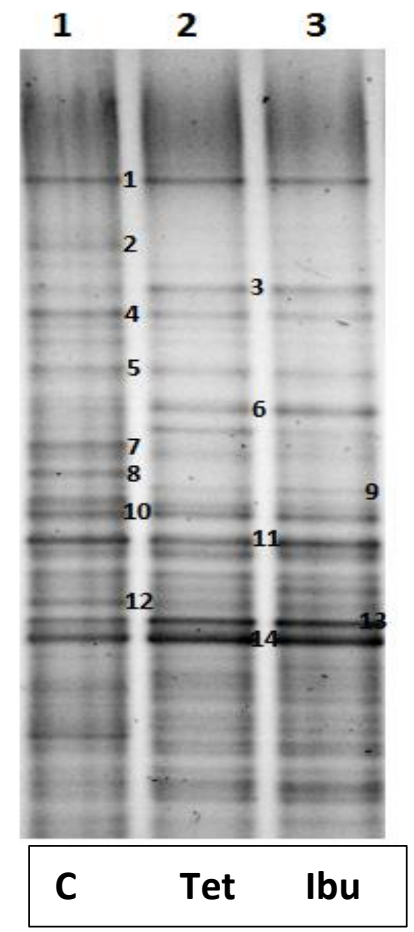

B)

Protozoa

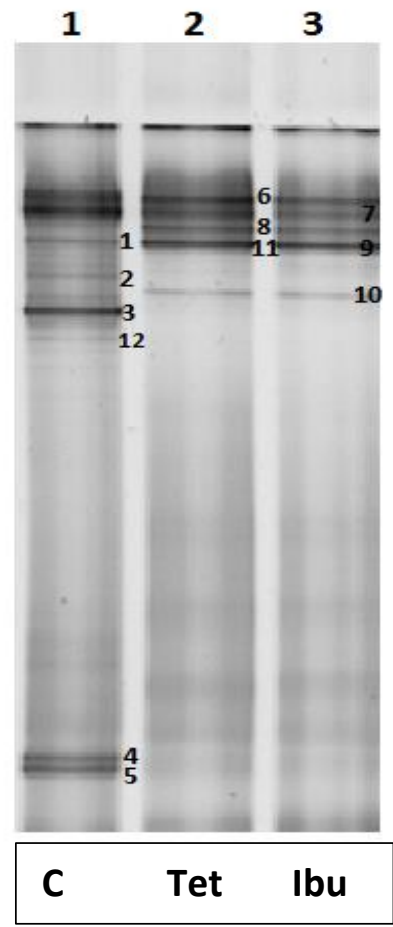


Figure 12. DGGE profiles of the A) bacterial and B) protozoan population in the reactors with various Tetracycline and Ibuprofen concentrations. A1-Control, A2-Tetracycline and A3Ibuprofen. B1-Control, B2-Tetracycline and B3-Ibuprofen.

Table 5a. Bacterial genera found in the communities exposed to Tetracycline and Ibuprofen.

\begin{tabular}{|c|c|c|c|c|}
\hline Band number & Identification & $\begin{array}{l}\text { Percent } \\
\text { similarity }\end{array}$ & $\begin{array}{l}\text { Presence in } \\
\text { reference } \\
\text { community }\end{array}$ & $\begin{array}{l}\text { Presence in } \\
\text { experimental } \\
\text { community }\end{array}$ \\
\hline 1 & $\begin{array}{l}\text { Uncultured } \\
\text { Polaromonas sp. }\end{array}$ & $98 \%$ & ++ & ++ \\
\hline 2 & $\begin{array}{l}\text { Uncultured } \\
\text { Raoultella sp. }\end{array}$ & $96 \%$ & + & - \\
\hline 3 & $\begin{array}{l}\text { Uncultured } \\
\text { Bacterium }\end{array}$ & $77 \%$ & + & ++ \\
\hline 4 & $\begin{array}{l}\text { Beta } \\
\text { proteobacterium }\end{array}$ & $76 \%$ & ++ & ++ \\
\hline 5 & $\begin{array}{l}\text { Uncultured } \\
\text { Bacterium }\end{array}$ & $80 \%$ & ++ & ++ \\
\hline 6 & $\begin{array}{l}\text { Xanthomonas } \\
\text { Sacchari }\end{array}$ & $95 \%$ & + & ++ \\
\hline 7 & $\begin{array}{l}\text { Uncultured } \\
\text { bacterium }\end{array}$ & $82 \%$ & + & - \\
\hline 8 & $\begin{array}{l}\text { Beta } \\
\text { proteobacterium }\end{array}$ & $81 \%$ & + & - \\
\hline 9 & $\begin{array}{l}\text { Uncultured } \\
\text { Dokdonella }\end{array}$ & $98 \%$ & - & + \\
\hline 10 & $\begin{array}{l}\text { Beta } \\
\text { protebacterium }\end{array}$ & $85 \%$ & ++ & ++ \\
\hline 11 & $\begin{array}{l}\text { Uncultured } \\
\text { bacterium }\end{array}$ & $87 \%$ & +++ & +++ \\
\hline 12 & $\begin{array}{l}\text { Beta } \\
\text { protebacterium }\end{array}$ & $87 \%$ & ++ & + \\
\hline 13 & $\begin{array}{l}\text { Uncultured } \\
\text { bacterium }\end{array}$ & $73 \%$ & ++ & +++ \\
\hline 14 & $\begin{array}{l}\text { Uncultured } \\
\text { bacterium }\end{array}$ & $78 \%$ & ++++ & ++++ \\
\hline
\end{tabular}


Table 5b. Protozoan genera found in the communities exposed to Tetracycline and Ibuprofen

\begin{tabular}{|c|c|c|c|c|}
\hline Band number & Identification & $\begin{array}{l}\text { Percent } \\
\text { similarity }\end{array}$ & $\begin{array}{l}\text { Present in } \\
\text { reference } \\
\text { community }\end{array}$ & $\begin{array}{l}\text { Present in } \\
\text { experimental } \\
\text { community }\end{array}$ \\
\hline \multirow[t]{2}{*}{ 1, (9), (11) } & $\begin{array}{l}\text { Uncultured } \\
\text { Cryptomycota }\end{array}$ & $90-93 \%$ & + & +++ \\
\hline & Lamproderma sp. & $86 \%$ & + & +++ \\
\hline \multirow[t]{2}{*}{2} & $\begin{array}{l}\text { Slavina } \\
\text { appendiculate }\end{array}$ & $99 \%$ & ++ & - \\
\hline & Paranais litoris & $99 \%$ & ++ & - \\
\hline \multirow[t]{3}{*}{3} & $\begin{array}{l}\text { Slavina } \\
\text { appendiculate }\end{array}$ & $99 \%$ & +++ & - \\
\hline & Paranais litoris & $99 \%$ & +++ & - \\
\hline & Nais communis & $90 \%$ & +++ & - \\
\hline 4 & Arcella vulgaris & $95 \%$ & ++ & + \\
\hline 5 & $\begin{array}{l}\text { Arcella } \\
\text { hemiphaenia }\end{array}$ & $98 \%$ & ++ & + \\
\hline 6 & $\begin{array}{l}\text { Unculture } \\
\text { eukayote }\end{array}$ & $92 \%$ & +++ & +++ \\
\hline 7 & Cercozoa sp. & $95 \%$ & ++++ & +++ \\
\hline \multirow[t]{2}{*}{8} & $\begin{array}{l}\text { Uncultured } \\
\text { cryptomycota }\end{array}$ & $92 \%$ & - & +++ \\
\hline & Lamproderma sp. & $86 \%$ & - & +++ \\
\hline 10 & $\begin{array}{l}\text { Uncultured } \\
\text { eukaryote }\end{array}$ & $95 \%$ & - & ++ \\
\hline \multirow[t]{4}{*}{12} & $\begin{array}{l}\text { Uncultured } \\
\text { eukaryote }\end{array}$ & $98 \%$ & - & + \\
\hline & $\begin{array}{l}\text { Slavania } \\
\text { appendiculate }\end{array}$ & $97 \%$ & - & + \\
\hline & Paranais litoris & $97 \%$ & - & + \\
\hline & Nais cummunis & $97 \%$ & - & + \\
\hline
\end{tabular}

Conversely, Figure 11b shows the pharmaceutical effects on the profiles of the protozoan population in the reference and experimental reactors. In this case, there was a noticeable difference between reactors that contained no pharmaceutical and those that did. Although the diversity of the protozoan was not significantly affected (approximately 1620 bands could be distinguished in each lane regardless of treatment) the composition of 
the community had shifted. Twelve bands from the gel were extracted and sequenced (Table 5b). The pharmaceuticals appeared to affect both presence and abundance of the protozoan members. First of all, Lamproderma sp. or Cryptomycota sp. (Bands 1, 9, 11), Arcella vulgaris (band 4), Arcells hemispherica, (band 5), an uncultured eukaryote (band 6), and Cercozoa (band 7) were found in all reactors although not always at the same abundance. Slavina appendiculata or Paranais litoralis (bands 2 and 3), Arcella vulgaris (band 4), Arcella hemispherica, (band 5), Cercozoa (band 7) and Slavina appendiculata or Paranais litoralis or Nais communis (band 12) were more dominant in the reference reactor, in fact, band 3 appeared to be absent from the reactors with $500 \mu \mathrm{g} / \mathrm{L}$ and 100 $\mu \mathrm{g} / \mathrm{ml}$ of Ibuprofen. On the other hand, Lamproderma sp. (band 8) or an uncultured eukaryote (bands 8 and 10) were only seen in the experimental reactor where band 1 (9, 11) (Lamproderma sp. or Crytomycota sp.) was also more prominent. Most of the bands were identified as protozoans but because the 18SrRNA primers did not discern between the types of eukaryotes, protists, amoebas, a worm and an uncultured eukaryote were identified. The low similarity percentage similarities found between the database and the sequenced rRNA gene amplicons from this system also indicates that many microorganisms in the wastewater treatment system have yet to be fully identified or included in the database. However, all the blast searches of the sequences verified that the closest identity of the sequences from our system was to an eukaryote that had been previously identified from an aquatic environment. 


\subsection{Detection of Ammonia Oxidizing Microorganisms in an Full Scale Activated Sludge Community}

The availability of culture independent molecular tools for the analyses of mixed microbial communities from contaminated soil and water have undoubtedly advanced the knowledge and understanding about microbial diversity and biochemistry. Due to the difficulty of isolation and purification of $\mathrm{AOA}$ and $\mathrm{AOB}$ strains, most of this project relied on cultivation-independent analysis for the diversity and quantity experiments. Polymerase chain reaction using primers for the $16 \mathrm{~S}$ rRNA gene and the amoA subunit of the ammonia monooxygenase gene was used to detect and quantify AOA and AOB from the activated sludge system.

\subsubsection{Detection of AOA and AOB in the Activated Sludge Process}

Experiments were performed using two distinct primer sets to detect $\mathrm{AOB}$ and AOA from the full scale activated sludge system. For AOB, primers CTO189f and CTO654r were used to amplify a 465 bp fragment. For AOA, primers Crenar771f and Crenar957r were used to amplify a 186 bp fragment. Samples from seven sampling sites (Four from the aerated tanks, one from returned sludge and two from digesters) in the activated sludge process were collected and tested for the presence of each of the ammoniaoxidizing group (Figure 13a). For AOB, the prominent bands for $16 \mathrm{~S}$ rDNA were observed in samples from aeration tanks $2,4,6,8$ and the recycled sludge samples. In comparison, the prominent bands for AOA $16 \mathrm{~S}$ rDNA appeared in samples arising from the anaerobic/anoxic digesters.

The samples were also screened for the amoA gene from each of the groups (Figure 13b). Amplification of $a m o A$ gene sequence for $\mathrm{AOB}$ were performed using primers 
amoA1f and amoA2r to amplify a $491 \mathrm{bp}$ fragment for AOB. Amplification of amoA gene sequence for AOA was performed using primers Arch-amoAf and Arch-amoAr to amplify a $635 \mathrm{bp}$ fragment for AOA. Similar to the 16S rRNA gene profiles for AOB, the most prominent bands for amoA gene was found in the aerated tank activated sludge samples. For the AOA specific amoA gene, bands were observed in activated sludge samples obtained from aerated tanks 2,4 , recycled sludge and digester 1 and 2 .

The amplicons generated for $16 \mathrm{~S}$ rRNA gene and the amoA gene were sequentially used for two future experiments. First, the amplicons were used to run on a DGGE gel to determine community composition and generate molecular community profiles of AOA and $\mathrm{AOB}$ of all reactors in the activated sludge system. Secondly, the amplicons were cloned into the P-GEM T-easy vector system, transformed into JM109 E. coli. Plasmids extracted from transformants were isolated and used as a template to generate standard curves for q-PCR analysis. The next section will discuss the community composition of ammonia oxidizers in the full scale activated sludge system. 


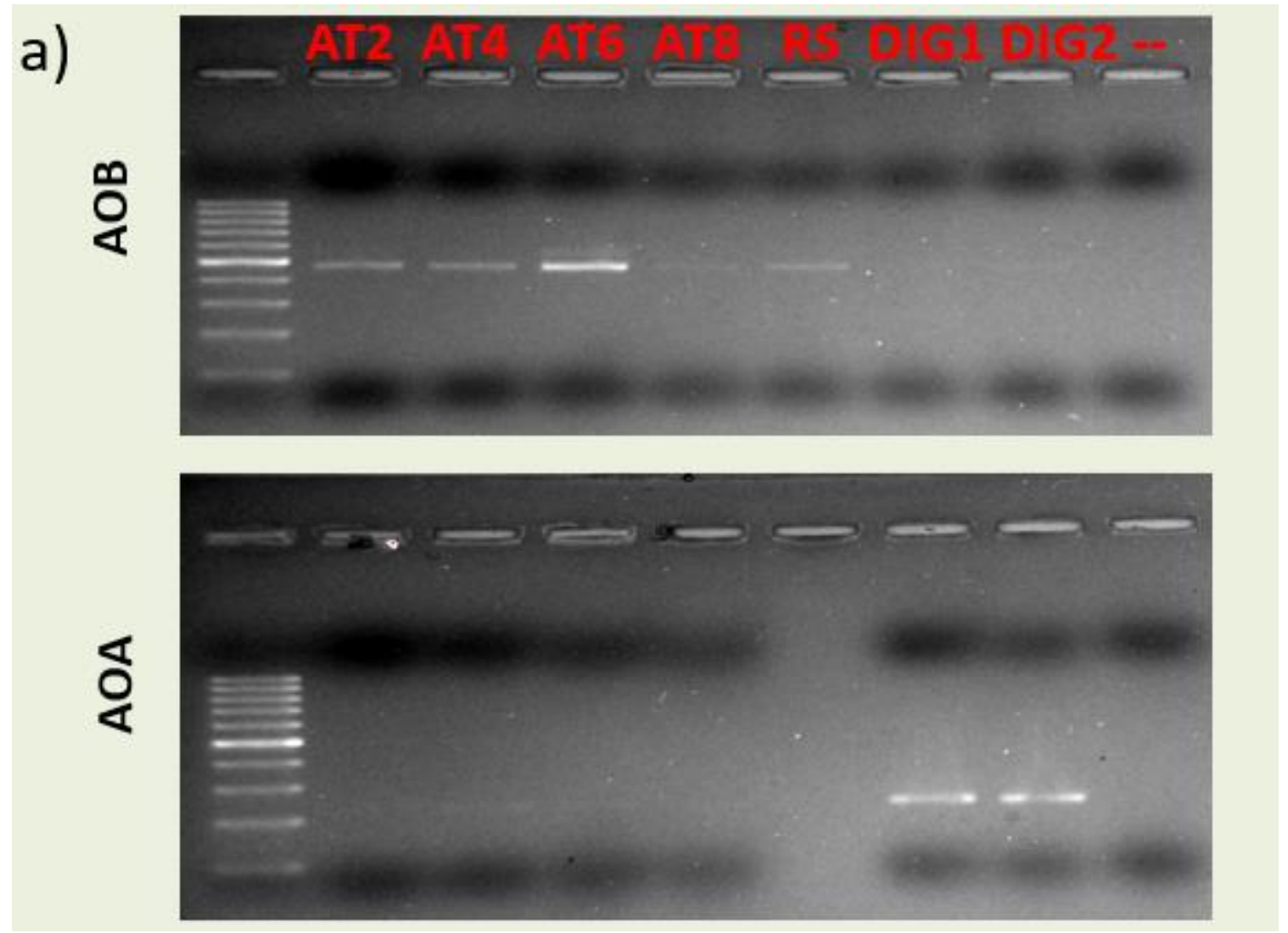

Figure 13a. Gel image of PCR product targeting $16 \mathrm{~S}$ rRNA gene fragment for AOB and AOA in a full-scale activated sludge system. Gel image of PCR products obtained after PCR with primers CTO189f and CTO654r targeting AOB to amplify a $465 \mathrm{bp}$ fragment. For AOA, primers Crenar771f and Crenar957r were used to amplify a 186 bp fragment. Volumes of template $5 \mu \mathrm{L}$ DNA was used for both samples. The well designated as -- is the negative control run for each sample consisting of the PCR amplification mix only with no DNA. The last lane consists of the 100bp DNA ladder (Froggabio, Toronto, ON). 


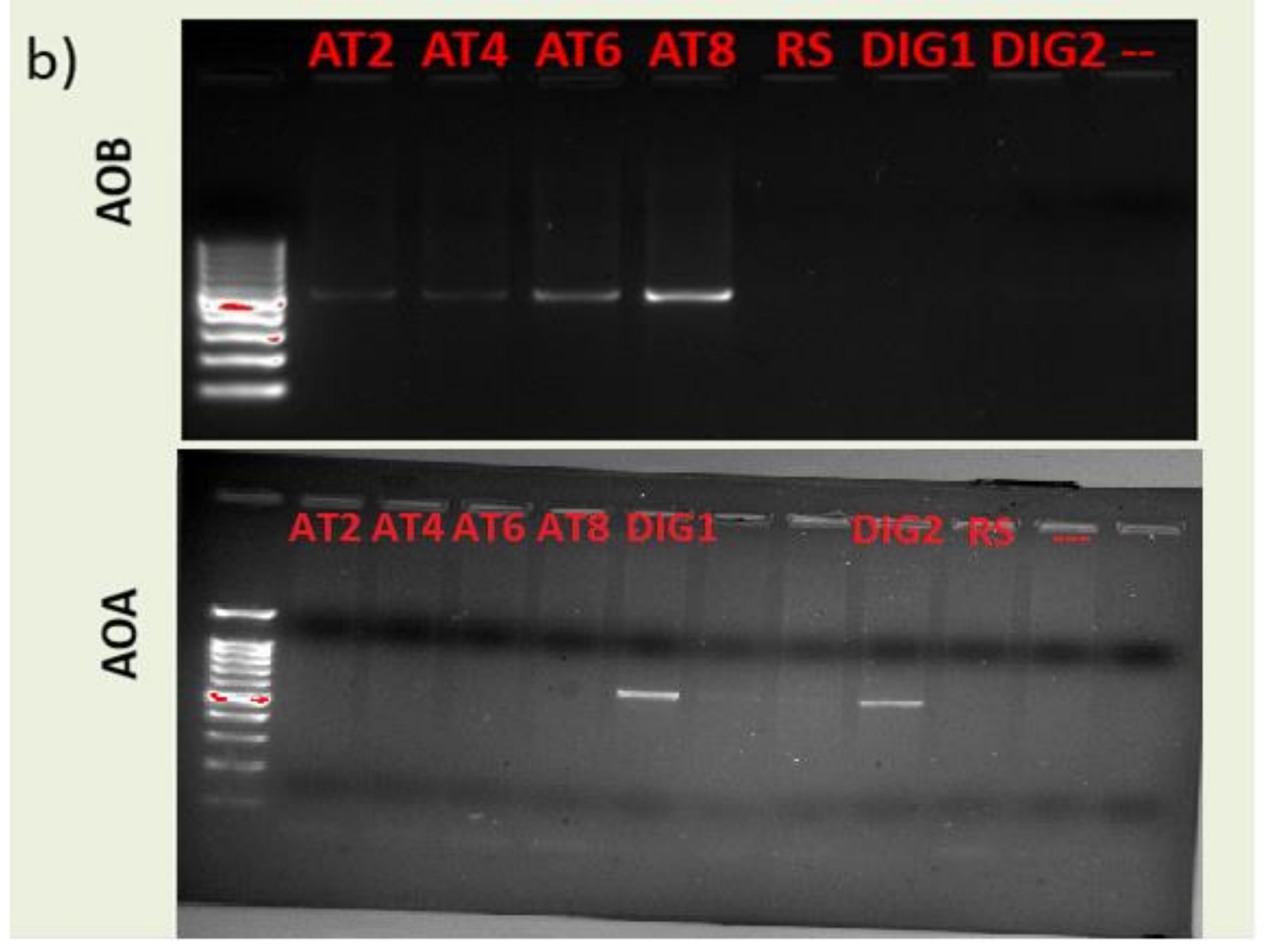

Figure 13b. Gel image of PCR product targeting amoA gene fragment for AOB and AOA. Gel image of PCR products obtained after PCR with using primers amoA1f and amoA2r to amplify a $491 \mathrm{bp}$ fragment for AOB. Amplification of amoA gene sequence for AOA was performed using primers Arch-amoAf and Arch-amoAr to amplify a $635 \mathrm{bp}$ fragment for AOA. Volumes of $5 \mu \mathrm{L}$ template DNA was used for both samples. The well designated as (--) is the negative control run for each sample consisting of the PCR amplification mix only with no DNA. The last lane consists of the 100bp DNA ladder (Froggabio, Toronto, ON). 


\subsubsection{Community Composition of AOA and AOB in the Activated Sludge System}

\subsubsection{AOB Community Composition}

To examine the composition of the AOA and $\mathrm{AOB}$ populations present in different activated sludge systems, community profiles from each reactor were generated by amplifying the $16 \mathrm{~S}$ rRNA and the amoA gene for the bacterial and archaeal populations respectively, and running the amplicons on a DGGE gel. Figure 14a shows the profiles generated with the $16 \mathrm{~S}$ rRNA gene from the AOB microbial community from all stages of the activated sludge system. Decreases in band intensity can be observed from AT2 and AT4 lanes in comparison to AT6 and AT 8 that may indicate some difference in abundances of $\mathrm{AOB}$ in each sample. In addition, the number of bands also decrease compared with the AT2 and DIG lanes, indication of fewer AOB being present in the anaerobic digester tank in comparison to the aeration tanks. The anaerobic digester (DIG) showed the least number bands for AOB.

The community profile generated from the AOB amoA gene profile is shown in Figure 14b. It can be observed that all samples share similar banding patterns for all activated sludge samples. Three major bands are visible in all samples. Interestingly, the

presence of a $4^{\text {th }}$ band in AT 8 , indicated some visible changes in communities present in the aeration tanks. Overall, comparing all reactors, there were very little differences in the community composition profiles indicating the same community members of AOB exist in activated sludge regardless of the environmental parameters such as differences in oxygen concentrations. 


\subsubsection{AOA Community Composition}

The AOA community profiles generated from the $16 \mathrm{~S}$ rDNA and AOA specific $a m o A$ gene are seen in Figure 15. Bands were observed in the anaerobic digesters for $16 \mathrm{~S}$ rRNA AOA community. Bands for AOA were not observed for aeration tank samples, because no PCR product could be amplified from the aeration tanks community DNA samples. For the AOA amoA gene amplicon, there were there were only 3 bands in the digester community suggesting that the same members of AOA exist in both the anaerobic digester tanks.

\subsubsection{Comparison of AOB and AOA Community Composition}

Overall, the DGGE community profile analysis demonstrated that very little diversity may exist for the AOB community within the different aeration tanks. It is likely that $\mathrm{AOB}$ are more prevalent due to the increased number of bands found in the aeration tanks in comparison to the anaerobic digesters. Comparatively, for the AOA community, similar profiles were observed between the two digester tanks however it is likely that they are more prevalent in the anaerobic tanks as no amplicons or bands could be observed in the aeration tanks. 


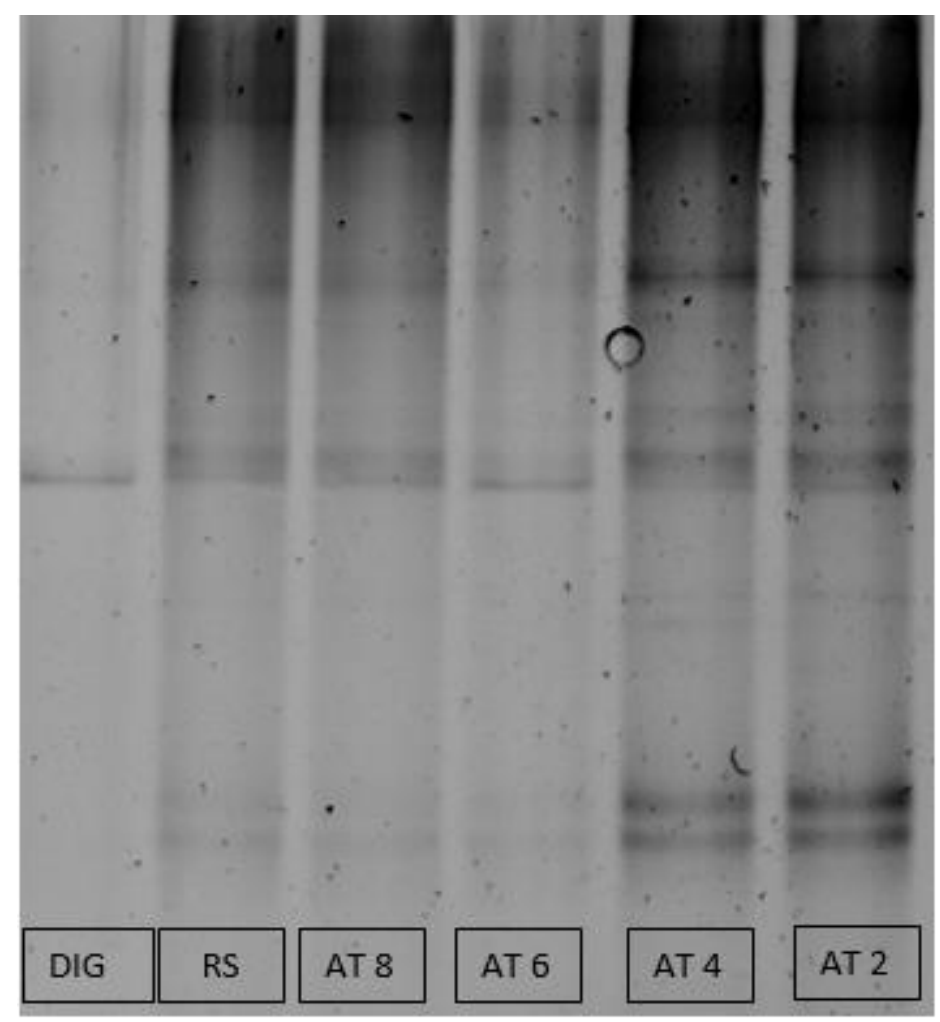

Figure 14a. Community profile of AOB using $16 \mathrm{~S}$ rDNA in a full scale activated sludge system. AT-aeration tank, RS-recycled sludge and DIG-anaerobic digester

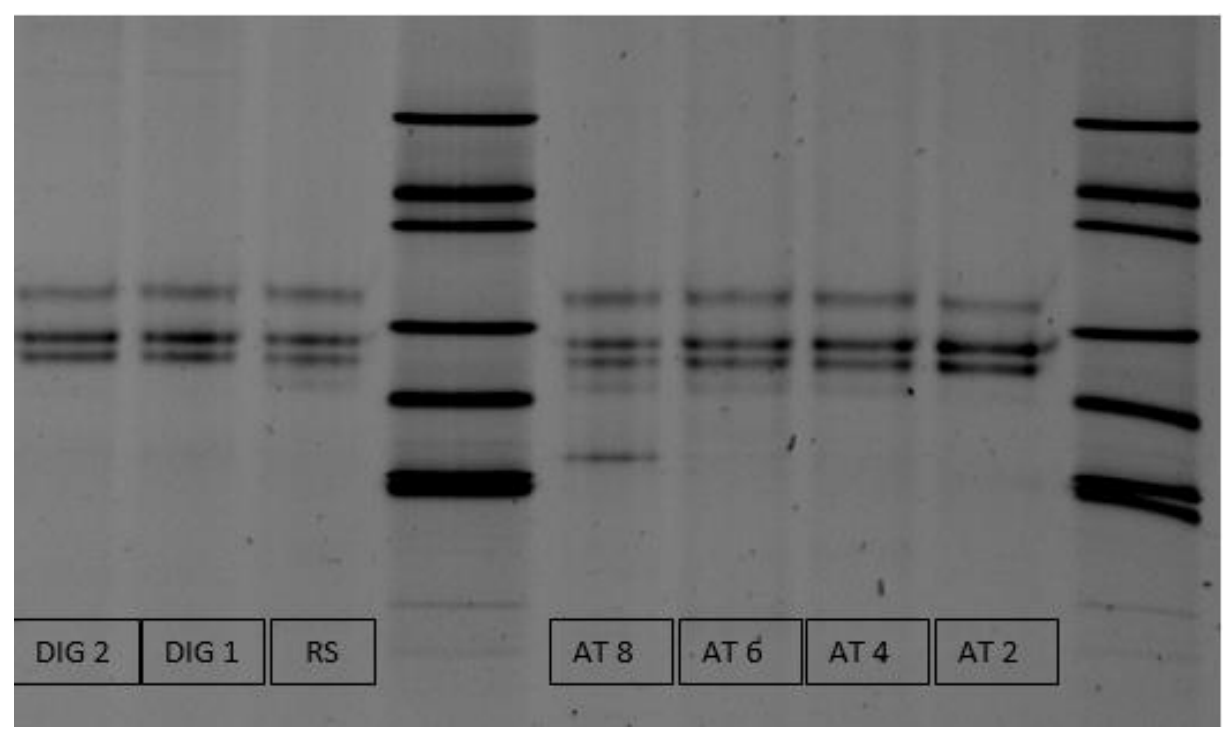

Figure 14b. Community profile of AOB using amoA gene in a full scale activated sludge system. AT-aeration tank, RS-recycled sludge and DIG-anaerobic digester 


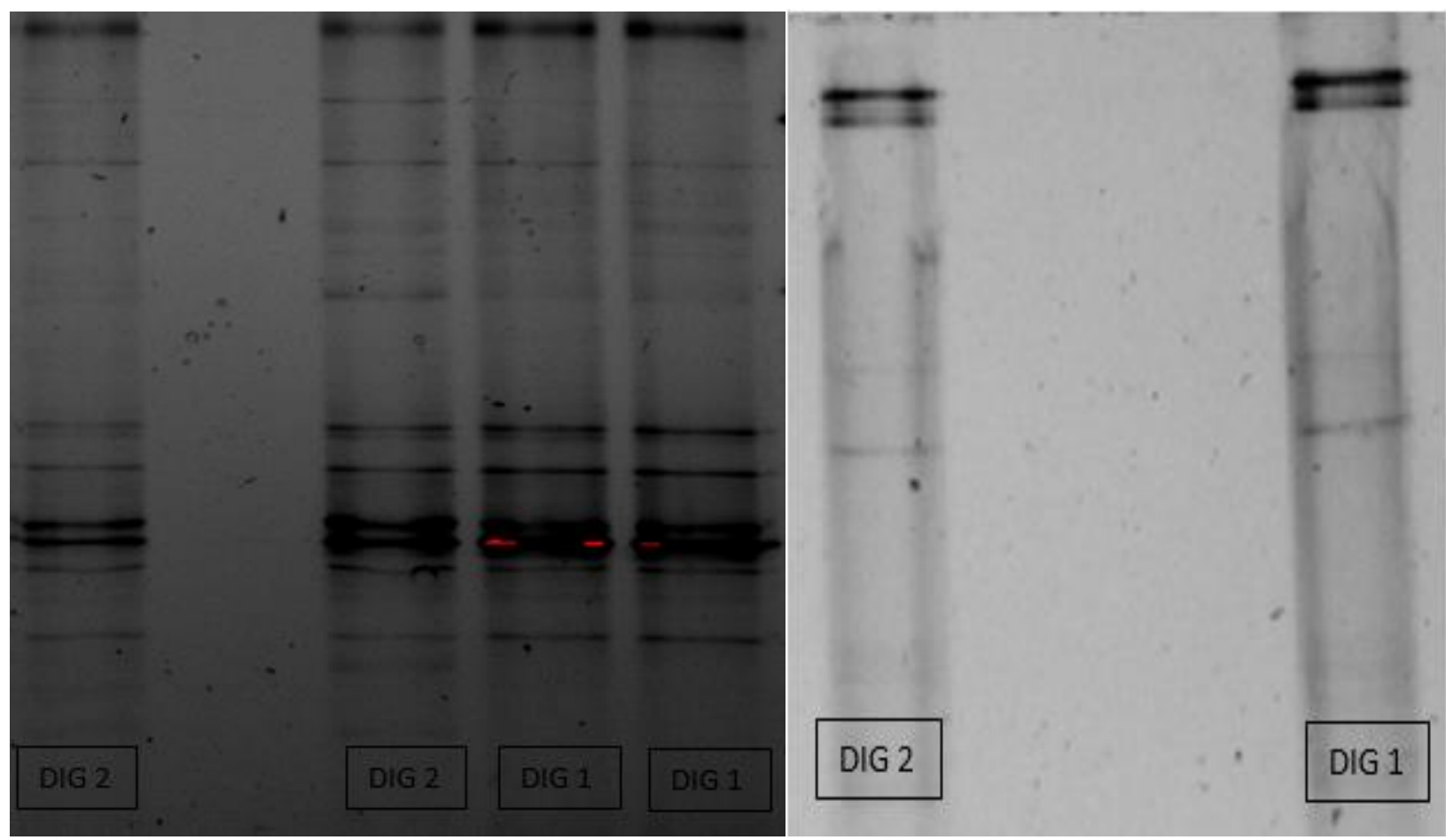

Figure 15. Community profile of AOA using the $16 \mathrm{~S}$ rDNA and $a m o A$ gene in a full scale activated sludge system. A) $16 \mathrm{~S}$ rDNA of AOA B) AOA amoA gene AT-aeration tank, RSrecycled sludge and DIG-anaerobic digester.

\subsection{Abundance of Ammonia Oxidizing Microorganisms in an Full Scale Activated Sludge Community}

\subsubsection{Relative Abundance of $\mathrm{AOB}$ and $\mathrm{AOA}$ in Activated Sludge Communities}

This experiment analyzed patterns of the relative abundance of ammonia oxidizing populations in each of the aeration tanks, recycled sludge and anaerobic digester samples in relation to potential total heterotrophs that are present in activated sludge. To target both populations of $\mathrm{AOB}$ and $\mathrm{AOA}$ and total heterotrophic population, quantitative PCR was performed using 3 sets of primers: Targeting the partial 16S rDNA of AOB and AOA and the total heterotrophic population. To estimate the relative abundance ratios, the normalization equation $\mathrm{R}=2^{-\Delta \mathrm{Cp}}$ where $\Delta \mathrm{Cp}=(\mathrm{Cp}$ experimental $-\mathrm{Cp}$ control $)$ was used to 
convert raw crossing point data into a linear from. This calculated the relative expression fold change of each population compared to total heterotrophs. The relative abundance of $\mathrm{AOB}$ in relation to the total heterotrophs appeared to be higher than AOA in aeration tanks 2,4,6,8 and the recycled sludge conditions (Figure 16). The relative abundance ratio of the AOB 16S rRNA gene was an average 387 times greater than the AOA in the aerated tanks (Table 6). In comparison, the AOA appeared to be 13 times higher in relative abundance within the anaerobic digester 1 (Figure 16) compared to the AOB 16S rRNA gene (Table 6).

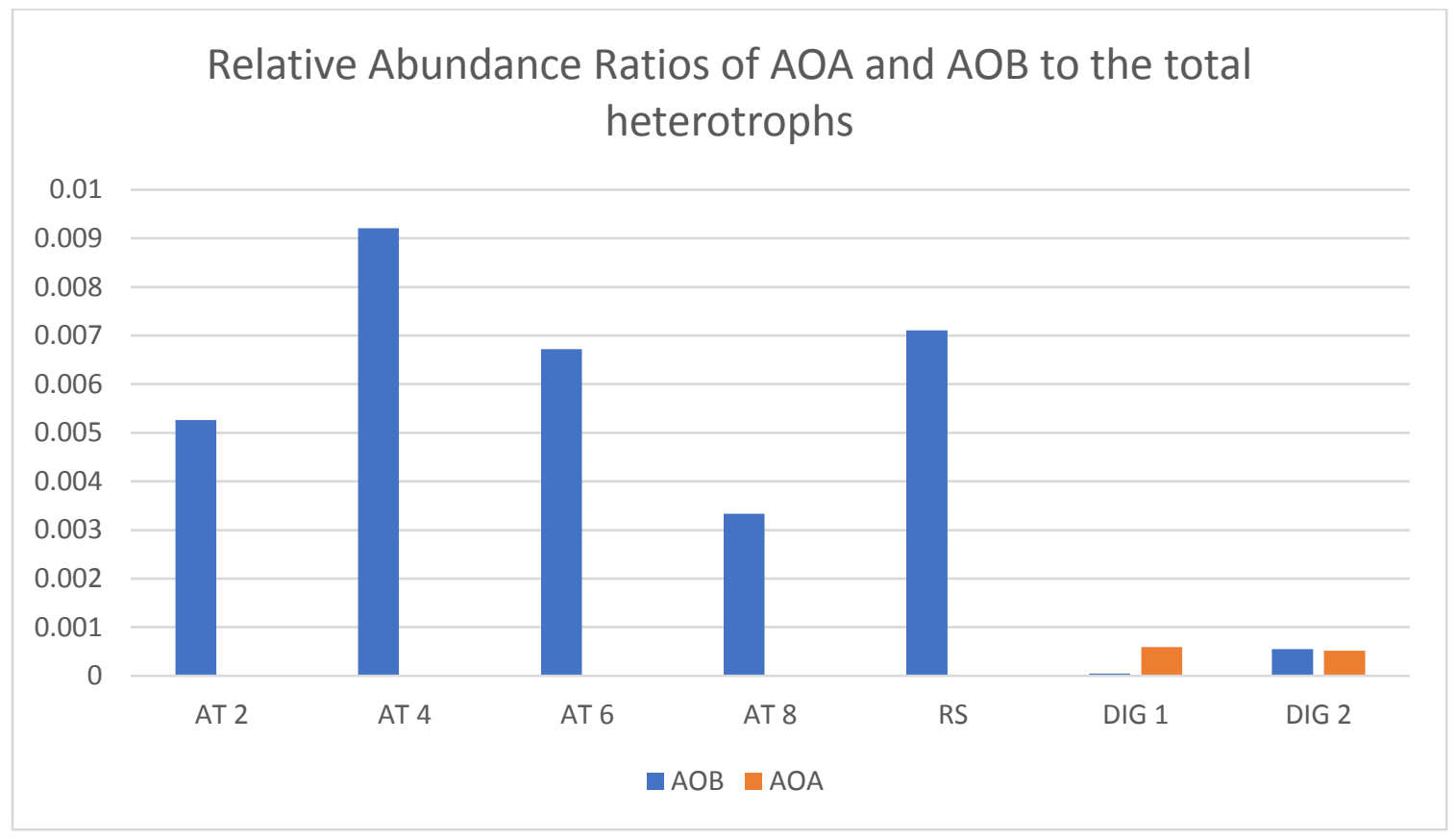

Figure 16. Relative abundance ratios of $\mathrm{AOB}$ and $\mathrm{AOA}$ to the total heterotrophs within a fullscale activated sludge system. AT-Aeration Tank, RS-Recycled Sludge and DIG- Anaerobic Digester 
Table 6. Relative abundance ratios of AOA and AOB communities to the total population of heterotrophs in the activated sludge system. Numbers expressed as $\mathrm{R}=2-\Delta \mathrm{Cp}$ where $\Delta \mathrm{Cp}=(\mathrm{Cp}$ experimental- $\mathrm{Cp}$ control).

\begin{tabular}{|l|l|l|}
\hline Activated Sludge Sample & AOB & AOA \\
\hline Aeration Tank 2 & 0.005263 & 0.000021 \\
\hline Aeration Tank 4 & 0.009205 & 0.00019 \\
\hline Aeration Tank 6 & 0.006723 & 0.000015 \\
\hline Aeration Tank 8 & 0.003331 & 0.000093 \\
\hline Recycled Sludge & 0.007106 & 0.000024 \\
\hline Anaerobic Digester 1 & 0.000045 & 0.000587 \\
\hline Anaerobic Digester 2 & 0.000549 & 0.000515 \\
\hline
\end{tabular}

\subsubsection{Absolute Abundance of AOB and AOA Populations}

The absolute abundance of $\mathrm{AOA}$ and $\mathrm{AOB}$ in the seven activated sludge samples was demonstrated by quantitative PCR by targeting the partial amoA gene sequence in AOA and AOB. It is observed that the AOB amoA gene varied significantly among the samples. The amoA gene for AOB was abundant in all aerated tanks and recycled sludge however decreased 5 times in number in the anaerobic digester 1 (Table 7 and Figure 17). The copy numbers fluctuated from $2.0 \times 10^{4}$ to $6.9 \times 10^{4}$ copies per $100 \mathrm{ng}$ of DNA.

In contrast, AOA amoA gene copy numbers were greater in the anaerobic digesters than in the aerated tanks and recycled sludge (Table 7 and Figure 18). However, the absolute AOA amoA gene copy number was less than those of the AOB community in all activated sludge samples. The AOA amoA gene copy numbers varied from $5.5 \times 10^{1}$ to 10 
x $10^{3}$ copies per $100 \mathrm{ng}$ of DNA (Table 7), with AOA being present 5 times greater in gene copy numbers in the anaerobic digester sludge 1 compared to all other systems. Overall, AOB were more abundant than AOA in all reactors with the abundance of AOA being the highest in the anaerobic digester tank 1.

Table 7. Copy numbers of the amoA gene of ammonia oxidizing bacteria and archaea in a full-scale activated sludge system

\begin{tabular}{|c|c|c|}
\hline Activated Sludge System & $\begin{array}{l}\text { Abundance of bacterial } \\
\text { amoA gene } \\
\text { (copy number per 100ng of } \\
\text { extracted DNA) }\end{array}$ & $\begin{array}{l}\text { Abundance of archaeal } \\
\text { amoA gene } \\
\text { (copy number per 100ng } \\
\text { of extracted DNA) }\end{array}$ \\
\hline Aeration Tank 2 & $6.9 \times 10^{4}$ & $1.4 \times 10^{2}$ \\
\hline Aeration Tank 4 & $7.9 \times 10^{4}$ & $1.8 \times 10^{2}$ \\
\hline Aeration Tank 6 & $7.2 \times 10^{4}$ & $5.5 \times 10^{1}$ \\
\hline Aeration Tank 8 & $1.8 \times 10^{5}$ & $6.7 \times 10^{1}$ \\
\hline Recycled Sludge & $5.7 \times 10^{4}$ & $1.3 \times 10^{2}$ \\
\hline Anaerobic Digester 1 & $2.0 \times 10^{4}$ & $7.3 \times 10^{2}$ \\
\hline Anaerobic Digester 2 & $4.1 \times 10^{4}$ & $1.4 \times 10^{2}$ \\
\hline
\end{tabular}




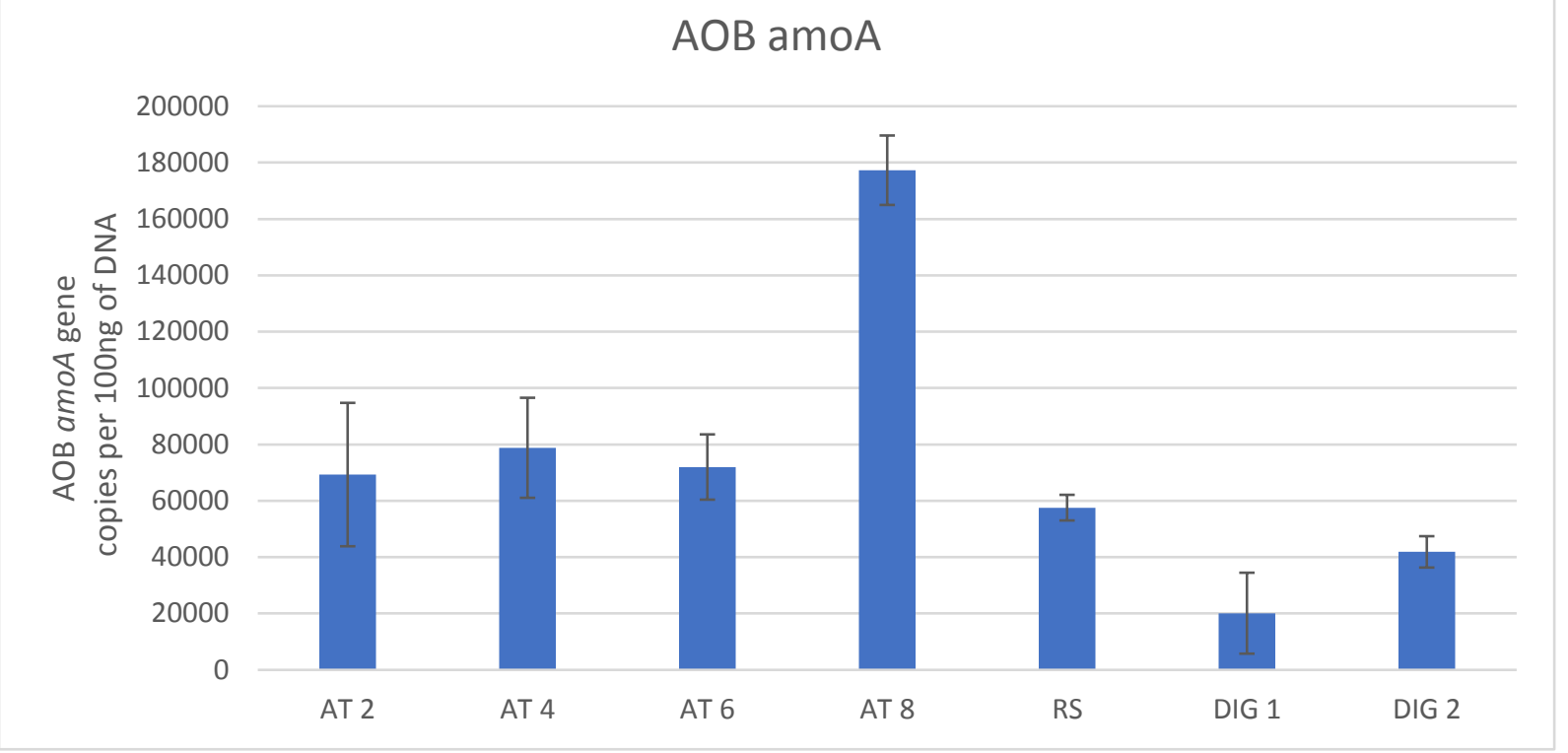

Figure 17. Number of bacterial $a m o A$ gene copies in the activated sludge system of a full scale municipal wastewater treatment plant. Error bars indicate one standard deviation of the average over 3 replicates.

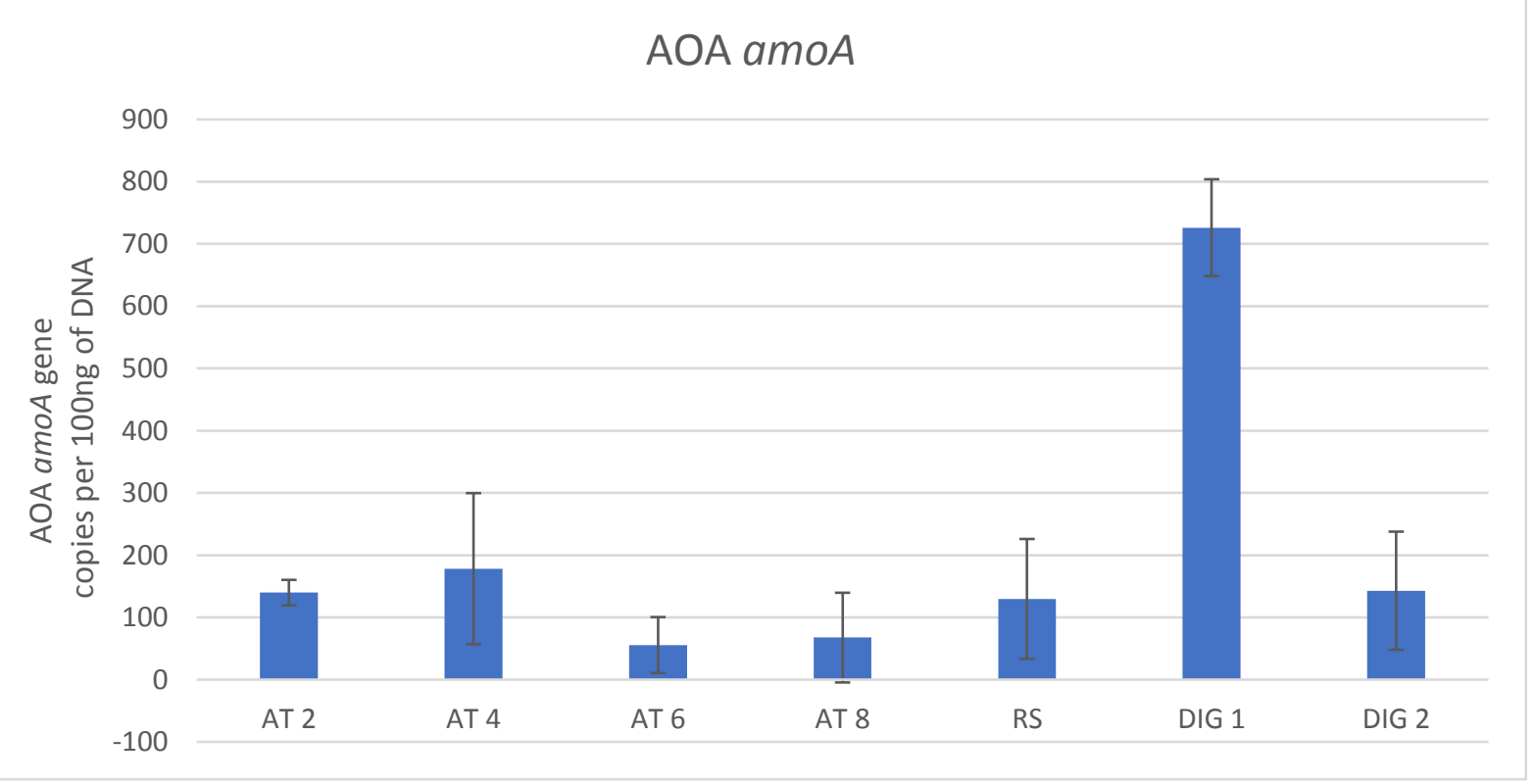

Figure 18. Number of archaeal $a m o A$ gene copies in the activated sludge system of a full scale municipal wastewater treatment plant. Error bars indicate one standard deviation of the average over 3 replicates. 


\subsection{The Activity of AOA and AOB in an Full Scale Activated Sludge Community}

\subsubsection{Quantification of AOB and AOA amoA Gene Transcription}

To determine whether amoA genes from $\mathrm{AOA}$ and $\mathrm{AOB}$ populations are actively transcribed in the activated sludge system, and whether transcription will be similar to the gene abundances, total RNA from seven activated sludge samples was isolated and relative cDNA copies of amoA genes was quantified using reverse transcription. Remarkably, amoA cDNA transcripts of both populations was detected in all activated sludge samples. In the aerated tank activated sludge samples, $\mathrm{AOB}$ amoA transcripts were higher than those found in the recycled and anaerobic sludge systems (Table 8 and Figure 19). For instance, the AOB amoA gene transcript was observed to be 19 times greater in the aeration tank 8 in comparison to the anaerobic digester sludge samples. The highest copy number of the AOB amoA transcripts were found aeration tank 6, which contained 25253.6 cDNA copies (Table 8). Overall, the AOB amoA gene transcripts appeared to be higher with the presence of oxygen concentrations above $2 \mathrm{mg} / \mathrm{mL}$ and higher ammonia concentrations found in the aeration tanks. This indicated that they may be more active in these environments.

The quantity of the AOA amoA gene transcript appeared to be higher in the anaerobic digesters than in the aerated tanks (Figure 20). The transcription of the AOA amoA gene was 2 times greater in copy number in the anaerobic digester sludge than the aerated activated sludge samples. Thus, showing a higher occurrence of AOA amoA transcription within the anoxic environment found within the anaerobic digesters. Within the digesters, the AOA amoA gene transcript copy numbers were highest in the anaerobic digester 2 sample compared to the rest containing 129 amoA cDNA copies. 
However, in comparison to the bacterial amoA transcripts. the total archaeal amoA transcripts was lower. Overall, it appears a larger percentage of the AOA population may be transcriptionally active in the anaerobic digesters.

Table 8. Copy numbers of the amoA cDNA of ammonia oxidizing bacteria and archaea in a full-scale activated sludge system

\begin{tabular}{|l|c|c|}
\hline Activated Sludge System & $\begin{array}{c}\text { Abundance of bacterial } \\
\text { amoA gene } \\
\text { (copy number per 100ng of } \\
\text { cDNA) }\end{array}$ & $\begin{array}{c}\text { Abundance of archaeal } \\
\text { amoA gene } \\
\text { (copy number per 100ng } \\
\text { of cDNA) }\end{array}$ \\
\hline Aeration Tank 2 & 5033.3 & 52.8 \\
\hline Aeration Tank 4 & 6089.8 & 76.5 \\
\hline Aeration Tank 6 & 25253.6 & 63.3 \\
\hline Recycled Sludge & 1894.6 & 80.1 \\
\hline Anaerobic Digester 1 & 1307.5 & 72.7 \\
\hline Anaerobic Digester 2 & 1383 & 129.4 \\
\hline
\end{tabular}




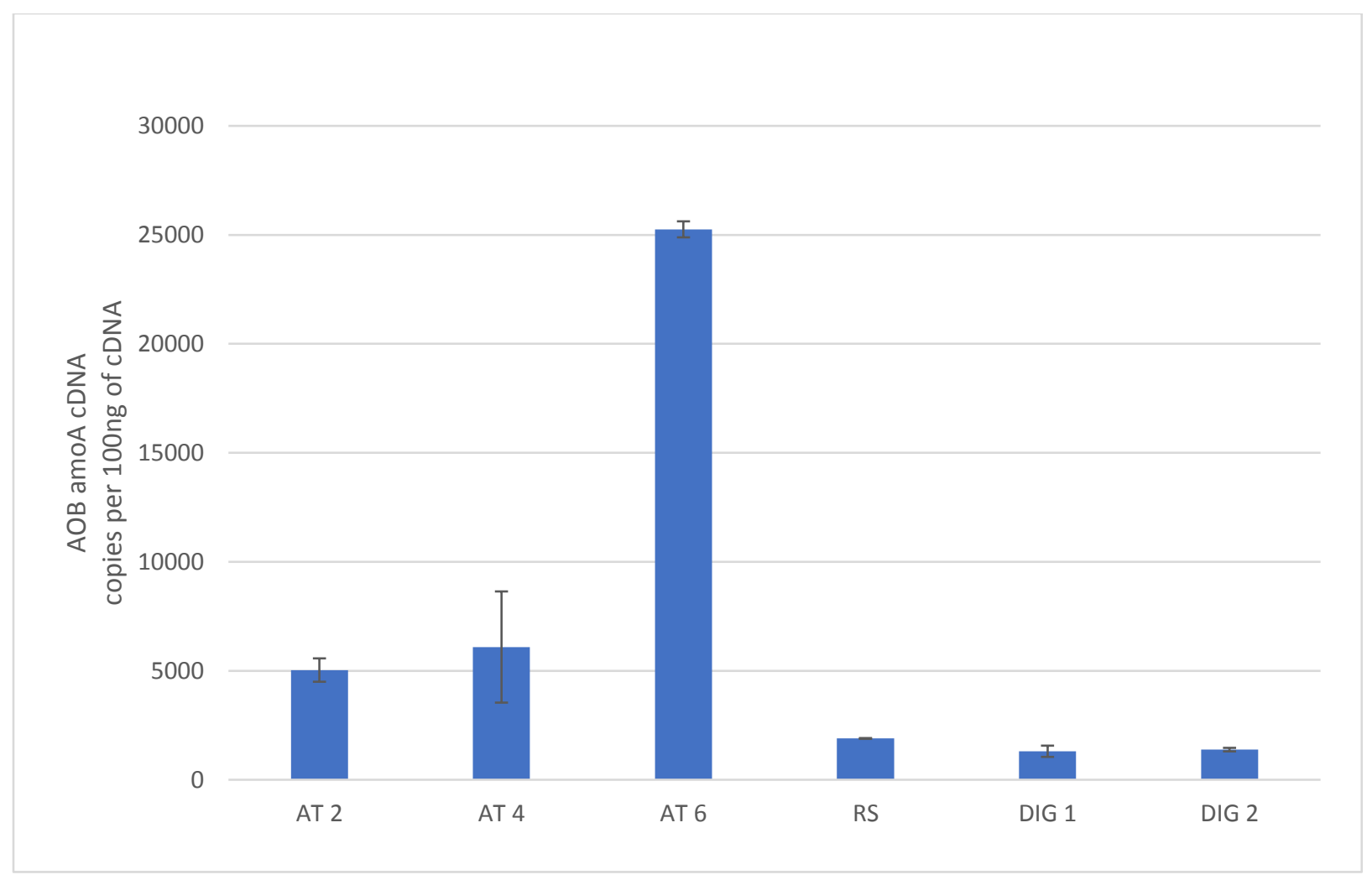

Figure 19. The expression of bacterial amoA gene in the activated sludge system of a full scale municipal wastewater treatment plant. Error bars indicate one standard deviation of the average over 3 replicates. 


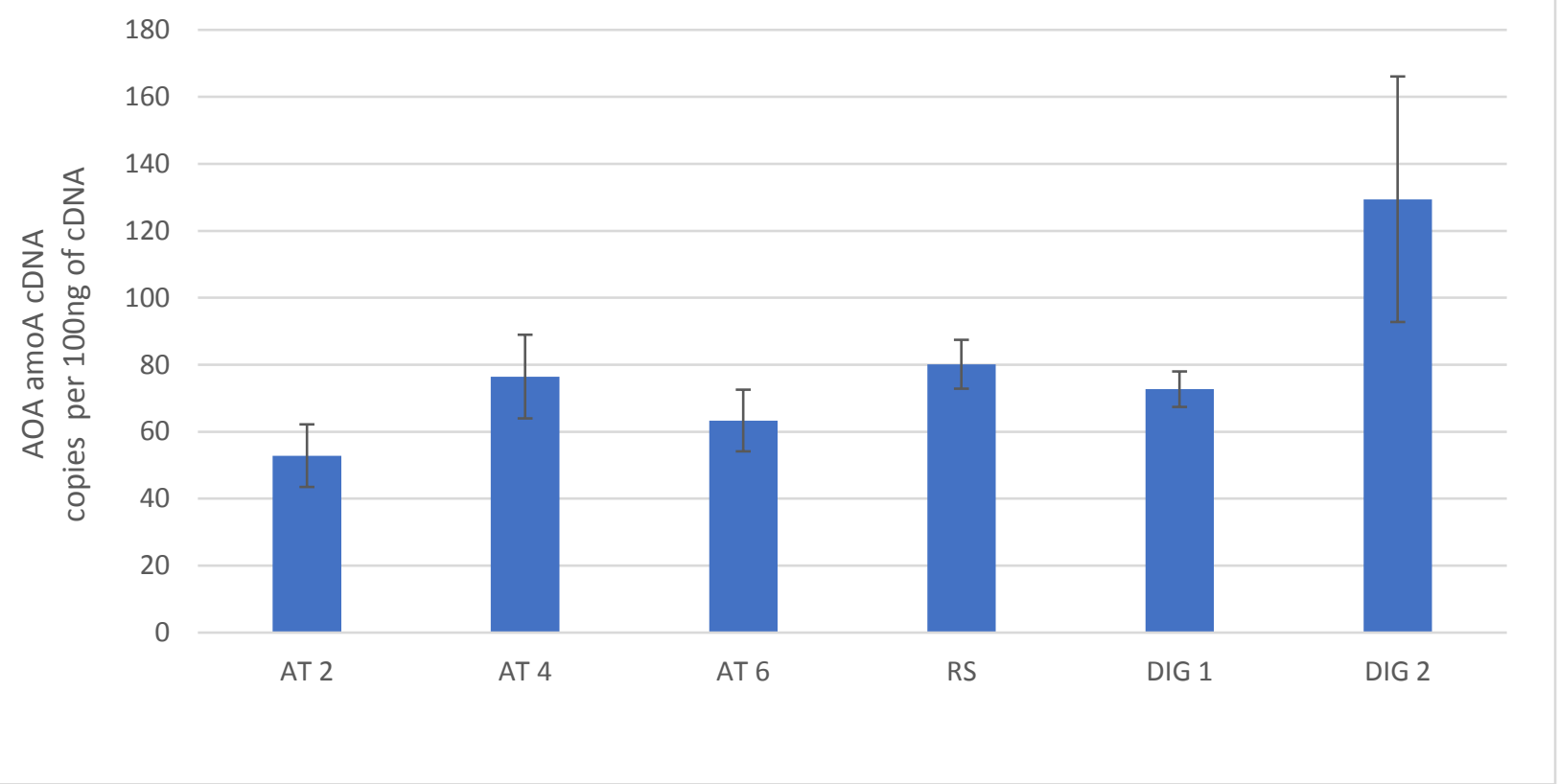

Figure 20. The expression of archaeal amoA gene in the activated sludge system of a full scale municipal wastewater treatment plant. Error bars indicate one standard deviation of the average over 3 replicates. 


\section{CHAPTER 5: DISCUSSION}




\subsection{Microbial Communities in Activated Sludge}

As an important microbially mediated process for wastewater treatment and nitrogen removal, the efficiency and stability of the activated sludge process is entirely dependent upon the concerted and syntrophic activity of microorganisms belonging to different functional groups performing nitrification, anammox and denitrification. One of the major classes of emerging contaminants that may affect the presence and function of these microorganisms are the pharmaceutical compounds that are consistently being detected in wastewater. The concentration of pharmaceuticals in urban waste streams is on the rise, yet the impact of these compounds on the composition of the microbial community and the efficiency of the wastewater treatment process is unknown. The concentration of these materials in domestic wastewater and surface water has been found to range between 0.3 $\mu \mathrm{g} / \mathrm{L}$ and $150 \mu \mathrm{g} / \mathrm{L}$ (Cetecioglu et al., 2014). However, pharmaceutical plants, hospitals, concentrated animal feeding operations, and aquaculture generate effluents that can have much higher antibiotic concentrations in the range of 100-500 mg/L (Cetecioglu et al., 2014). In large urban cities such as Toronto, where many hospitals contribute to the municipal waste stream, the immediate impact of antibiotics and other pharmaceuticals that are present in the wastewater on the functioning of the bacterial population in the MWWTPs has not been extensively studied. This study examined the effect of one antibiotic, tetracycline, and one NSAID, Ibuprofen, on the diversity and abundance of the wastewater microbial community exposed to both environmental levels and artificially high levels of tetracycline. 


\subsubsection{The Impact of Tetracycline on the Community Composition and Functioning of Bacteria in the Activated Sludge System}

The semi-batch reactor is probably the most frequent type of reactor in the chemical industry, particularly in the fine chemical branch, in organic chemistry laboratories and in biotechnological processes (Williams, 2002). In a semi-batch reactor, fresh media is continuous or sometimes periodically added to the bioreactor but unlike a continuous reactor, there is no continuous removal. However, similar to the continuous reactor, it is possible to achieve high productivities due to the fact that controlling the flow rate of the feed entering the reactor enables optimization of the growth rate of bacterial cells (Williams, 2002). The semi-batch reactor system was chosen for the present study to investigate the impact of the pharmaceuticals on the microbial community present in the secondary treatment of a municipal WWTP.

To ensure the reactors contained active wastewater microbial communities, the removal of carbon from the reactors was monitored by measuring DOC. It was found that all the reactors were able to remove the carbon load within 2 weeks to less than $1 \%$ of the initial concentrations. This indicates that the bacterial community was actively metabolizing during the experiment and the DOC removal was not affected by SRT or the antibiotic.

Using 16S rRNA primers targeting the 16S rRNA gene, community molecular profiles were generated and compared. It was found that the microbial community had shifted over time as shown by the change in the succession of bands in the DGGE images (Figure 11). This progression was evident in the control as well as the experimental reactors. Statistical analysis of the position and density of the bands in the profiles indicated 
that the communities varied from each other (Table 4), however, the community profiles could still be grouped into 2 clusters based on the SRT rates. Thus, it was observed that the differences in community composition were apparently not caused by the antibiotics or the carbon supply but rather by varying process conditions. This shift represents the evolution of the dominant species (abundance changes) in communities that are subject to changing environmental conditions as demonstrated within the reactors. It appears that the SRT played more of a role than the antibiotic in determining which heterotroph is more abundant (change in the intensity of the bands). Sludge retention time has a major implication on the diversity and abundance of the microbial community present in activated sludge. Of the multitude of operational parameters that can be used to constrain niche development, SRT (also known as sludge age and mean cell retention time) and HRT (hydraulic retention time) are of the most powerful (Winkler et al., 2012). This parameter is traditionally used in the design and operation of biological nutrient removal (BNR) systems to control for the presence or absence of desired microbial populations (e.g. nitrifiers) (Kim et al., 2013). For example, increasing SRT and HRT is correlated with a reduction in COD, nitrogen and phosphorus content due to the increased exposure time the organic material to the microbial communities present and increased time for the slow growing microorganisms responsible for nutrient removal to grow and become established. In this study, when reactors were tested at a steady SRT and at very high tetracycline concentrations, almost little to no changes were observed in community diversity. Thus, again confirming that SRT had a more profound impact than the antibiotic. The sludge retention time can also have an impact of floc formation and composition. Microbial flocs are present in wastewater and may be crucial to the biological nutrient removal. Winkler 
et al (2012) found that the SRT of populations found on the exterior of granules is lower than the SRT for population in the interior. It was observed that total bacterial SRT for the flocculent sludge and aerobic granular sludge systems were 11 and 20 days. Specifically, results from granular sludge samples indicated that the SRT of nitrifying bacteria (exterior layer of granules; $11+/-3$ days) was slightly lower than the SRT for bacteria present within the interior of the granules (PAO, GAO, actinoPAO, archaea) $(13+/-4$ days).

The hydraulic retention time can also impact the community composition. One study performed by Zhang et al (2015) demonstrated that in the microbial community of anaerobic sludge, the percentages of bacterial groups in each sample varied depending on HRTs levels.

Limiting factors such as the relatively small sample size of this study and short duration of the experiment may lead to some generalization of its findings, and consequently, the analysis is intended to only describe the sites and dates within the current dataset. However, the community response to specific pharmaceuticals enabled the inspection of relationships between the potential inhibitory effect of two classes of pharmaceuticals and microbial groups that may be responsible for nutrient removal. Ideally, the experimental evaluation of the inhibitory action of antibiotics should include two different approaches: Short-term (acute) and long-term (chronic) tests: Acute experiments involve a microbial community selected and sustained by the selected organic substrate in the system and not previously exposed to the inhibitor. In long-term experiments with continuous feeding of the inhibitor, the test may reflect, aside from changes in substrate removal and utilization, adaptation and/or resistance of the microbial community or even shifts in microbial composition in response to continuous exposure to 
the selected inhibitor. A full insight on the inhibitory action can only be acquired when the response of the microbial community is tested for both acute and chronic inhibition impacts (Cetecioglu and Atasoy, 2018). In this study, tetracycline may not have had an impact on the microbial community due to biotransformation and or sorption. Cetecioglu et al. (2013) showed the major fraction $(>80 \%)$ of the tetracycline introduced could be fully or partially biodegraded along with the organic substrate; however, the transformation products of tetracycline are still unknown. Thus, it may be possible, that the effect of tetracycline may have been nullified because biodegradation by the microbial communities that are present in wastewater. One possibility that could decrease the bioavailability of antibiotics and thus minimize or even neutralize their impact are extracellular polymeric substances (EPSs), which consist mainly of carbohydrates, proteins, and humic substances. These polymers are excreted by bacteria of activated sludge and are major components of sludge flocs, which could be defined as a "swimming biofilm" It is known that the EPS network inside the flocs is capable of adsorbing pollutants (Comte et al., 2007). This is one reason why bacteria in biofilms were more resistant to antibiotics and other harmful substances than single, freely floating bacteria. EPS might also have some relevance for our results in that it adsorbs antibiotics and decreases their toxicity.

Antibiotics should have a more drastic influence on nitrification than on COD elimination because the autotrophic nitrifiers are less numerous in activated sludge and grow slowly (Halling-Sørensen, 1993). It is known that within nitrification, nitrite oxidation is particularly sensitive. Inhibition of nitratation leads to the accumulation of nitrite, a particularly toxic nitrogen compound, in WWTPs (Schmidt et al., 2012). Although this study did not look at the nitrifier community specifically rather focusing on community 
composition of the total heterotrophs, previously it was shown that within these reactors, nitrogen removal was not hindered by the presence of tetracycline (Islam, 2012). Interestingly, the removal of nitrogen in these reactors indicated that the introduction of tetracycline under low nutrient replacement led to a dramatic decrease in ammonia concentration from day 7 to day 9 (from $1297.33 \mu \mathrm{M}$ on day 7 to $135.18 \mu \mathrm{M}$ in the low tetracycline reactors and to $121.53 \mu \mathrm{M}$ in high tetracycline reactors). Between days 7-9, the decrease in ammonia concentrations was much greater when tetracycline was present in low feed reactors conditions compared to high feed reactors. This suggests that under low nutrient replacement conditions, the tetracycline may be positively correlated with ammonia oxidation (Islam, 2012). This is supported by Schmidt et al (2012), who studied influence of $1.2-40 \mathrm{mg} / \mathrm{L}$ antibiotic mixture containing equal amounts of ciprofloxacin (CIP), gentamycin (GM), sulfamethoxazole (SXT), and vancomycin (VA) on nitrification of the population of an activated sludge system that was fed with synthetic OECD (Organization for Economic Cooperation and Development) wastewater in batch assays. Similarly, to the results obtained from this study, it was observed that ammonia oxidation by activated sludge was not inhibited by increasing concentrations of the antibiotic mixture even at very high concentrations $(40 \mathrm{mg} / \mathrm{L})$ in a short-term nitrification-inhibition test (Schmidt et al., 2012). Rather, compared with the control assay, the reactors that contained $1.2,2.4,7.2,12,13.2,15.6$, and $40 \mathrm{mg} / \mathrm{L}$ antibiotic mixture showed a non-significantly increased ammonia-oxidation efficiency (Schmidt et al., 2012).

Since the universal 16S rRNA gene primers used to generate the community composition profiles were aimed to target a majority of the bacterial organisms that make up more than $99.9 \%$ of the population. However, it may be possible that due to the 
limitations of the DGGE technique, it is unlikely that any of the visible bands represent ammonia-oxidizing organisms, since they typically make up less than $0.1 \%$ of the population. Since the addition of tetracycline caused an increase in ammonia, nitrite and total nitrogen removal, it was expected that there would be shifts in the nitrification population as well however our results did not show that. Similarly, Cydzik-Kwiatkowski et al (2014) who used specific primers to 16S rRNA gene of ammonia-oxidizing bacteria to follow their diversity in aerobic granules, found that lengthening the SRT caused a high variation in the relative number of $\mathrm{AOB}$ (abundance values) but that the diversity was similar independent of operational conditions. It appears therefore that operational process conditions including the presence of antibiotics cannot be monitored by DGGE molecular profiles of the 16S rRNA gene alone as they are not sensitive enough to represent minor species in a community. Secondly, any shifts in community composition does not necessarily mean that the effectiveness of the process has been compromised.

\subsection{Impact of Tetracycline and Ibuprofen on Protozoa in Activated Sludge}

Although bacteria dominate and are most directly involved in wastewater treatment, protozoa have a role to play in clarification of the wastewater effluent. In modern systems, where there is a low load and high sludge retention time, the presence of protozoa such as ciliates, flagellates, and amoebae, or even small metazoa, is very common (Madoni, 2011). These eukaryotic organisms can feed on particulates, such as suspended bacteria. In this study, although the diversity of the protozoan community was not significantly affected (approximately 16-20 bands could be distinguished in each lane regardless of treatment), it appeared that the composition of the community had shifted in the presence of Ibuprofen

(Figure 12b). In the reference reactor containing activated sludge without added 
pharmaceutical, Slavina appendiculata or Paranais litoralis (bands 2 and 3), Arcella vulgaris (band 4), Arcella hemispherica, (band 5), Cercozoa (band 7) and Slavina appendiculata or Paranais litoralis or Nais communis (band 12) were more dominant (Table 5b). In a well-functioning activated-sludge plant, the protozoa community is dominated by peritrichs (Vorticella spp., Carchesium spp., Zoothamnium spp., Epistylis spp.) and hypotrichs (Aspidisca spp., Euplotes spp.) (Madoni, 2011). Upon the introduction of Ibuprofen in the experimental reactors, Paranais litoralis was absent, however on the other hand, Lamproderma sp. (band 8) or an uncultured eukaryote (bands 8 and 10) were only seen in the experimental reactor where band $1(9,11)$ (Lamproderma sp. or Crytomycota sp.) was also more prominent. Overall, it appeared that the presence of Ibuprofen at $100 \mu \mathrm{g} / \mathrm{ml}$ concentration led to shifts in the protozoan community composition.

The role of protozoa predation in nitrogen cycling in activated sludge has been observed where the presence of protozoa increases the per-cell nitrification rate, probably because of the ability of protozoa to influence bacterial growth (Pogue and Gilbride, 2007). Also, protozoa release inorganic and organic products into their surroundings. These products are mainly recycled nutrients, such as nitrogen, phosphorous, and organic carbon, but might also include stimulatory compounds that contribute to the dissolved organic carbon pool and affect the physiological state and growth of bacteria (Madoni, 2011).

Microbial communities in wastewater are of the utmost importance because of their functional abilities to degrade various contaminants such as organic, inorganic and xenobiotic compounds. The occurrence in and potential effects on aquatic and terrestrial organisms of human and veterinary pharmaceuticals are relatively new issues, however, 
the increasing flux of various pharmaceutical compounds into the wastewater deems it necessary to have complete studies on the inhibitory effects of these compounds on the microbial community. This study shows that when analyzing community structure more closely using DGGE, the presence of extremely high concentrations of Tetracycline and Ibuprofen appears to lead to acute effects on the least dominant bacteria and on the presence and abundance of protozoa. This demonstrates the importance of future studies on the effects of pharmaceuticals on the wastewater microbial communities. The quantity of pharmaceuticals in the environment must be minimized by all strategies available. Prospective approaches such as environmental risk assessment play an important role in minimizing problems before pharmaceuticals enter the environment. These strategies should be strengthened and adjusted to minimize the quantity of pharmaceuticals entering the environment (Küster and Adler, 2014).

\subsection{Location of Ammonia Oxidizing Bacteria and Archaea in a Full-Scale Wastewater Treatment Plant}

Recent discovery of the ammonia oxidizing archaea has challenged perceptions that AOB carry out ammonia oxidation and are critical to global nitrogen cycling. Due to the significance of nitrogen removal in wastewater, and the importance of nitrifiers to the overall process, a reassessment of wastewater ammonia oxidizers, their community ecology and contribution to wastewater ammonia oxidation is overdue. Thus far, research on AOA have focused on many natural environments such as marine sediments (Francis et al., 2005, 2007), soil (Leininger et al., 2009; He at al., 2007) and seawater (Beman et al., 2007). Only a few studies have focused on the wastewater treatment plants (Park et al., 2006; Zhang et al., 2008). The goal of this study was to investigate the diversity and 
abundance of ammonia-oxidizing bacteria and archaea in a full scale municipal wastewater treatment plant that utilizes the activated sludge process and evaluate their potential contribution to nitrification. For this purpose, this study focused on the 16S rDNA and the amoA gene as the biomarkers. The divergence of the amoA gene in bacteria and archaea allowed the use two distinct primer sets and qPCR to determine the absolute and relative abundance of bacterial and archaeal ammonia oxidizers.

The initial end-point PCR results from seven locations in the WWTP including the aeration tanks, recycled sludge and anaerobic digesters of a full scale municipal wastewater treatment plant demonstrate that the $\mathrm{AOB}$ and $\mathrm{AOA}$ are both present in the system but do not occupy the same niche. For instance, the $16 \mathrm{~S}$ rRNA gene for AOB were more readily detected in the aeration tank samples rather than the digesters (Figure 13a). It could be inferred that due to the aeration, sufficient oxygen concentrations were provided for the aerobic ammonia oxidizing bacteria to be present in the aeration tanks. Ammonia oxidizing bacteria utilize reduced nitrogen (e.g., ammonia) as an energy source, carbon dioxide as a carbon source, and molecular oxygen as an electron acceptor (Jia et al., 2009). Furthermore, all samples demonstrated the exact same profile (Figure 13b) when using the primers to target the $a m o A$ gene for $\mathrm{AOB}$, where it appeared that the amoA gene for $\mathrm{AOB}$ was also more prominently detected in the aeration tanks. Besides dissolved oxygen, others have suggested that particularly high and low ammonia concentrations also generally constrain AOB diversity in wastewater systems (Martens-Habbena et al., 2009; Park and Noguera, 2004). Prior investigations into the ecology of ammonia oxidisers in wastewater treatment systems have demonstrated the overtly site-specific nature of these communities; 
community composition and diversity often vary widely from site-to-site and there is a growing body of evidence for tight habitat-phylogeny associations (Short et al., 2013).

Interestingly, the ammonia oxidizing archaea were only detected with end-point PCR in the anaerobic digester samples with the $16 \mathrm{~S}$ rRNA gene primers and amoA primers for AOA (Figure 13). It appears that low dissolved oxygen concentrations may be related to the presence of AOA within the WWTP. Although the digesters are designed to function as anaerobic chambers, the environment is most likely anoxic. The WWTP is not able to measure the DO in these tanks due to the opacity of the samples but agreed it is likely they are not completely devoid of oxygen. Another parameter that may provide a niche for AOAs within the anaerobic digesters is SRT. Increased sludge retention times may be beneficial for slow growing AOA to proliferate. The results of this experiment are in agreement with the study by Park et al (2006) who first reported that AOA in five out of nine full-scale WWTPs in the USA were observed to prefer the condition of low dissolved oxygen (DO) concentrations and long sludge retention times (SRT) (Park et al., 2006). Additionally, in other natural systems, such as in estuarine sediments, it was evident that diverse communities of Crenarchaeota capable of ammonia oxidation are present in low dissolved oxygen and brackish environments where the crenarchaeal amoA is nearly 10 times more abundant than bacterial amoA (Santoro et al., 2011).

This experiment provided an interesting observation on the niche differentiation of AOA and AOB. The discovery of AOA in the anaerobic digester tanks may provide important insight into the ecophysiology of AOA and their abundance within the WWTP. The significance arises from the fact that initial physiological studies of N. maritimus strain SCM1, the only available marine isolate, have provided important insights into the basis 
for the ecological success of AOA. Studies of reaction stoichiometry using microrespirometry to measure oxygen and ammonia consumption relative to nitrite production showed that the overall stoichiometry of ammonia oxidation by $N$. maritimus is indistinguishable from that of AOB (Martens-Habbena et al., 2009). The next section will discuss the community composition of AOA and AOB.

\subsection{Community Composition of $A O A$ and $A O B$ in a Full-Scale Activated Sludge System}

DGGE community profile analysis demonstrated that very little diversity may exist for the AOB community within the different aeration tanks. It is likely that AOB are more prevalent due to the increased number of bands found in the aeration tanks in comparison to the anaerobic digesters (Figure 14). Comparatively, for the AOA community, similar profiles were observed between the two digester tanks however it is likely that they are more prevalent in the anaerobic tanks as no amplicons or bands for AOA could be observed in the aeration tanks (Figure 15). Furthermore, for the low diversity of AOA communities, Bernhard et al., (2016), discovered that terminal restriction fragment patterns of archaeal amoA genes were surprisingly similar between oiled and unoiled sites when investigating estuaries and salt marshes, inferring that even oil which may be a deterrent did not change AOA community patterns and they concurred that nitrifiers may be more resistant to environmental perturbation than other microbial populations.

Additionally, investigating the community composition in two large Chinese lakes, Wu et al (2010) did not find significant variations in the relative abundance or the community composition of AOA and AOB with the trophic states, as these authors stated that "no significant differences in the relative abundance or the community composition of 
AOA and AOB between A -(algae-dominating) and M- (macrophyte- dominating) type areas were found".

Zhang et al. (2006) also state that AOA show limited diversity in samples obtained from both lab scale and two full scale wastewater treatment plants. This low diversity of microbial populations in the activated sludge systems, including the AOA and AOB, may be attributed to the specific environmental parameters such as oxygen, ammonia and $\mathrm{pH}$ which are providing unique niches in the activated sludge, where only microorganisms belonging to just a few ecotypes are able to adapt and survive the extreme nutrient conditions (Park et al., 2006). These microorganisms are adapted to high nutrients environments and have the potential to remain dormant until the environmental conditions become optimal for their function and growth. ration tanks.

\subsection{Quantification of AOA and AOB Abundances in a Full-Scale Activated Sludge System of Municipal Wastewater Treatment Plant}

\subsubsection{Comparing Relative Abundance of Ammonia-Oxidizing Communities}

To determine the relative abundance ratios, the crossing point (CP or CT), of both $\mathrm{AOA}$ and $\mathrm{AOB}$ was compared to the total heterotrophic population present in activated sludge. Using the linear form by the $2^{\wedge}(-\Delta \mathrm{CT})$ calculation, the relative abundance of the AOB 16S rRNA gene was an average 387 times greater than the AOA in the aerated tanks (Figure 16). In comparison, The AOA 16S rRNA gene was relatively 13 times higher in abundance in the anaerobic digester one compared to the AOB. In digester two however, the relative abundance of both $\mathrm{AOA}$ and $\mathrm{AOB}$ were similar. These results confirm that AOB appear to be more prevalent in the aerated tanks with higher oxygen/ammonia concentrations and the AOA are more prevalent in digester tanks with lower 
oxygen/ammonia concentrations. The process flow of the Humber WWTP indicates that effluent flows through the aerated tanks in parallel and then combines to enter digester one which then flows serially into digester 2 . As the wastewater flows from the beginning to end of the treatment process, two important parameters are shifting or decreasing. According to Table 1, it is observed that the ammonia concentration decreases as the influent is converted into treated effluent, with the average concentration being reduced from $28.19 \mathrm{mg} / \mathrm{L}$ to $1.24 \mathrm{mg} / \mathrm{L}$. Thus, it is assumed that within the digesters, there is lower concentrations of ammonia that may be present. Secondly, it may also be inferred that as the water moves along from secondary treatment aeration tanks to anaerobic digestion, the dissolved oxygen concentrations are also decreasing along the path. Thus, it appears that the dissolved oxygen and ammonia concentrations may be linked with the abundance and proliferation of $\mathrm{AOA}$ and $\mathrm{AOB}$ within the activated sludge process. The effluent from digester one flows into digester two, thus creating an even lower oxygen environment in the second digester, one that is not ideal for either population and therefore the low abundance of both populations are observed. The first anaerobic digester, which contains an anoxic environment and low ammonia concentrations may provide advantages to the AOA community.

All the factors affecting $\mathrm{AOA}$ and $\mathrm{AOB}$ and the dominance of $\mathrm{AOA}$ or $\mathrm{AOB}$ in WWTPs are still unclear. There is on going debate regarding which group of ammonia oxidizers are more prevalent in wastewater treatment and their contributions to the overall nitrification process. Using qPCR, several studies have found that AOB generally are found to be more prevalent in WWTPs with different operational conditions than their AOA counterpart. Recently, Gao et al (2013) have found the abundance of AOB amoA gene were 
higher in all ten wastewater samples tested, varying from $4.63 \times 10^{4}$ and $9.99 \times 10^{9}$ copies $\mathrm{g}^{-1}$ MLSS. Specifically, in the samples obtained from the full scale WWTPs, the abundance of AOB ranged from $5.65 \times 10^{5}$ to $4.80 \times 10^{8}$ copies $\mathrm{g}^{-1}$ MLSS (Gao et al., 2013.). In contrast, Kayee et al. (2011) investigated the abundance of archaeal (AOA) and bacterial (AOB) amoA genes in eight of Bangkok's municipal WWTPs and found that AOA amoA genes ranging from $3.28 \times 10^{7} \pm 1.74 \times 10^{7}$ to $2.23 \times 10^{11} \pm 1.92 \times 10^{11}$ copies per L of sludge and outnumbered AOB amoA genes in most of the WWTPs even though the plants treatment processes, influent and effluent characteristics, removal efficiencies, and operation varied (Kayee et al., 2011).

Zhou et al. (2015) found relative abundance of AOA compared with AOB varied throughout the sampling sites, AOA outnumbered AOB in almost all the lakes and rivers, while the opposite was true in the other inland waters with strong human activities such as paddy fields, reservoirs, polluted groundwater, tidal land and constructed wetland (Hou et al., 2013). This result implied that AOA predominates the ammonia oxidizer population in inland waters with less human activities, while AOB dominates in inland waters with more human disturbance. Generally, ammonia concentrations, dissolved oxygen concentrations and the $\mathrm{pH}$ are factors that have been shown to influence the relative abundance of AOA to $\mathrm{AOB}$ although the precise levels of each can vary greatly depending on the environment (Erguder et al., 2009). Considering the complex status of various ecosystems, the relative predominance of $\mathrm{AOA}$ and $\mathrm{AOB}$ may be not affected solely by a single parameter, but by a combination of influencing factors (Bai et al., 2012). Evolutionary considerations suggest that archaea can grow under conditions of extreme salinity, temperature, and $\mathrm{pH}$ and low nutrient availability (Hatzenpichler et al., 2008). However, archaea are at a disadvantage 
when competing with $\mathrm{AOB}$ in ammonium-rich environments such as nitrification reactors (Zhang et al., 2011), fertile soils (You et al., 2009) or wetlands (Sims et al., 2012).

\subsubsection{Absolute Abundance of AOA and AOB Populations}

To investigate the presence and absolute abundance of $\mathrm{AOA}$ and $\mathrm{AOB}$ in a full scale activated sludge system from a municipal wastewater treatment plants, samples from all stages including aeration, recycle and anaerobic were obtained. Absolute abundance was obtained by quantitative PCR using primers which targeted the amoA gene of AOA and AOB.

It is observed that the AOB amoA gene varied significantly among the samples (Table 7). The amoA gene for $\mathrm{AOB}$ was abundant in all aerated tanks and recycled sludge however decreased 5 times in number in the anaerobic digester 1 (Table 7 and Figure 17). However, compared to the AOA, the AOB simply were greater in abundance in all samples regardless of the differences in environmental parameters. The copy numbers of AOB fluctuated from $6.9 \times 10^{4}$ to $2.0 \times 10^{4}$ copies per $100 \mathrm{ng}$ of DNA (Table 7). It appears the presence of high ammonia concentrations and DO concentrations equal or greater than 2 $\mathrm{mg} / \mathrm{mL}$ in the aerated tanks favour the growth of AOB over AOA. Similar abundances were found by Short et al., (2013), according to their findings the gene abundance for AOB were found to be $5.4 \times 10^{2}$ copies per ng of DNA in activated sludge. And the exact same trend was observed where the $\mathrm{AOB}$ generally dominated $\mathrm{AOA}$ in abundance under all conditions. The results in this study are in accordance with several other studies others studies that revealed that $\mathrm{AOB}$ communities were more abundant than AOA, such as a fullscale municipal WWTP in the USA (Wells et al. 2009), a lab-scale wastewater treatment system in Hong Kong, China (Tong Zhang, Jin, and Yan, 2010), eight full-scale WWTPs 
(five from China, one from the USA, one from Singapore, and one from Canada) (Zhang et al. 2011), three industrial WWTPs in China (Bai et al., 2012), and eight full-scale WWTPs in China (Gao et al., 2013)

The AOA amoA gene copy number was less than those of the AOB community in all activated sludge samples. The AOA amoA gene copy numbers varied from $5.5 \times 10^{1}$ to $10 \times 10^{3}$ copies per $100 \mathrm{ng}$ of DNA (Table 7 and Figure 18), with AOA being present 5 times greater in gene copy numbers in the anaerobic digester 1 sludge samples compared to all other systems. There may be several explanations that support this finding. Firstly, all the samples which detected the presence of AOAs were collected from an WWTP that operated with an aerated-anoxic process. In this strategy, extremely low DO concentrations and longer SRT are utilized, enabling simultaneous nitrification and denitrification within the anaerobic digester tanks. Thus, it can be suggested that AOA which were found to be more abundant in the anaerobic digesters were higher in abundance due to longer sludge retention time and very low dissolved oxygen concentration environments. Park et al. (2006) comparatively demonstrated that AOA were more abundant in samples that were

collected from WWTPs operating with long retention times (approximately 15 days of solids retention time and $24 \mathrm{~h}$ of hydraulic retention time). They agree that it is possible that either or both of these features (low DO levels and long retention times) facilitate the growth of AOA.

\subsection{Activity of AOB and AOA in the WWTP}

Efficient nitrification in environments with minimal aeration and low DO concentrations (i.e., aerated-anoxic conditions) has long been a mystery. The answer to whether AOA play a role in low-DO nitrification or "nitrifier denitrification" awaits 
quantitative information regarding the activity of AOA in these plants. This study aimed to fill that gap by quantifying the transcriptional activity or expression of the amoA gene to determine whether amoA genes from the AOA and $\mathrm{AOB}$ populations were actively transcribed in activated sludge and whether transcription correlated with gene abundance. Total RNA was isolated from the seven samples including aeration tanks, recycled sludge and anaerobic digester tanks and the number of copies of the amoA gene transcripts was measured using reverse transcription-qPCR. This measurement signified how many times the amoA gene has been transcribed. The first step in ammonia oxidation is the oxidation of ammonia to hydroxylamine which is catalyzed by the enzyme ammonia monooxygenase (AMO). The amoA gene encodes the active-site polypeptide of ammonia monooxygenase (Rotthauwe and Witzel, 1997), and since bacteria transcribe genes only when they need the gene product, it can be assumed that transcriptional numbers represent the amount of the enzyme in the samples. The enzyme presence thus correlates directly with nitrification activity.

In the aerated activated sludge samples, the expression of the AOB amoA gene was higher than the expression in the recycled and anaerobic sludge (Figure 19). Specifically, the abundance of the cDNA AOB amoA gene transcript was 19 times greater in the aerated tanks when compared to the anaerobic digester (Table 8). Similar to their dominance in abundance in high oxygen and high ammonia concentrations, it appears that they are also actively expressing the $a m o A$ gene and may be contributing greatly to the ammonia oxidation process in the aerated tanks. This study may be one of the first to confirm that the transcriptional activity of AOB $a m o A$ in a full-scale activated sludge system is highest within the aerated tanks. However, the results obtained in this study agree with the findings 
of Wells et al., (2009) who suggested, based on T-RFLP surveys of AOB community dynamics of a municipal WWTP, that DO is one of the most influential variables on AOB community dynamics. Similar results which also confirm that DO concentrations influence the activity of AOB have been obtained from several full-scale WWTPs (Limpiyakorn et al., 2011; Park et al., 2006), however they did not determine the activity by quantifying the expression of amoA gene transcripts.

In comparison, the expression of the AOA amoA gene was higher in the anaerobic digesters than in the aerated tanks (Figure 20). Again, this study may be the first to contribute findings on the activity of AOA by quantifying the expression of the AOA amoA transcript within activated sludge systems of full-scale WWTP. The expression of the AOA amoA gene was 2 times greater in copy number in the anaerobic digester sludge than the aerated activated sludge samples (Table 8). This was a very novel finding because previous activity of ammonia oxidizers was assumed based on chemical parameter measurements and not on actual presence of the enzyme. Previously, Leininger et al., (2006) first acknowledged that AOA were greater contributors of ammonia oxidation in all soil samples, they found archaeal amoA genes dominated over bacterial amoA genes in all soils, with AOA ratios ranging from 1.5 to over 230 when compared to AOB in top soils. However, in wastewater treatment, AOA much are lower in abundance and do not play a major role in ammonia oxidation (Gao et al., n.d.; Park et al., 2006). The possible reasoning that they are found to be increasingly active within the digesters may be due to their preference for a niche containing low DO level (Park and Noguera, 2004; Park et al., 2006). Lower ammonia concentrations within the anaerobic digesters may also possibly be contributing to the increase in activity of AOA within the anaerobic digesters. Limpiyakorn 
et al. (2011), discovered the magnitude order of AOA was up to $10^{11}$, which was further greater than AOA abundance in other WTTPs and predicted that the key factor was the wastewater quality, especially the low ammonia concentration. Another interesting observation was found, when it appeared that the AOA amoA gene transcripts were higher in digester 2 than compared to digester 1. Previously, it was found that the abundance of AOA amoA was highest in the digester 1 tanks, but when examining the activity through the quantification of $a m o A$ gene transcription, it appears the AOA are more active within digester 2 tank samples.

In this experiment however, $\mathrm{AOB}$ amoA transcripts were present in higher abundance than the AOA counter parts, lower ammonia concentrations and very low oxygen concentrations may lead to AOA outperforming the AOB in the anaerobic digesters but further experiments on function and contribution of $\mathrm{AOA}$ are required. Ammonia oxidizing archaea are suggested to have a higher substrate affinity for ammonia than that of bacteria which grants them an advantage in low ammonia concentrated environments (Stahl and De La Torre, 2012). In soils, studies linking nitrification rates to the nitrifier abundance and activity (using molecular proxies such as amoA gene and transcript abundances) have suggested that high affinity for ammonia also appears to provide soil AOA with a competitive advantage over AOB. Stahl and De la Torre (2012) state in their review that in general, $\mathrm{AOB}$ tend to dominate in systems receiving high direct additions of inorganic ammonia (Jia and Conrad, 2009; Pratscher et al., 2011), whereas systems sustained by mineralization (ammonification) of organic material select for AOA (Prosser and Nicol, 2008). Thus, with representatives that function as extreme oligotrophs, these chemoautotrophic organisms presumably function as a key valve in nitrification by 
controlling the rate of ammonia oxidation, generally considered to be the rate-limiting step in nitrification. This has significant implications for the global nitrogen cycle and for trophic interactions in both terrestrial and marine environments (Stahl and De la Torre, 2012).

\subsection{Conclusion and Future Recommendations}

Although the presence of ammonia oxidizing archaea in municipal wastewater treatment has been previously observed in activated sludge samples (Park et al., 2006; Zhang et al., 2009), the abundance of AOB and AOA populations and their relative contribution to the ammonia oxidation process under various operational parameters of the activated sludge system was not elucidated. The results from this study clearly show that AOB are dominant in both relative and absolute abundance in all activated sludge samples from a full-scale municipal wastewater treatment plant, especially in the aerated bioreactors where the dissolved oxygen concentration is $>2 \mathrm{mg} / \mathrm{L}$ and contained high ammonia concentrations. The decrease in the abundance of both the 16S rRNA and amoA genes for $\mathrm{AOB}$ within the anaerobic digester tanks demonstrated that $\mathrm{AOB}$ decrease in abundance in the extremely low DO and low ammonia conditions of the anaerobic digester 1.

Interestingly, although both $\mathrm{AOA}$ and $\mathrm{AOB}$ have indistinguishable stoichiometry when it comes to ammonia oxidation (Martens-Habbena and Stahl, 2011), it was surprising to find the AOA to be increasingly abundant within anaerobic digesters where the amount of oxygen is miniscule for the AOA to grow. It is possible that sources of oxygen utilized by the AOA may differ from $\mathrm{AOB}$ and allow them to survive in a minimal oxygen environment. Analysis of archaeal amoA sequences from different activated sludge 
processes in a municipal WWTP suggests that AOA may be ubiquitous in activated sludge systems that are operated at relatively longer solids retention time (10.9 days), with low DO and low ammonia concentrations. Their high abundance in this ecosystem with very low oxygen and ammonia concentrations indicate that these organisms are adapted to a broad range of growth conditions and might therefore have a more versatile metabolism than AOB.

Evidently, this study suggests that AOB represent the most abundant ammoniaoxidizing organisms in the activated sludge system and may responsible for majority of the ammonia oxidation that occurs within the activated sludge process. However, it is interesting to note that although AOBs greatly outnumber the AOAs in all samples of the activated sludge system, quantification of the $\mathrm{AOB}$ and $\mathrm{AOA}$ amoA gene shows that the AOB abundance decreased by a factor of 5 as the wastewater goes through aerobic to anaerobic treatment. Meanwhile, the AOA amoA abundance increased by a factor of 14 in the anaerobic digesters compared to the aeration tanks. This may suggest that some redundancy exists between these two ammonia oxidizing groups present in the activated sludge community which enables the oxidation of ammonia to be a stable process. Although the exact parameter data from the anaerobic digesters could not be obtained, it is expected that the conditions here are represented very low concentrations of ammonia and very low amount of dissolved oxygen. Both conditions may provide the ideal niche for AOA to be present in greater numbers and be more active.

According to RT-qPCR, higher cDNA transcripts of the AOB amoA gene was detected in the aerated tanks and recycled sludge than the anaerobic digester reactors, an indication that $\mathrm{AOB}$ are more active in the aerated activated sludge systems. The presence 
of higher cDNA transcripts for the AOA amoA gene in the anaerobic digester 2 demonstrated that they are more transcriptionally active in low oxygen and low ammonia environments. However, this study can confirm, although both are co-existing in different stages of the activated sludge system, AOB play a greater role in ammonia oxidation in the activated sludge systems of a municipal wastewater treatment plant as their abundance and activity is found to be greater in comparison to AOA in all stages of the activated sludge process.

The ammonia oxidizing archaea are found to be ubiquitous in the activated sludge process however based on abundances of the amoA gene and quantification of $a m o A$ gene transcripts, archaeal amoA genes is several orders of magnitude lower than that of AOB, it is speculated that AOA represent a small fraction (a few percent) of activated sludge biomass, and therefore would be unlikely play a substantial role in ammonia oxidation in WWTPs. Future studies should focus on improving techniques in sample preservation and obtaining quality DNA and RNA from wastewater. It is also imperative to ensure that parameter data such as DO, BOD, SRT and HRT of each reactor can be collected and recorded prior to analysis so that the link between abundance and activity and operational parameters can be deduced.

The significance of this study simply relies on the importance of the global nitrogen cycle. In a continuously changing world, where input of fixed $\mathrm{N}$ compounds into the environment mostly through human activities such as agriculture has nearly doubled (USEPA, 2015), it is imperative that the microorganisms responsible for these key biogeochemical processes are examined and their functional capabilities be resolved. Ammonia oxidizing microorganisms are engines that are essential to the nitrogen cycle, 
because they produce the oxidized nitrogen species that are required by other important microorganisms such as anammox and denitrifiers that aid the conversion of bioavailable nitrogen into atmospheric molecular nitrogen. With the remarkable discovery that AOA can also oxidize ammonia and may be responsible for ammonia oxidation on a global level there is immediate demand for information regarding their presence and contribution to wastewater treatment where ammonia reduction is essential. This study contributed the links between environmental parameters such as dissolved oxygen and ammonia concentrations and the presence and abundance of AOA and AOB within an activated sludge system from a municipal wastewater treatment plant in order to elucidate relationships between operational parameters and $\mathrm{AOA}$ and $\mathrm{AOB}$ community structures. Besides confirming the importance of AOB in the activated sludge process, this study also demonstrated AOA may be increasingly abundant within anaerobic digesters in WWTP where the extremely low DO and low ammonia concentrations are providing an ideal niche. The idea that both AOA and $\mathrm{AOB}$ co-exist within the wastewater treatment plant and may share some redundancy is one that will pave the path for future studies examining the importance of AOA to the ammonia oxidation process in WWTPs. 


\section{APPENDIX}

\section{APPENDIX A: PCR}

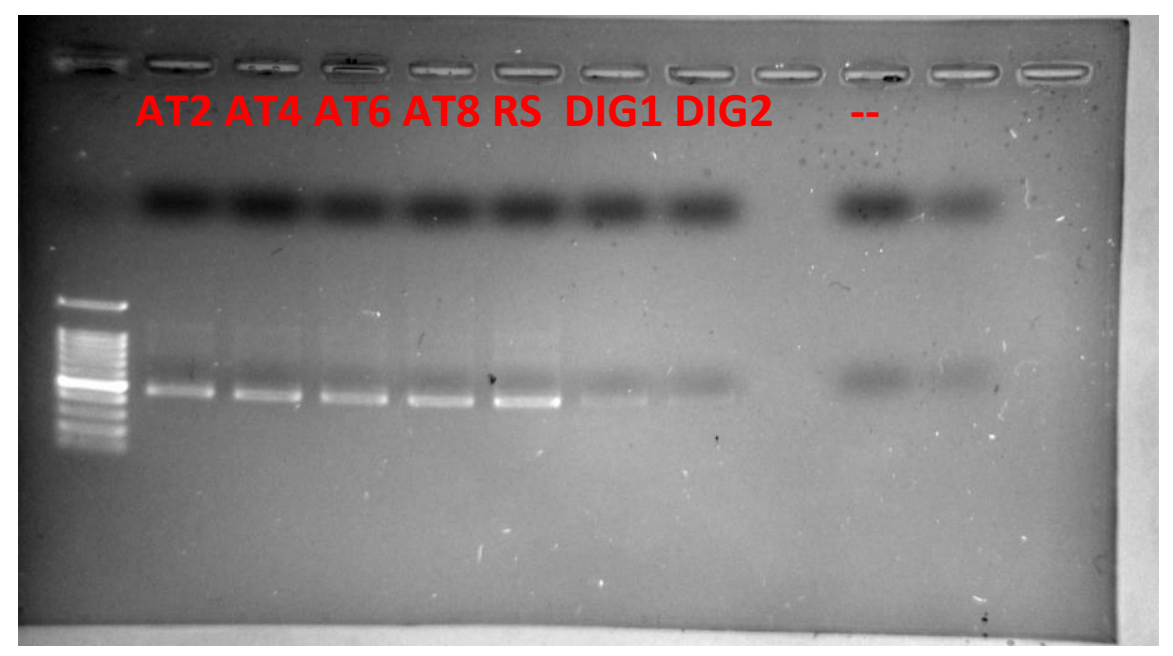

Figure 21. Gel image of PCR product targeting 16S rRNA gene fragment for AOB in a full-scale activated sludge system. Gel image of PCR products obtained after PCR with primers CTO189f and CTO654r targeting AOB to amplify a 465 bp fragment. $500 \mathrm{ng}$ of DNA was loaded into each well.

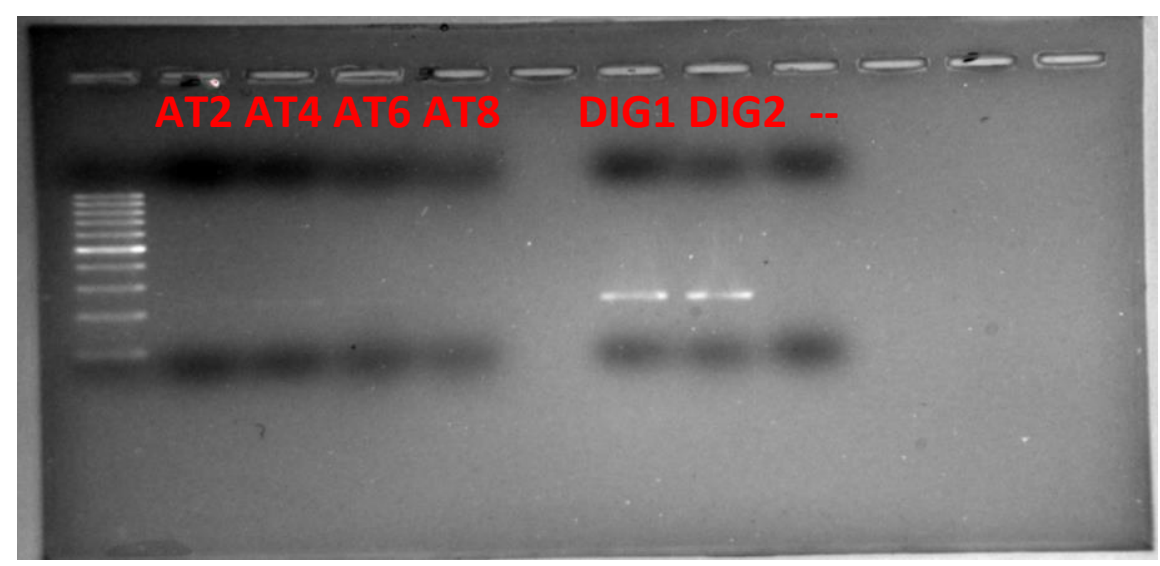

Figure 22. Gel image of PCR product targeting 16S rRNA gene for AOA, primers Crenar771f and Crenar957r were used to amplify a 186 bp fragment. $500 \mathrm{ng}$ of DNA was loaded into each well. 


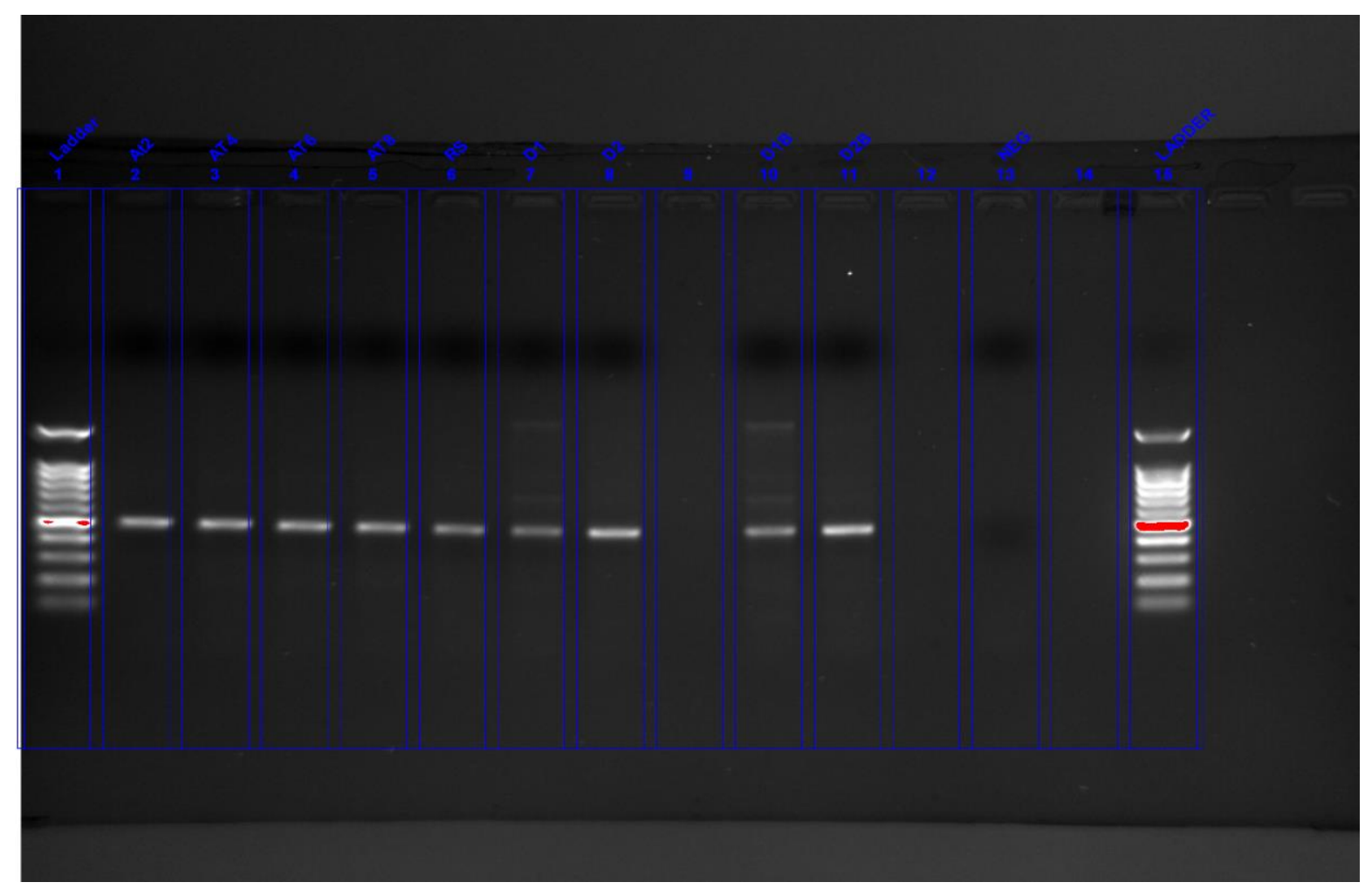

Figure 23. Gel image of PCR product targeting amoA gene fragment for AOB. Gel image of PCR products obtained after PCR with using primers amoA1f and amoA2r to amplify a $491 \mathrm{bp}$ fragment for AOB. $500 \mathrm{ng}$ of template DNA was loaded in each well. The well designated as (--) is the negative control run for each sample consisting of the PCR amplification mix only with no DNA. The last lane consists of the 100bp DNA ladder (Froggabio, Toronto, ON). 


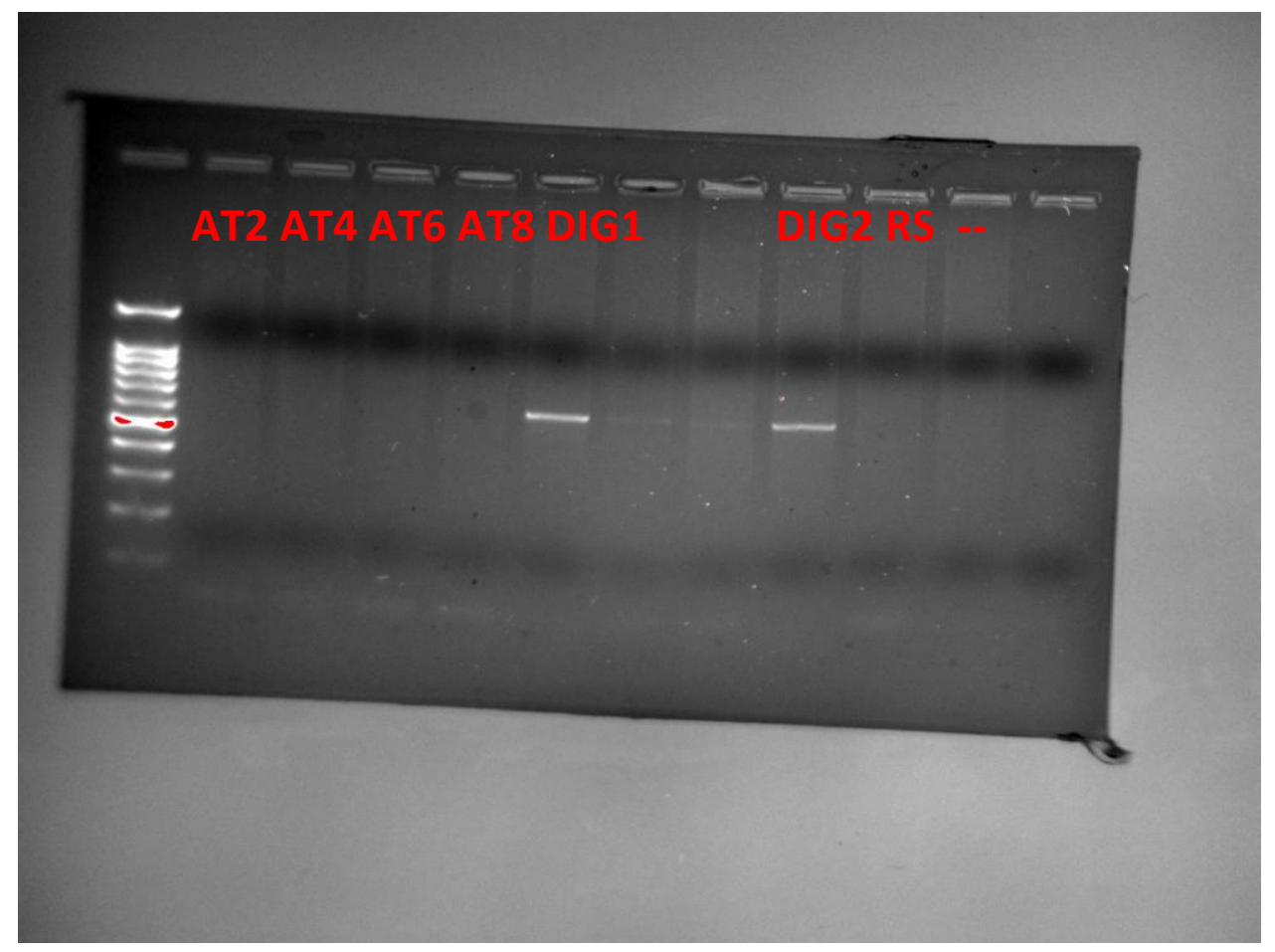

Figure 24. Gel image of PCR product targeting amoA gene fragment for AOA. Gel image of PCR products obtained after sequence for AOA was performed using primers Arch-amoAf and ArchamoAr to amplify a 635 bp fragment for AOA. 500ng of template DNA was loaded into each well. The well designated as (--) is the negative control run for each sample consisting of the PCR amplification mix only with no DNA. The first lane consists of the 100bp DNA ladder (Froggabio, Toronto, ON) 


\section{APPENDIX B- Quantitative PCR and RT-PCR}

Table 9. Threshold Cycles $\left(C_{t}\right)$ values obtained from qPCR. Universal primers $341 \mathrm{~F}$ and v3R were used to target the $16 \mathrm{~S}$ gene in all heterotrophic microorganisms.

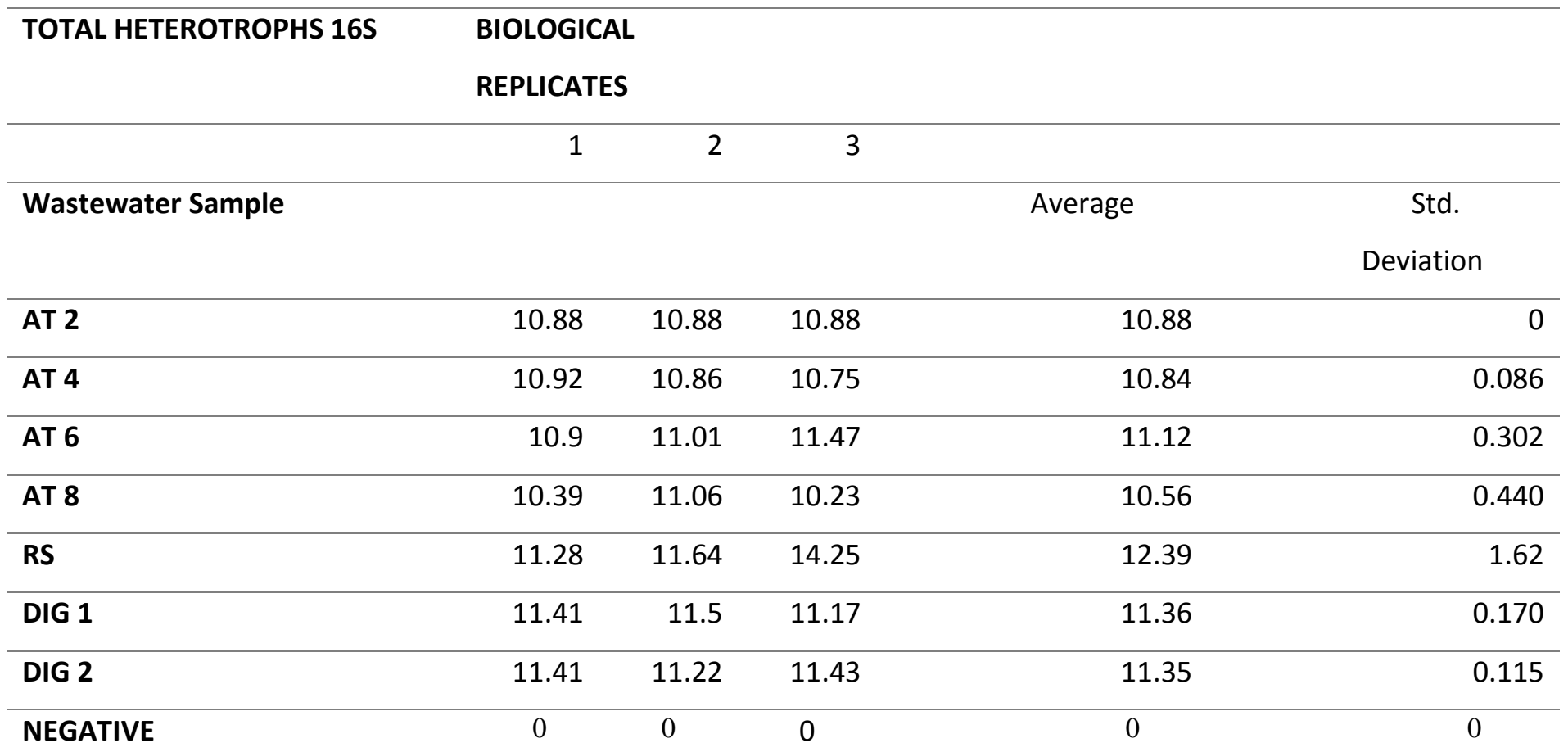


Table 10. Threshold Cycles $\left(\mathrm{C}_{\mathrm{t}}\right)$ values obtained from qPCR. AOA $16 \mathrm{~S}$ gene was amplified using primers Crenar771f and Crenar957r.

\begin{tabular}{lrrrrr}
\hline AOA 16S & \multicolumn{2}{l}{$\begin{array}{l}\text { BIOLOGICAL } \\
\text { REPLICATE }\end{array}$} \\
$\begin{array}{lrrrr}\text { Wastewater Sample } \\
\text { AT 2 }\end{array}$ & 26.18 & 26.26 & 26.85 & AVERAGE & STD. DEVIATION \\
\hline AT 4 & 26.32 & 26.2 & 27.01 & 26.43 & 0.366 \\
\hline AT 6 & 27.2 & 27.22 & 27.12 & 26.51 & 0.437 \\
\hline AT 8 & 27.34 & 27.15 & 27.35 & 27.18 & 0.052 \\
\hline RS & 27.49 & 27.3 & 28.33 & 27.28 & 0.112 \\
\hline DIG 1 & 22.15 & 22.15 & 21.98 & 27.70 & 0.548 \\
\hline DIG 2 & 22.24 & 22.46 & 22.13 & 22.09 & 0.098 \\
\hline NEGATIVE & 0 & 0 & 0 & 22.27 & 0.168 \\
\hline
\end{tabular}

Table 11. Threshold Cycles $\left(C_{t}\right)$ values obtained from $q P C R$. The $16 \mathrm{~S}$ gene for AOB was amplified using primers CTO189f and CTO654r.

\begin{tabular}{lrrrrr}
\hline AOB 16S & $\begin{array}{l}\text { BIOLOGICAL } \\
\text { REPLICATE }\end{array}$ & & & \\
\hline & 1 & 2 & 3 & & STD. DEVIATION \\
\hline Wastewater Sample & & & & 18.45 & 0.883 \\
\hline AT 2 & 17.69 & 18.24 & 19.42 & 17.60 & 1.496 \\
\hline AT 4 & 16.3 & 17.28 & 19.24 & 18.34 & 0.762 \\
\hline AT 6 & 17.83 & 17.98 & 19.22 & 18.79 & 1.118 \\
\hline AT 8 & 17.76 & 18.63 & 19.98 & 19.55 & 1.473 \\
\hline RS & 18.47 & 18.9 & 21.21 & 25.82 & 1.625 \\
\hline DIG 1 & 24.64 & 25.16 & 27.68 & 22.18 & 1.453 \\
\hline DIG 2 & 21.12 & 21.59 & 23.84 & 21.07 & 31.85 \\
\hline NEGATIVE & 32.27 & 32.42 & 30.87 & 0.855 \\
\hline
\end{tabular}


Table 12. Threshold Cycles $\left(\mathrm{C}_{\mathrm{t}}\right)$ values obtained from $\mathrm{qPCR}$. The amoA gene in AOA was amplified using the primers Arch amo1F and Arch amo2R.

\begin{tabular}{lrrrrrr}
\hline AOA AMOA & BIOLOGICAL REPLICATES & & & \\
\hline Wastewater Sample & 1 & 2 & 3 & 4 & AVERAGE & ST. DEV \\
\hline AT 2 & 30 & 30.43 & 30.48 & 30.19 & 30.27 & 0.222 \\
\hline AT 4 & 29.33 & 29.31 & 29.72 & 29.45 & 0.231 \\
\hline AT 6 & 31.05 & 30.79 & 32.32 & 31.38 & 0.818 \\
\hline AT 8 & 31.08 & 30.03 & 33 & 31.37 & 1.506 \\
\hline RS & 30.13 & 30.35 & 29.47 & 29.98 & 0.457 \\
\hline DIG 1 & 26.16 & 27.53 & 27.84 & 27.77 & 27.32 & 0.787 \\
\hline DIG 2 & 29.72 & 29.79 & 29.85 & 29.78 & 0.065 \\
\hline
\end{tabular}

NEGATIVE

Table 13. Threshold Cycles $\left(\mathrm{C}_{t}\right)$ values obtained from $q P C R$. The amoA gene in AOB was amplified using the primers amo1f and amo2r.

\section{AOB AMOA \\ BIOLOGICAL \\ REPLICATES}

$\begin{array}{llllll}1 & 2 & 3 & 4 & \text { ST. DEV }\end{array}$

\begin{tabular}{lrrrrrr}
\multicolumn{1}{l}{$\begin{array}{l}\text { AVERAGE } \\
\text { Wastewater } \\
\text { Sample }\end{array}$} & 20.67 & 20.95 & 20.03 & 20.83 & 20.62 & 0.409 \\
\hline AT 2 & & & & & & \\
\hline AT 4 & 20.73 & 20.79 & 20.22 & 20.14 & 20.47 & 0.337 \\
\hline AT 6 & 19.85 & 20.64 & 20.62 & 20.24 & 20.34 & 0.373 \\
\hline AT 8 & 20.13 & 19.29 & 19.09 & 19.15 & 19.41 & 0.483 \\
\hline RS & 20.09 & 20.93 & 20.82 & 20.7 & 20.63 & 0.375 \\
\hline DIG 1 & 20.47 & 23.1 & 21.47 & 23.14 & 22.04 & 1.306 \\
\hline DIG 2 & 20.03 & 21.16 & 21.52 & 21.18 & 20.97 & 0.649 \\
\hline
\end{tabular}




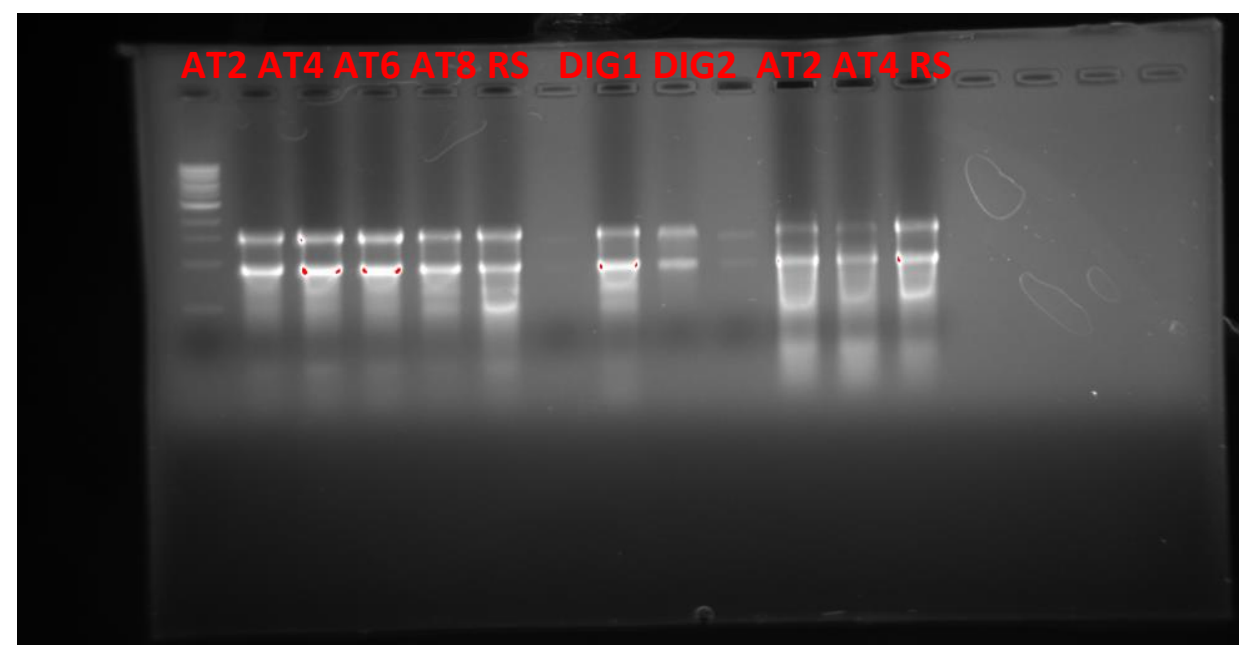

Figure 25. Gel image of RNA extractions using the TRIZOL method. 500ng of RNA was loaded into each well.

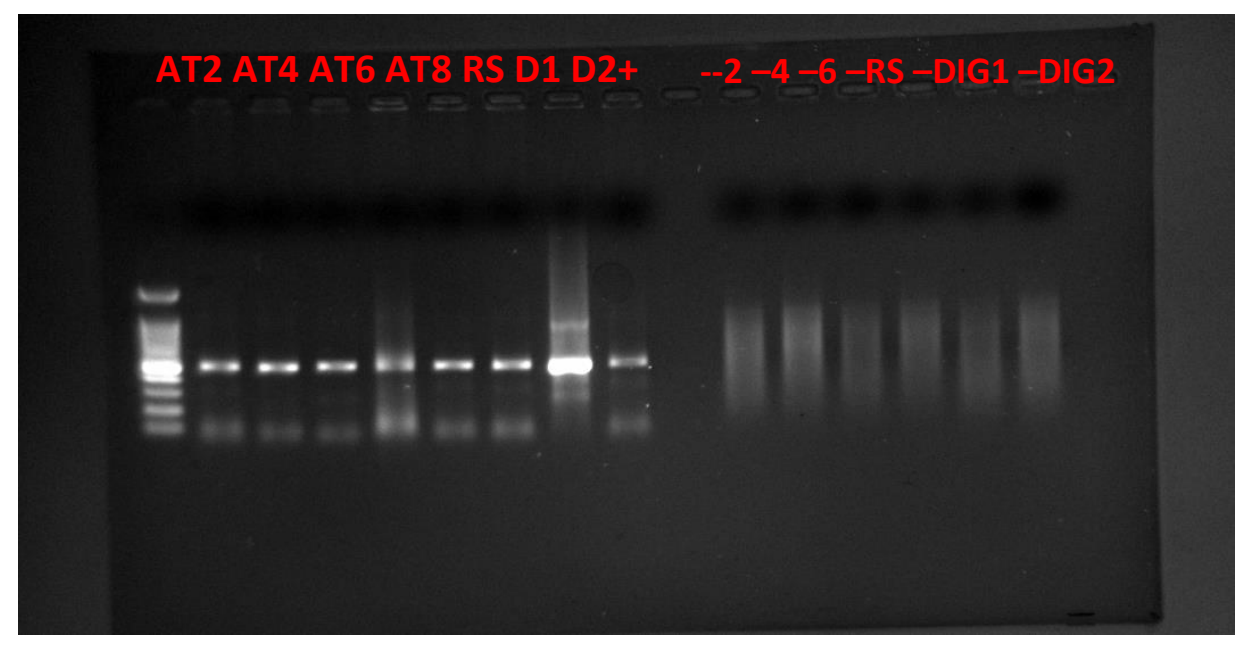

Figure 26. Gel image of RT-PCR products using primers amo1f and amo2r from activated sludge samples. The - is indicating the NORT reactions for each sample which were reactions without any reverse transcriptase enzyme to ensure there was no DNA contamination. $500 \mathrm{ng}$ of PCR product was loaded into each well. 


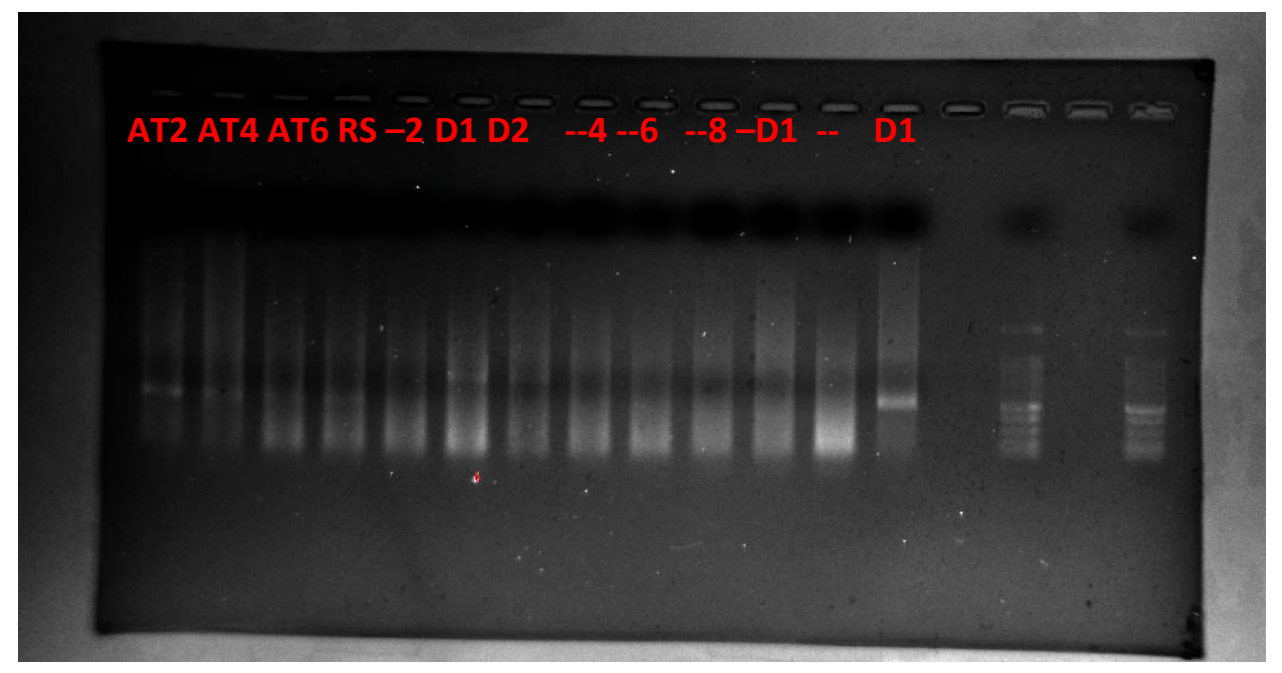

Figure 27. Gel image RT-PCR products using primers Arch amo1f and Arch amo2r from activated sludge samples. $500 \mathrm{ng}$ of PCR product was loaded into each well. The - is indicating the NORT reactions for each sample which were reactions without any reverse transcriptase enzyme to ensure there was no DNA contamination. 


\section{APPENDIX C-STANDARD CURVES}

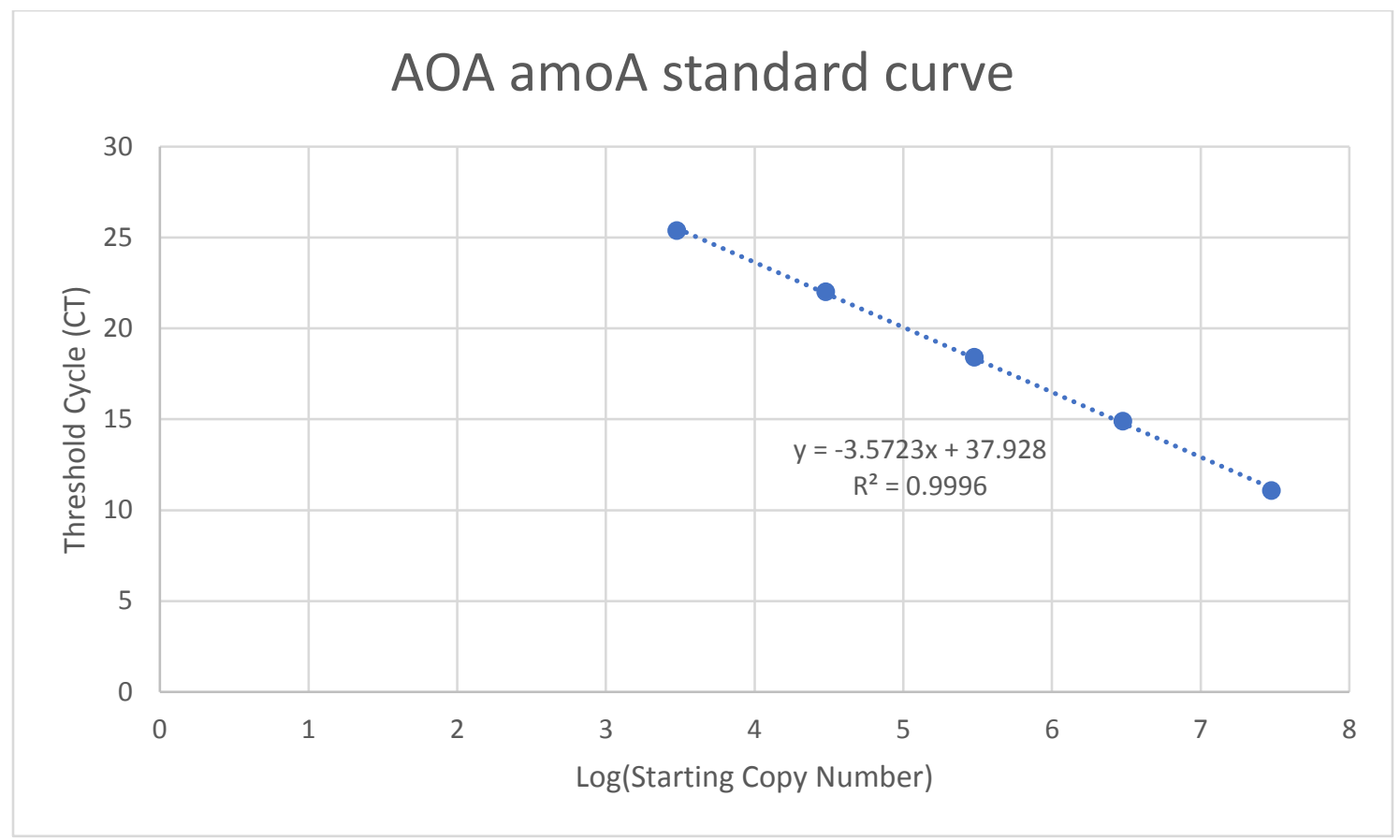

Figure 28. Standard Curve obtained from qPCR experiment which used plasmids containing the AOB amoA gene as template. Dilution series was prepared with known copy numbers and qPCR Threshold Cycles $\left(\mathrm{C}_{\mathrm{t}}\right)$ values were plotted against the log of copy numbers. 


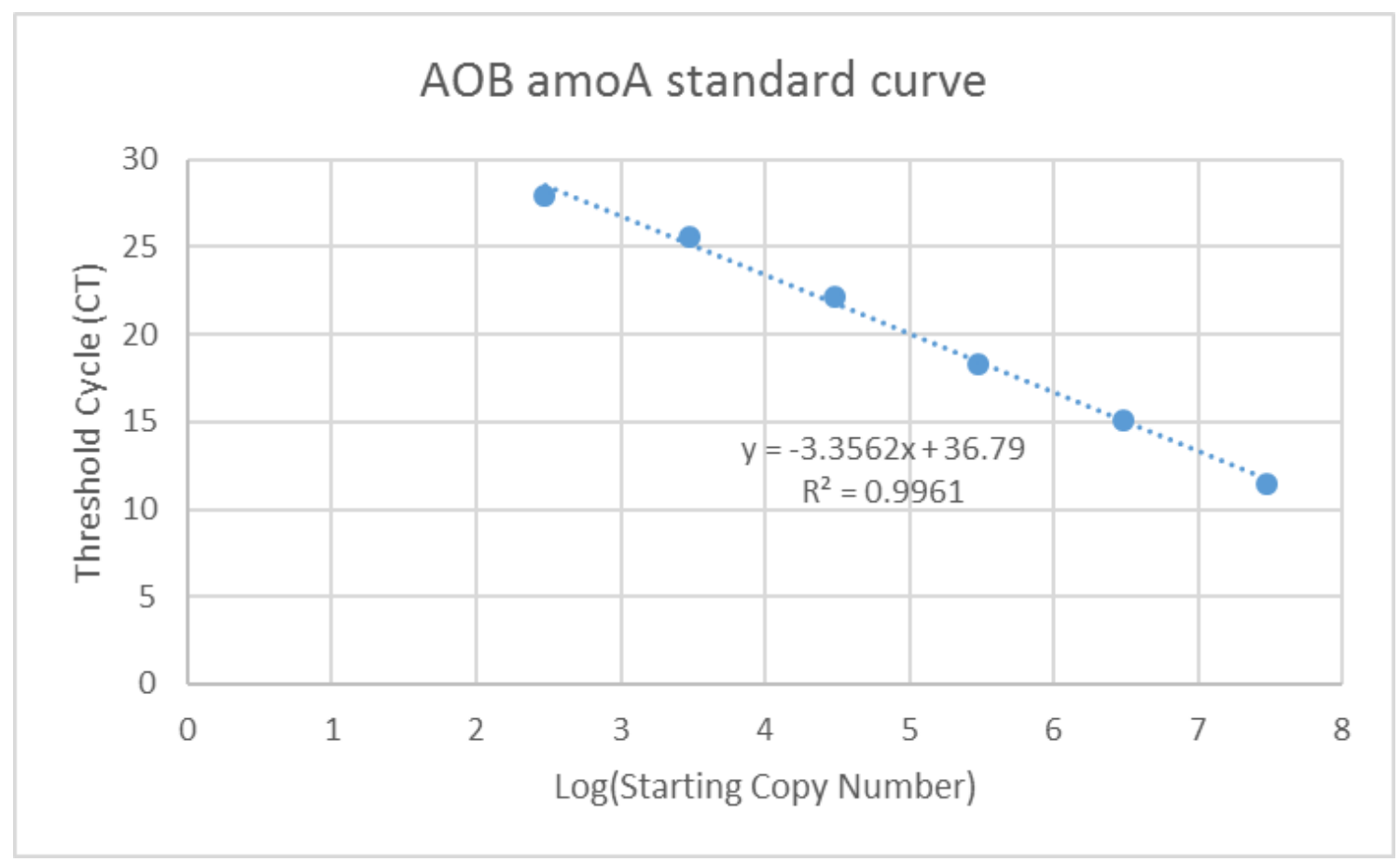

Figure 29. Standard Curve obtained from qPCR experiment which used plasmids containing the AOB amoA gene as template. Dilution series was prepared with known copy numbers and qPCR Threshold Cycles $\left(C_{t}\right)$ values were plotted against the log of copy numbers. 


\section{REFERENCES}

Ahn, Y. H. (2006). Sustainable nitrogen elimination biotechnologies: A review. Process Biochemistry, 41(8), 1709-1721. https://doi.org/10.1016/j.procbio.2006.03.033

Awata, T., Tanabe, K., Kindaichi, T., Ozaki, N., \& Ohashi, A. (2012). Influence of temperature and salinity on microbial structure of marine anammox bacteria. Water Science and Technology, 66(5), 958-964. https://doi.org/10.2166/wst.2012.234

Bai, Y., Sun, Q., Wen, D., \& Tang, X. (2012). Abundance of ammonia-oxidizing bacteria and archaea in industrial and domestic wastewater treatment systems. FEMS Microbiology Ecology, 80(2), 323-330. https://doi.org/10.1111/j.1574-6941.2012.01296.x

Beman, J. M., \& Francis, C. A. (2006). Diversity of ammonia-oxidizing archaea and bacteria in the sediments of a hypernutrified subtropical estuary: Bahía del Tóbari, Mexico. Applied and Environmental Microbiology, 72(12), 7767-7777. https://doi.org/10.1128/AEM.0094606

Berktay, A., \& Nas, B. (2008). Biogas production and utilization potential of wastewater treatment sludge. Energy Sources, Part A: Recovery, Utilization and Environmental Effects, 30(2), 179-188. https://doi.org/10.1080/00908310600712489

Bernhard, A. (2010). The Nitrogen Cycle: Processes, Players, and Human Impact. Nature Education Knowledge, 3(10), 25.

Bernhard, A. E., Landry, Z. C., Blevins, A., De La Torre, J. R., Giblin, A. E., \& Stahl, D. A. (2010). Abundance of ammonia-oxidizing archaea and bacteria along an estuarine salinity gradient in relation to potential nitrification rates. Applied and Environmental Microbiology, 76(4), 1285-1289. https://doi.org/10.1128/AEM.02018-09

Bitton, G. (2005). Activated Sludge Process. Wastewater Microbiology. https://doi.org/10.1002/0471717967.ch8

Bocchiaro, P., \& Zamperini, A. (2016). World â€ $€^{\mathrm{TM}}$ s largest Science, Technology \& Medicine Open Access book publisher c. In RFID Technology, Security Vulnerabilities, and Countermeasures. https://doi.org/10.5772/711

Cetecioglu, Z., Ince, B., \& Azman, S. (2014). Biodegradation of Tetracycline Under Various Conditions and Effects on Microbial Community, 631-640. https://doi.org/10.1007/s12010013-0559-6

Chen, H., Yue, Y., Jin, W., Zhou, X., Wang, Q., Gao, S. hong, ... Guo, K. (2017). Enrichment and characteristics of ammonia-oxidizing archaea in wastewater treatment process. Chemical Engineering Journal. https://doi.org/10.1016/j.cej.2017.04.130

City of Guelph. (2012). 2012 Wastewater Annual Report. Retrieved from http://guelph.ca/wpcontent/uploads/2012WastewaterAnnualReport.pdf

City of Toronto. (2010). Humber Wastewater Treatment Plant - 2010 Annual Report. Retrieved from 
https://www1.toronto.ca/city_of_toronto/toronto_water/files/pdf/htp_annual_report_2010.p df

City of Toronto. (2013). North Toronto Wastewater Treatment plant 2012 Annual Report.

Retrieved from

https://www1.toronto.ca/city_of_toronto/toronto_water/files/pdf/nttp_annual_report_2012.p

df

Comte, S., Guibaud, G., \& Baudu, M. (2007). Effect of extraction method on EPS from activated sludge: An HPSEC investigation. Journal of Hazardous Materials, 140(1-2), 129-137. https://doi.org/10.1016/j.jhazmat.2006.06.058

Cydzik-Kwiatkowska, A., \& Zielińska, M. (2016). Bacterial communities in full-scale wastewater treatment systems. World Journal of Microbiology and Biotechnology, 32(4), 18. https://doi.org/10.1007/s11274-016-2012-9

Dang, H. Y., Huang, R. F., \& Jiao, N. Z. (2016). Inspirations from the scientific discovery of the anammox bacteria: A classic example of how scientific principles can guide discovery and development. Science China Earth Sciences. https://doi.org/10.1007/s11430-015-5203-6

De La Torre, J. R., Walker, C. B., Ingalls, A. E., Könneke, M., \& Stahl, D. A. (2008). Cultivation of a thermophilic ammonia oxidizing archaeon synthesizing crenarchaeol. Environmental Microbiology, 10(3), 810-818. https://doi.org/10.1111/j.14622920.2007.01506.x

Enderlein, U. S., E. Enderlein, R., \& Williams, W. P. (1997). Water Quality Requirements. Water Pollution Control - A Guide to the Use of Water Quality Management Principles. https://doi.org/10.4324/9780203477540

EPA. (2017). EPA (Enviromental Protection Agency). Retrieved from https://www.epa.gov/salish-sea/freshwater-quality

Erguder, T. H., Boon, N., Wittebolle, L., Marzorati, M., \& Verstraete, W. (2009). Environmental factors shaping the ecological niches of ammonia-oxidizing archaea. FEMS Microbiology Reviews. https://doi.org/10.1111/j.1574-6976.2009.00179.x

Espy, M. J., Uhl, J. R., Sloan, L. M., Buckwalter, S. P., Jones, M. F., Vetter, E. A., ... Smith, T. F. (2006). Real-time PCR in clinical microbiology: Applications for routine laboratory testing. Clinical Microbiology Reviews, 19(1), 165-256. https://doi.org/10.1128/CMR.19.1.165-256.2006

Fischer, S. G., \& Lerman, L. S. (1983). DNA fragments differing by single base-pair substitutions are separated in denaturing gradient gels: correspondence with melting theory. Proceedings of the National Academy of Sciences of the United States of America, 80(6), 1579-1583. https://doi.org/10.1073/pnas.80.6.1579

Francis, C. A., Roberts, K. J., Beman, J. M., Santoro, A. E., \& Oakley, B. B. (2005). Ubiquity and diversity of ammonia-oxidizing archaea in water columns and sediments of the ocean. Proceedings of the National Academy of Sciences, 102(41), 14683-14688. https://doi.org/10.1073/pnas.0506625102

Gao, J., Luo, X., Wu, G., Li, T., \& Peng, Y. (n.d.). Abundance and diversity based on amoA 
genes of ammonia-oxidizing archaea and bacteria in ten wastewater treatment systems.

Ge, H., Jensen, P. D., \& Batstone, D. J. (2010). Pre-treatment mechanisms during thermophilicmesophilic temperature phased anaerobic digestion of primary sludge. Water Research, 44(1), 123-130. https://doi.org/10.1016/j.watres.2009.09.005

Geissen, V., Mol, H., Klumpp, E., Umlauf, G., Nadal, M., van der Ploeg, M., ... Ritsema, C. J. (2015). Emerging pollutants in the environment: A challenge for water resource management. International Soil and Water Conservation Research, 3(1), 57-65. https://doi.org/10.1016/j.iswcr.2015.03.002

Gogate, P. R., \& Pandit, A. B. (2004). A review of imperative technologies for wastewater treatment I: Oxidation technologies at ambient conditions. Advances in Environmental Research. https://doi.org/10.1016/S1093-0191(03)00032-7

HAO, C., WANG, H., LIU, Q., \& LI, X. (2009). Quantification of anaerobic ammoniumoxidizing bacteria in enrichment cultures by quantitative competitive PCR. Journal of Environmental Sciences. https://doi.org/10.1016/S1001-0742(08)62455-9

Hatzenpichler, R. (2012). Diversity, physiology, and niche differentiation of ammonia-oxidizing archaea. Applied and Environmental Microbiology, 78(21), 7501-7510. https://doi.org/10.1128/AEM.01960-12

Hatzenpichler, R., Lebedeva, E. V, Spieck, E., Stoecker, K., Richter, A., Daims, H., \& Wagner, M. (2008). A moderately thermophilic ammonia-oxidizing crenarchaeote from a hot spring. Proceedings of the National Academy of Sciences of the United States of America, 105(6), 2134-2139. https://doi.org/10.1073/pnas.0708857105

Heid, C. A., Stevens, J., Livak, K. J., \& Williams, P. M. (1996). Real time quantitative PCR. Genome Research, 6(10), 986-994. https://doi.org/10.1101/gr.6.10.986

Higuchi, R., Fockler, C., Dollinger, G., \& Watson, R. (1993). Kinetic PCR analysis: real-time monitoring of DNA amplification reactions. Bio/technology. https://doi.org/10.1038/nbt0993-1026

Holger Daims. (2001). Population Structure and Functional Analyses , by In Situ Techniques, of Nitrifying Bacteria in Wastewater Treatment Plants Holger Daims Doktors der Naturwissenschaften. Technischen Universität München, 227.

Hou, J., Song, C., Cao, X., \& Zhou, Y. (2013). Shifts between ammonia-oxidizing bacteria and archaea in relation to nitrification potential across trophic gradients in two large Chinese lakes (Lake Taihu and Lake Chaohu). Water Research. https://doi.org/10.1016/j.watres.2013.01.042

Islam, G.(2012). Impact of Tetracycline on Microbial Communities in the Secondary Treatment Process of Wastewater Treatment Systems.Unpublished master's thesis. Ryerson University.

Jetten, M. S. M., Niftrik, L. van, Strous, M., Kartal, B., Keltjens, J. T., \& Op den Camp, H. J. M. (2009). Biochemistry and molecular biology of anammox bacteria. Critical Reviews in Biochemistry and Molecular Biology. https://doi.org/10.1080/10409230902722783

Jetten, M., Schmid, M., Van De Pas-Schoonen, K., Damsté, J. S., \& Strous, M. (2005). 
Anammox organisms: Enrichment, cultivation, and environmental analysis. Methods in Enzymology, 397, 34-57. https://doi.org/10.1016/S0076-6879(05)97003-1

Jia, Z., \& Conrad, R. (2009). Bacteria rather than Archaea dominate microbial ammonia oxidation in an agricultural soil. Environmental Microbiology. https://doi.org/10.1111/j.1462-2920.2009.01891.x

Jury, K. L., Khan, S. J., Vancov, T., Stuetz, R. M., \& Ashbolt, N. J. (2011). Are sewage treatment plants promoting antibiotic resistance? Critical Reviews in Environmental Science and Technology, 41(3), 243-270. https://doi.org/10.1080/10643380902772589

Kayee, P., Sonthiphand, P., Rongsayamanont, C., \& Limpiyakorn, T. (2011). Archaeal amoA genes outnumber bacterial amoA genes in municipal wastewater treatment plants in Bangkok. Microbial Ecology, 62(4), 776-788. https://doi.org/10.1007/s00248-011-9893-9

Kelly, D. P., \& Wood, A. P. (2006). The Chemolithotrophic Prokaryotes. In M. Dworkin, S. Falkow, E. Rosenberg, K.-H. Schleifer, \& E. Stackebrandt (Eds.), The Prokaryotes: Volume 2: Ecophysiology and Biochemistry (pp. 441-456). New York, NY: Springer New York. https://doi.org/10.1007/0-387-30742-7_15

Kim, Y. M., Park, H., Cho, K. H., \& Park, J. M. (2013). Long term assessment of factors affecting nitrifying bacteria communities and N-removal in a full-scale biological process treating high strength hazardous wastewater. Bioresource Technology, 134, 180-189. https://doi.org/10.1016/j.biortech.2013.02.036

Könneke, M., Bernhard, A. E., de la Torre, J. R., Walker, C. B., Waterbury, J. B., \& Stahl, D. A. (2005). Isolation of an autotrophic ammonia-oxidizing marine archaeon. Nature. https://doi.org/10.1038/nature03911

Kowalchuk, G. a, \& Stephen, J. R. (2001). Ammonia-oxidizing bacteria: a model for molecular microbial ecology. Annual Review of Microbiology, 55, 485-529. https://doi.org/10.1146/annurev.micro.55.1.485

Küster, A., \& Adler, N. (2014). Pharmaceuticals in the environment: scientific evidence of risks and its regulation. Philosophical Transactions of the Royal Society B: Biological Sciences, 369(1656). Retrieved from http://rstb.royalsocietypublishing.org/content/369/1656/20130587.abstract

Lee, T. T., Wang, F. Y., \& Newell, R. B. (2006). Advances in distributed parameter approach to the dynamics and control of activated sludge processes for wastewater treatment. Water Research. https://doi.org/10.1016/j.watres.2005.12.025

Lehtovirta-Morley, L. E., Stoecker, K., Vilcinskas, A., Prosser, J. I., \& Nicol, G. W. (2011). Cultivation of an obligate acidophilic ammonia oxidizer from a nitrifying acid soil. Proceedings of the National Academy of Sciences, 108(38), 15892-15897. https://doi.org/10.1073/pnas.1107196108

Leininger, S., Urich, T., Schloter, M., Schwark, L., Qi, J., Nicol, G. W., ... Schleper, C. (2006). Archaea predominate among ammonia-oxidizing prokaryotes in soils. Nature. https://doi.org/10.1038/nature04983

Liao B.Q., Allen D.G., Droppo I.G., Leppard G.G. and Liss S.N. (2001) Surface properties of 
sludge and their role in bioflocculation and settleability. Water Research. 35: 339-350.

Li, Y., Ding, K., Wen, X., Zhang, B., Shen, B., \& Yang, Y. (2016). A novel ammonia-oxidizing archaeon from wastewater treatment plant: Its enrichment, physiological and genomic characteristics. Scientific Reports. https://doi.org/10.1038/srep23747

Limpiyakorn, T., Sonthiphand, P., Rongsayamanont, C., \& Polprasert, C. (2011). Abundance of amoA genes of ammonia-oxidizing archaea and bacteria in activated sludge of full-scale wastewater treatment plants. Bioresource Technology, 102(4), 3694-3701. https://doi.org/10.1016/j.biortech.2010.11.085

Lydmark, P., Almstrand, R., Samuelsson, K., Mattsson, A., Sörensson, F., Lindgren, P. E., \& Hermansson, M. (2007). Effects of environmental conditions on the nitrifying population dynamics in a pilot wastewater treatment plant. Environmental Microbiology, 9(9), 22202233. https://doi.org/10.1111/j.1462-2920.2007.01336.x

Madigan, M. T., \& Martinko, J. M. (2006). Brock Biology of Microorganisms. International Microbiology (Vol. Chapter 6).

Madoni, P. (2011). Protozoa in wastewater treatment processes: A minireview. Italian Journal of Zoology. https://doi.org/10.1080/11250000903373797

Malik, S., Beer, M., Megharaj, M., \& Naidu, R. (2008). The use of molecular techniques to characterize the microbial communities in contaminated soil and water, 34, 265-276. https://doi.org/10.1016/j.envint.2007.09.001

Martens-Habbena, W., Berube, P. M., Urakawa, H., de la Torre, J. R., \& Stahl, D. A. (2009). Ammonia oxidation kinetics determine niche separation of nitrifying Archaea and Bacteria. Nature, 461(7266), 976-979. https://doi.org/10.1038/nature08465

Martens-Habbena, W., \& Stahl, D. A. (2011). Nitrogen metabolism and kinetics of ammoniaoxidizing archaea. Methods in Enzymology, 496, 465-487. https://doi.org/10.1016/B978-012-386489-5.00019-1

Metcalf, E., \& Eddy, H. (2003). Wastewater engineering: treatment and reuse. Wastewater Engineering, Treatment, Disposal and Reuse. Techobanoglous G, Burton FL, Stensel HD (eds). Tata McGraw-Hill Publishing Company Limited, 4th edition. New Delhi, India. https://doi.org/10.1016/0309-1708(80)90067-6

Mohamedali, T., Roberts, M., \& Sackmann, B. (2011). Puget Sound Dissolved Oxygen Model Nutrient Load Summary for 1999-2008. Washington Department of Ecology. Retrieved from https://fortress.wa.gov/ecy/publications/documents/1103057.pdf

Moore, T. A., Xing, Y., Lazenby, B., Lynch, M. D. J., Schiff, S., Robertson, W. D., ... Neufeld, J. D. (2011). Prevalence of anaerobic ammonium-oxidizing bacteria in contaminated groundwater. Environmental Science and Technology, 45(17), 7217-7225. https://doi.org/10.1021/es201243t

Muyzer, G., \& Ramsing, N. (1995). Molecular methods to study the organization of microbial communities. Water Science and Technology. https://doi.org/10.1016/0273-1223(96)000017 
Muyzer, G., \& Smalla, K. (1998). Application of denaturing gradient gel electrophoresis (DGGE) and temperature gradient gel electrophoresis (TGGE) in microbial ecology. Antonie van Leeuwenhoek, 73(1), 127-41. https://doi.org/10.1023/A:1000669317571

Nesc. (2003). Explaining the Activated Sludge Process. Pipeline (Vol. 14).

Nielsen, P. H., Mielczarek, A. T., Kragelund, C., Nielsen, J. L., Saunders, A. M., Kong, Y., ... Vollertsen, J. (2010). A conceptual ecosystem model of microbial communities in enhanced biological phosphorus removal plants. Water Research, 44(17), 5070-5088. https://doi.org/https://doi.org/10.1016/j.watres.2010.07.036

Of, P., For, E., Thaur, E. D., Lemoine, C., Daniel, O., Moatamri, N., ... Recherche, A. (2005). Optimisation of aeration for activated sludge treatment (pp. 1-7).

Park, H.-D., \& Noguera, D. R. (2004). Evaluating the effect of dissolved oxygen on ammoniaoxidizing bacterial communities in activated sludge. Water Research, 38(14-15), 32753286. https://doi.org/10.1016/j.watres.2004.04.047

Park, H. D., Wells, G. F., Bae, H., Griddle, C. S., \& Francis, C. A. (2006). Occurrence of ammonia-oxidizing archaea in wastewater treatment plant bioreactors. Applied and Environmental Microbiology. https://doi.org/10.1128/AEM.00402-06

Pholchan, M. K., Baptista, J. de C., Davenport, R. J., \& Curtis, T. P. (2010). Systematic study of the effect of operating variables on reactor performance and microbial diversity in laboratory-scale activated sludge reactors. Water Research. https://doi.org/10.1016/j.watres.2009.11.005

Piterina, A. V., \& Pembroke, J. T. (2013). Use of PCR-DGGE Based Molecular Methods to Analyse Microbial Community Diversity and Stability during the Thermophilic Stages of an ATAD Wastewater Sludge Treatment Process as an Aid to Performance Monitoring. ISRN Biotechnology, 2013, 1-13. https://doi.org/10.5402/2013/162645

Pogue, A. J., \& Gilbride, K. a. (2007). Impact of protozoan grazing on nitrification and the ammonia- and nitrite-oxidizing bacterial communities in activated sludge. Canadian Journal of Microbiology, 53(5), 559-571. https://doi.org/10.1139/W07-027

Pratscher, J., Dumont, M. G., \& Conrad, R. (2011). Ammonia oxidation coupled to CO2 fixation by archaea and bacteria in an agricultural soil. Proceedings of the National Academy of Sciences, 108(10), 4170-4175. https://doi.org/10.1073/pnas.1010981108

Prosser, J. I., \& Nicol, G. W. (2008). Relative contributions of archaea and bacteria to aerobic ammonia oxidation in the environment. Environmental Microbiology. https://doi.org/10.1111/j.1462-2920.2008.01775.x

Rotthauwe, J., \& Witzel, K. (1997). The Ammonia Monooxygenase Structural Gene amoA as a Functional Marker : Molecular Fine-Scale Analysis of Natural Ammonia-Oxidizing Populations. Applied and Environmental Microbiology, 63(12), 4704-4712.

Russell, D. L. (2006). Practical Wastewater Treatment. Practical Wastewater Treatment. https://doi.org/10.1002/0470067926

Santoro, A. E., Buchwald, C., McIlvin, M. R., \& Casciotti, K. L. (2011). Isotopic Signature of 
N2O Produced by Marine Ammonia-Oxidizing Archaea. Science, 333(6047), 1282-1285. https://doi.org/10.1126/science.1208239

Sauder, L. A., Peterse, F., Schouten, S., \& Neufeld, J. D. (2012). Low-ammonia niche of ammonia-oxidizing archaea in rotating biological contactors of a municipal wastewater treatment plant. Environmental Microbiology, 14(9), 2589-2600. https://doi.org/10.1111/j.1462-2920.2012.02786.x

Schmidt, S., Winter, J., \& Gallert, C. (2012). Long-term effects of antibiotics on the elimination of chemical oxygen demand, nitrification, and viable bacteria in laboratory-scale wastewater treatment plants. Archives of Environmental Contamination and Toxicology, 63(3), 354-364. https://doi.org/10.1007/s00244-012-9773-4

Short, M. D., Abell, G. C. J., Bodrossy, L., \& van den Akker, B. (2013). Application of a Novel Functional Gene Microarray to Probe the Functional Ecology of Ammonia Oxidation in Nitrifying Activated Sludge. PLoS ONE. https://doi.org/10.1371/journal.pone.0077139

Sims, A., Horton, J., Gajaraj, S., McIntosh, S., Miles, R. J., Mueller, R., ... Hu, Z. (2012). Temporal and spatial distributions of ammonia-oxidizing archaea and bacteria and their ratio as an indicator of oligotrophic conditions in natural wetlands. Water Research. https://doi.org/10.1016/j.watres.2012.05.007

Siripong, S., \& Rittmann, B. E. (2007). Diversity study of nitrifying bacteria in full-scale municipal wastewater treatment plants. Water Research, 41(5), 1110-1120. https://doi.org/https://doi.org/10.1016/j.watres.2006.11.050

Stahl, D. A., \& de la Torre, J. R. (2012a). Physiology and Diversity of Ammonia-Oxidizing Archaea. Annual Review of Microbiology. https://doi.org/10.1146/annurev-micro-092611150128

Stahl, D. A., \& de la Torre, J. R. (2012b). Physiology and Diversity of Ammonia-Oxidizing Archaea. Annual Review of Microbiology, 66(1), 83-101. https://doi.org/10.1146/annurevmicro-092611-150128

Ternes, T. A., Joss, A., \& Sigriest, H. (2004). Scrutinizing pharmaceuticals and personal care products in wastewater treatment. Environmental Science \& Technology, 38, 338A-352A. https://doi.org/10.1021/es040639t

Thamdrup, B., \& Dalsgaard, T. (2008). Nitrogen Cycling in Sediments. In Microbial Ecology of the Oceans: Second Edition (pp. 527-568). https://doi.org/10.1002/9780470281840.ch14

Unicef. (2015). Annual Report 2015. https://doi.org/10.1039/C1DT90165F

USEPA. (2015). Case Studies on Implementing Low-Cost Modifications to Improve Nutrient Reduction at Wastewater Treatment Plants. United States Environmental Protection Agency, Office of Wetlands Oceans and Watersheds, Office of Science and Technology, Office of Wastewater Management, (August). Retrieved from https://www.epa.gov/sites/production/files/201508/documents/case_studies_on_implementing_lowcost_modification_to_improve_potw_nutrient_reduction-combined_508_-_august.pdf

Wagner, M., \& Loy, A. (2002). Bacterial community composition and function in sewage 
treatment systems. Current Opinion in Biotechnology. https://doi.org/10.1016/S09581669(02)00315-4

WANG, X., ZHANG, K., REN, N., LI, N., \& REN, L. (2009). Monitoring microbial community structure and succession of an A/O SBR during start-up period using PCR-DGGE. Journal of Environmental Sciences. https://doi.org/10.1016/S1001-0742(08)62255-X

Watkinson, A. J., Murby, E. J., \& Costanzo, S. D. (2007). Removal of antibiotics in conventional and advanced wastewater treatment: Implications for environmental discharge and wastewater recycling. Water Research, 41(18), 4164-4176. https://doi.org/10.1016/j.watres.2007.04.005

WHO. (2014). Preventing diarrhoea through better water, sanitation and hygiene. WHO Library Cataloguing-in-Publication Data, 1-48. https://doi.org/ISBN 9789241564823

Williams, J. A. (2002). bioreactors. Keys to Bioreactor Selections, 34-41.

Winkler, M. K. H., Yang, J., Kleerebezem, R., Plaza, E., Trela, J., Hultman, B., \& van Loosdrecht, M. C. M. (2012). Nitrate reduction by organotrophic Anammox bacteria in a nitritation/anammox granular sludge and a moving bed biofilm reactor. Bioresource Technology. https://doi.org/10.1016/j.biortech.2012.03.070

Wintzingerode, F., Göbel, U. B., \& Stackebrandt, E. (1997). Determination if microbial diversity in environmental samples: pitfalls of PCR-based analysis. FEMS Microbiol. Rev., 21, 213229. https://doi.org/10.1111/j.1574-6976.1997.tb00351.x

Wuchter, C., Abbas, B., Coolen, M. J. L., Herfort, L., van Bleijswijk, J., Timmers, P., ... Sinninghe Damste, J. S. (2006). Archaeal nitrification in the ocean. Proceedings of the National Academy of Sciences, 103(33), 12317-12322. https://doi.org/10.1073/pnas.0600756103

Wwdr 2003. (n.d.).

Xu, D., Liu, S., Chen, Q., \& Ni, J. (2017). Microbial community compositions in different functional zones of Carrousel oxidation ditch system for domestic wastewater treatment. AMB Express. https://doi.org/10.1186/s13568-017-0336-y

You, J., Das, A., Dolan, E. M., \& Hu, Z. (2009). Ammonia-oxidizing archaea involved in nitrogen removal. Water Research. https://doi.org/10.1016/j.watres.2009.01.016

Zhang, T., Jin, T., \& Yan, Q. (2010). Characterization and quantification of ammonia-oxidizing archaea (AOA) and bacteria (AOB) in a nitrogen-removing reactor using T-RFLP and qPCR. Applied Microbiology and Biotechnology, 87(3), 1167-1176. https://doi.org/10.1007/s00253-010-2595-2

Zhang, T., Jin, T., Yan, Q., Shao, M., Wells, G., Criddle, C., \& Fang, H. H. P. (2009). Occurrence of ammonia-oxidizing Archaea in activated sludges of a laboratory scale reactor and two wastewater treatment plants. Journal of Applied Microbiology. https://doi.org/10.1111/j.1365-2672.2009.04283.x

Zhang, T., Ye, L., Tong, A. H. Y., Shao, M. F., \& Lok, S. (2011). Ammonia-oxidizing archaea and ammonia-oxidizing bacteria in six full-scale wastewater treatment bioreactors. Applied 
Microbiology and Biotechnology, 91(4), 1215-1225. https://doi.org/10.1007/s00253-0113408-y 